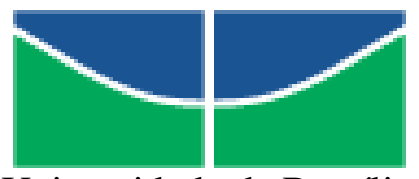

Universidade de Brasília

Instituto de Ciências Biológicas

Programa de Pós-Graduação em Ecologia

\title{
Diversidade e variação na abundância de recursos e biologia de imaturos de Eumaeini (Lycaenidae, Theclinae) em plantas do Cerrado
}

Neuza Aparecida Pereira da Silva 


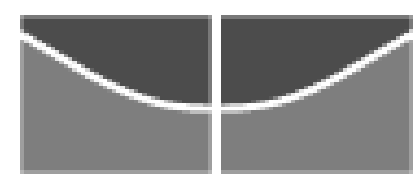

Programa de Pós-Graduação em Ecologia

Departamento de Ecologia

Instituto de Ciências Biológicas

Universidade de Brasília

\title{
Diversidade e variação na abundância de recursos e biologia de imaturos de Eumaeini (Lycaenidae, Theclinae) em plantas do Cerrado
}

\author{
Neuza Aparecida Pereira da Silva
}

Tese apresentada como requerimento parcial à obtenção do título de Doutora, junto ao Programa de Pós-Graduação em Ecologia do Departamento de Ecologia, Instituto de Ciências Biológicas da Universidade de Brasília.

Orientadora: Helena Castanheira de Morais Co-orientador: Lucas Augusto Kaminski

Brasília - DF

Setembro de 2016 
Água, mato, areia, terra,

pau a pique, palha, terra batida,

adobe, telha, eimento queimado, conereto...!

Conereto..., terra, areia,... água, mato, travessia pelo eerrado que não se eneerra com uma mata eerrada, mas que ini eia eom o eneerramento da chegada ao cume do eerro que é apenas uma serra e que deverá ser deseida, só isso!

Dedico à vida da natureza e a natureza da vida com suas diferentes batalhas, adaptações e conquistas no dia a dia. 


\section{AGRADECIMENTOS}

Agradeço a meu companheiro, Michael Wilberg, por me trazer até aqui!!

À minha querida orientadora, Helena C. Morais, pelos ensinamentos, confiança e incentivo ao longo desses tantos anos de convivência.

À Profa. Ivone Diniz por todo o apoio, ajuda e acolhimento em seu laboratório nesses últimos anos.

À Profa. Marina Frizzas que lá na graduação me mostrou o mundo dos insetos.

Ao Lee Dyer pelo grande auxílio com as aulas de estatísticas no programa $\mathrm{R}$ e ao Neander Heming pelas dicas sobre as análises.

Ao prof. John Hay por toda a troca de informações e auxílios na minha passagem pela UnB e especialmente na tradução do "abstract" da tese.

Ao Prof. Paulo César Mota... Tri!! Obrigada das "neuzas neuzinhas" pelas palavras de incentivo e animação de sempre.

Aos grandes amigos conquistados por meio das lagartinhas, ou antes, e que sempre ajudaram de alguma forma, além das coletas de campo: Michely Ferreira, Raiane Serejo, Thayane Pereira, Tacito Trindade (Tito), Hanna Rodrigues, Scheila Scherrer, Ricardo Mattos, Geraldo Freire e André Nascimento. À Andreza Barbosa e Nayara Milena agradeço pela ajuda inicial com as coletas de campo para a tese.

Agradeço em especial às amigonas, Cintia Lepesqueur e Laura Braga pela amizade, companheirismo e por dividir a alegria em conhecer nossos lepidópteros do Cerrado.

À Profa. Cássia B. Munhoz e Jair Eustáquio pelo auxílio na identificação das plantas. Ao laboratório de Microscopia Eletrônica do IB representado pela Profa. Sônia N. Baó e, principalmente, a Ingrid Matos pelo auxílio na preparação das amostras e na execução das imagens microscópicas e ao Miguel Garcia pelas imagens realizadas no laboratório de microscopia do Departamento da Engenharia Mecânica (UnB).

Aos seguranças da Fazenda Água Limpa que me tranquilizavam no campo com rondas periódicas. À Universidade de Brasília e ao Programa de Pós-graduação em Ecologia por toda a infraestrutura. Ao suporte financeiro concedido pelo CNPq e DPPUnB, e CAPES e CNPq pelo financiamento da bolsa de Doutorado.

Ao Dr. Marcelo Duarte (MZUSP) pela identificação dos Lycaenidae e ao Dr. Robert K. Robbins do National Museum of Natural History, Smithsonian Institution, Washington, por fornecer informações valiosas sobre a ecologia e distribuição dos 
licenídeos na região Neotropical, além da revisão crítica e correções do artigo, último capítulo dessa tese, e por incentivar que eu continue a mostrar essas riquezas do nosso Cerrado.

Agradeço a Lucas A. Kaminski por ensinar, incentivar e mostrar com entusiasmo o quanto é lindo e importante conhecer a vida desses bichinhos, obrigada de coração!

À amiga Rosângela dos Santos (Rose) que está sempre a cuidar dos meus enquanto me dedico às lagartinhas. E à minha família que entendeu a necessidade de manter-me tanto tempo distante para conseguir chegar até aqui!

A todos que acreditaram e me incentivaram, obrigadésimo!!! 


\section{SUMÁRIO}

Lista de tabelas.......................................................................................................................vii

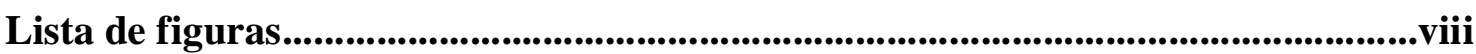

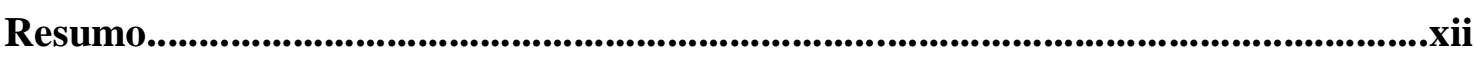

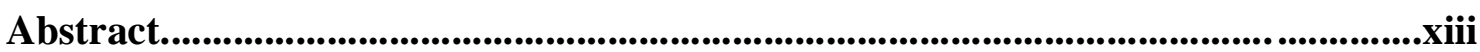

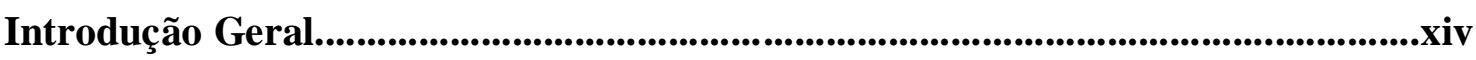

Referências Bibliográficas..............................................................................................

Capítulo I. Efeitos da abundância e diversidade de recursos florais e formigas mutualistas em uma comunidade de lagartas florívoras (Lepidoptera: Lycaenidae)

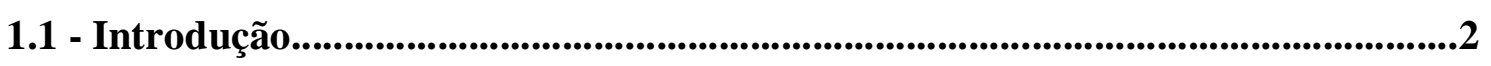

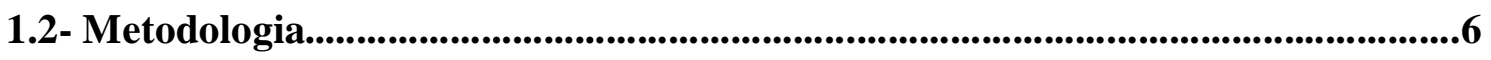

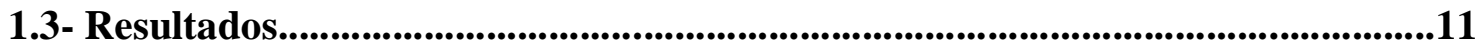

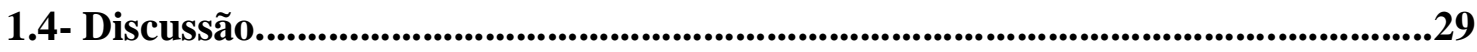

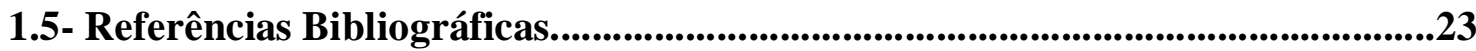

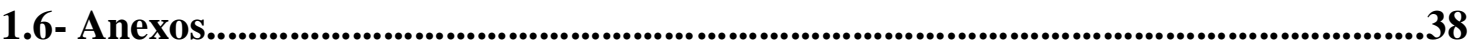

Capítulo II. História natural e morfologia dos estágios imaturos de duas espécies de Paiwarria (Eumaeini) com notas sobre mimetismo larval

2.1 - Introdução............................................................................................................................45

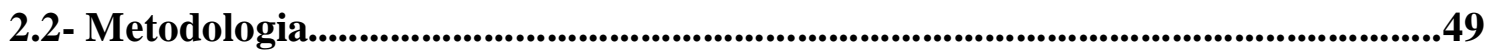

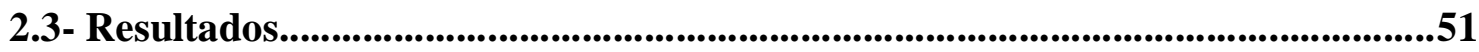

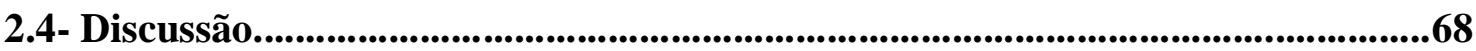

2.5- Referências Bibliográficas........................................................................72

Capítulo III. Biologia dos estágios imaturos de Strymon crambusa (Lycaenidae: Theclinae) em Oxalidaceae. Artigo publicado na Revista Brasileira de Entomologia, $60(2016) 68-72$ 


\section{LISTA DE TABELAS}

\section{Capítulo I. Efeitos da abundância e diversidade de recursos florais e formigas mutualistas em uma comunidade de lagartas florívoras (Lepidoptera: Lycaenidae)}

Tabela 1. Referências da localização das quatro áreas de campo sujo com inflorescências coletadas nas parcelas e examinadas em busca de imaturos de Lycaenidae na Fazenda Água Limpa/DF entre janeiro e abril de 2014. Número de parcelas e total $\left(\mathrm{m}^{2}\right)$ das áreas amostradas nos campos sujos. A1E-A3E= Elevadas, áreas distantes de córregos e $\mathrm{A} 2 \mathrm{~B}-\mathrm{A} 4 \mathrm{~B}=\mathrm{Baixada}$, áreas próximas a córregos. As parcelas são consideradas replicas das áreas.

Tabela 2. Riqueza de espécies de plantas, de famílias e total de plantas e inflorescências examinadas em $200 \mathrm{~m}^{2}$ de cada uma das quatro áreas de campo sujo amostradas na Fazenda Água Limpa/DF entre janeiro e abril de 2014. A1E-A3E= Elevadas, áreas distantes de córregos e A2B-A4=Baixada, áreas próximas córregos.

Tabela 3. Famílias e espécies de plantas com inflorescências utilizadas como recurso pelos Lycaenidae nas quatro áreas de campo sujo amostradas na Fazenda Água Limpa/DF entre janeiro e abril de 2014. Total geral das plantas com inflorescências disponíveis como recurso, número efetivo de plantas utilizadas e de inflorescências presentes nelas; número de imaturos e de espécies de Lycaenidae encontrados. 17

Tabela 4. Espécies de Lycaenidae, abundância de imaturos em cada área e número de espécies de plantas hospedeiras dos licenídeos imaturos encontrados nas quatro áreas de campo sujo amostradas na Fazenda Água Limpa/DF entre janeiro e abril de 2014. A1E, $\mathrm{A} 3 \mathrm{E}=$ Elevadas, áreas distantes de córregos e $\mathrm{A} 2 \mathrm{~B}, \mathrm{~A} 4 \mathrm{~B}=\mathrm{Baixada}$, áreas próximas a córregos.

Tabela 5. Total de plantas em cada área, indivíduos de plantas com presença de formigas; número de plantas com formigas e imaturos, número de imaturos em plantas com formigas e número total geral de imaturos nas quatro áreas de campo sujo amostradas na Fazenda Água Limpa/DF entre janeiro e abril de 2014. A1E, A3E= Elevadas, áreas distantes de córregos e A2B, A4B=Baixada, áreas próximas a córregos

Tabela 6. Famílias e espécies de plantas com presença de formigas e imaturos, com ou sem nectários extraflorais (NEFs); número de plantas e inflorescências, número de imaturos, espécies de licenídeos e número de indivíduos por espécie (n.) que ocorreram nas plantas com formigas nas quatro áreas de campo sujo amostradas na Fazenda Água Limpa/DF entre janeiro e abril de 2014. 


\section{LISTA DE FIGURAS}

\section{Capítulo I. Efeitos da abundância e diversidade de recursos florais e formigas} mutualistas em uma comunidade de lagartas florívoras (Lepidoptera: Lycaenidae)

Figura 1. Localização das quatro áreas de campo sujo onde foram feitas parcelas para coleta e vistoria de inflorescências em busca de imaturos de Lycaenidae na Fazenda Água Limpa (FAL), DF, entre janeiro e abril de 2014. Áreas A1E e A3E=Elevadas, campos sujos mais distantes de córregos e A2B e A4B=Baixada, campos sujos próximos aos córregos Gama e Taquara..................................................................

Figura 2. (a) Abundância média (+erro padrão) de plantas e (b) de inflorescências em cada uma das quatro áreas de campo sujo amostradas na Fazenda Água Limpa/DF entre janeiro e abril de 2014. A1E, A3E= Elevadas, áreas distantes de córregos e A2B, A4B=Baixada, áreas próximas a córregos .13

Figura 3. Curvas de rarefação de indivíduos de plantas em floração (com intervalo de 95\% de confiança) examinadas em busca de imaturos de Lycaenidae em quatro áreas de campo sujo amostradas na Fazenda Água Limpa/DF entre janeiro e abril de 2014. A1E, $\mathrm{A} 3 \mathrm{E}=$ Elevadas, áreas distantes de córregos e A2B, A4B=Baixada, áreas próximas a córregos. .13

Figura 4. Perfis de diversidade de Rényi das espécies de plantas examinadas em busca de imaturos de Lycaenidae nas quatro áreas de campo sujo amostradas na Fazenda Água Limpa/DF entre janeiro e abril de 2014. (a) Diversidade nas quatro áreas e (b) Diversidade nas áreas agrupadas: $\mathrm{A} 1 \mathrm{E}-\mathrm{A} 3 \mathrm{E}=$ Elevadas, áreas distantes de córregos $\mathrm{e}$ $\mathrm{A} 2 \mathrm{~B}-\mathrm{A} 4 \mathrm{~B}=\mathrm{B}$ aixada, áreas próximas a córregos .14

Figura 5. Dendograma de similaridade das espécies de plantas em floração examinadas em busca de imaturos de Lycaenidae nas quatro áreas de campo sujo amostradas na Fazenda Água Limpa/DF entre janeiro e abril de 2014. A1E, A3E= Elevadas, áreas distantes de córregos e A2B, A4B=Baixada, áreas próximas a córregos Análise pelo índice de similaridade Bray-Curtis, método de ligação simples.

Figura 6. Riqueza (barras) e abundância (linha) de Lycaenidae imaturos em cada família de plantas hospedeiras em quatro áreas de campo sujo amostradas na Fazenda Água Limpa/DF entre janeiro e abril de 2014.

Figura 7: Curva de rarefação individual (com intervalo de $95 \%$ de confiança) de espécies de Lycaenidae nas quatro áreas de campo sujo amostradas na Fazenda Água Limpa/DF entre janeiro e abril de 2014. A1E, A3E= Elevadas, áreas distantes de córregos e A2B, A4B=Baixada, próximas a córregos.

Figura 8. Abundância média (+erro padrão) de imaturos de Lycaenidae nas quatro áreas de campo sujo amostradas na Fazenda Água Limpa/DF entre janeiro e abril de 2014. $\mathrm{A} 1 \mathrm{E}, \mathrm{A} 3 \mathrm{E}=$ Elevadas, áreas distantes de córregos e A2B, A4B=Baixada, áreas próximas a córregos. $\mathrm{O}$ asterisco $\left(^{*}\right)$ indica diferença significativa em relação em às outras áreas. $(\mathrm{P}<0,001)$. 
Figura 9. Perfis de diversidade de Rényi para espécies de Lycaenidae em plantas em floração nas quatro áreas de campo sujo amostradas na Fazenda Água Limpa/DF entre janeiro e abril de 2014. (a) Diversidade nas quatro áreas e (b) diversidade nas áreas agrupadas. A1E, A3E= Elevadas, áreas distantes de córregos e A2B, A4B=Baixada, áreas próximas a córregos.

Figura 10. Dendograma de similaridade da composição dos imaturos de Lycaenidae nas quatro áreas de campo sujo amostradas na Fazenda Água Limpa/DF entre janeiro e abril de 2014. A1E, A3E= Elevadas, áreas distantes de córregos e A2B, A4B=Baixada, áreas próximas a córregos. Análise de agrupamento pelo índice Bray-Curtis, método de ligação simples. .22

Figura 11: Resposta da abundância de imaturos de Lycaenidae em relação à abundância total de inflorescências examinadas nas áreas de campo sujo amostradas na Fazenda Água Limpa/DF entre janeiro e abril de 2014. .23

Figura 12. (a) Resposta da abundância de imaturos de Lycaenidae em relação à abundância total das espécies de plantas e (b) abundância de imaturos de Lycaenidae em relação à abundância total das 24 espécies de plantas hospedeiras nas áreas de campo sujo amostradas na Fazenda Água Limpa/DF entre janeiro e abril de 2014 .23

Figura 13. Abundância relativa das espécies de plantas hospedeiras $(n=24)$ e das inflorescências disponíveis ao longo do período de coletas e proporção dos Lycaenidae imaturos encontrados sobre elas nas quatro áreas de campo sujo amostradas na Fazenda Água Limpa/DF entre janeiro e abril de 2014. Ranking da maior para a menor porcentagem de inflorescências por planta..

Figura 14. (a) Abundância absoluta de plantas com e sem a presença de formigas nas áreas de campo sujo e (b) abundância média (+erro padrão) de plantas registradas com presença de formigas nas quatro áreas de campo sujo amostradas na Fazenda Água Limpa/DF entre janeiro e abril de 2014. A1E, A3E= Elevadas, áreas distantes de córregos e $\mathrm{A} 2 \mathrm{~B}, \mathrm{~A} 4 \mathrm{~B}=\mathrm{Baixada}$, áreas próximas a córregos. $\mathrm{O}$ asterisco (*) indica diferença significativa da área em relação às demais $(\mathrm{P}<0,05)$. .25

Figura 15. (a) Abundância absoluta de Lycaenidae imaturos registrados nas plantas hospedeiras com e sem a presença de formigas e (b) abundância média (+erro padrão) dos imaturos em plantas com presença de formigas nas quatro áreas de campo sujo amostradas na Fazenda Água Limpa/DF entre janeiro e abril de 2014. A1E, A3E= Elevadas, áreas distantes de córregos e A2B, A4B=Baixada, áreas próximas a córregos. $\mathrm{O}$ asterisco $(*)$ indica diferença significativa da área em relação às demais $(\mathrm{P}<0,05) \ldots 26$

Figura 16. Abundância média (+erro padrão) de Lycaenidae imaturos em plantas com e sem a presença de formigas em todas as áreas de campo sujo amostradas na Fazenda Água Limpa/DF entre janeiro e abril de 2014. O asterisco (*) indica diferença significativa entre os grupos $(\mathrm{P}<0,001)$. 
Capítulo II. História natural e morfologia dos estágios imaturos de duas espécies de Paiwarria (Eumaeini) com notas sobre mimetismo larval

Figura 1. Adultos de (A) Paiwarria aphaca e (B) P. venulius (Lycaenidae, Theclinae,

Eumaeini) (Fotos L. Kaminski).

Figura 2. Localização dos ovos (setas) de Paiwarria aphaca e $P$. venulius nas espécies de Celastraceae. (F) detalhe à direita mostrando ovo de Emesis russula Stichel (Riodinidae) ao lado de ovo de Paiwarria (seta). (Fotos: Neuza Silva). .52

Figura 3. (A, B) Paiwarria aphaca, lagarta de segundo ínstar logo após a ecdise, setas indicam a placa protorácica; (C) lagarta de terceiro ínstar imóvel, em fase de ecdise, e (D) imediatamente após a liberação da exúvia. (Fotos: Neuza Silva)..... .53

Figura 4. Pupa encontrada sobre uma espécie de Myrtaceae no campo (4B-C). (4A) Círculo amarelo indica localização da planta hospedeira, Peritassa campestris, círculo vermelho mostra onde a pupa foi encontrada. (Fotos: Neuza Silva). .54

Figura 5. (A, B, C) Lagartas de primeiro ínstar de Paiwarria venulius sobre folha, botões e flor; (D, E) lagarta de Paiwarria aphaca em último ínstar em folha de Peritassa campestris no campo. (Fotos: Neuza Silva). .54

Figura 6. (A) Paiwarria aphaca último ínstar, letras e números indicando os segmentos: protórax (T1), mesotórax (T2), metatórax (T3) e segmentos abdominais (A1-10). (B) Paiwarria venulius, segmentos mais amarelados em T2, A2 e A6. (Fotos: Neuza Silva). .55

Figura 7. (A-C) Paiwarria aphaca, último ínstar, setas indicando a placa protorácica (A-B) e (C) detalhe mostrando ausência de órgão nectário dorsal (DNO) sobre o sétimo segmento abdominal. (D-E) $P$. venulius, último ínstar, setas indicam placa protorácica e (F) DNO sobre o A7. (Fotos: Neuza Silva). .56

Figura 8. (A-F) Paiwarria aphaca, lagartas de terceiro ínstar (A-C) e de quarto ínstar (último) (D-F). (G-L) Paiwarria venulius, lagartas de terceiro ínstar (G-I) e de quarto ínstar (último) (J-L). (Fotos: Neuza Silva). .56

Figura 9. (A-D) Paiwarria aphaca. (A) Lagarta de terceiro ínstar em inflorescência de Salacia crassifolia no campo e (B-D) lagartas de quarto ínstar criadas com inflorescências de Peritassa campestris em laboratório. (E-F) Paiwarria venulius, terceiro e quarto ínstar, criadas com inflorescências. (Fotos: Neuza Silva). .57

Figura 10. (A) ovo parasitado, seta indica abertura de saída do (B) parasitoide, (C) ovo predado no campo, (D-E) ovos eclodidos utilizados como abrigo e berçário pelos ácaros. (F-I) Lagartas de Paiwarria venulius parasitadas, seta $(\mathrm{H})$ indicando local de empupação do parasita, (J) lagarta "mumificada" e abertura de saída do himenóptero Braconidae (K). (Fotos: Neuza Silva). .58

Figura 11. (A-R) Lagartas de lepidópteros e (S) Symphyta (Hymenoptera) presentes nas espécies de Celastraceae examinadas entre janeiro de 2015 a maio de 2016. (A-B) 
lagartas de Riodinidae, (C) não identificada, (D-E) Dalceridae, (F) Arctidae, (G-L) Limacodidae, (M) Saturniidae, (N-P) Megalopygidae, (Q) Triommatodes subrita (Noctuidae) e (R) Geometridae. (Fotos: Neuza Silva).

Figura 12. (A-B) Parides sp. e Paiwarria venulius último ínstar. (C-E) Parides sp. logo após a ecdise (C), (E) Parides sp. em último ínstar. (Fotos: Neuza Silva).

Figura 13. Paiwarria aphaca, estágios imaturos criados em folhas de Celastraceae: (A) ovo, (B) primeiro ínstar, (C) segundo ínstar, (D) terceiro ínstar e (E) quarto ínstar, (F) pré-pupa, (G-H) pupa, vista dorsal e lateral. (Fotos: Neuza Silva)..... .64

Figura 14. Microscopia eletrônica de varredura de ovos de Paiwarria aphaca. (A) vista anterior, (B) área micropilar, (C) seta indica aeropila. .65

Figura 15. Microscopia eletrônica de varredura de P. aphaca. (A) detalhe do tegumento com PCOs sobre A7 em terceiro ínstar e quarto instar (B, D), (C) detalhe da placa protóracica, $(\mathrm{E}-\mathrm{F})$ pupa, detalhe do espiráculo no mesotórax e $(\mathrm{F})$ detalhe do segmento abdominal da pupa com cerdas dendríticas (seta). .65

Figura 16. Paiwarria venulius, estágios imaturos criados sobre folhas de Celastraceae: (A) ovo, (B) primeiro ínstar, (C) segundo ínstar, (D) terceiro ínstar e (E) quarto ínstar, (F) pré-pupa, (G-H) pupa, vista dorso-lateral e dorsal. (Fotos: Neuza Silva). .67

Figura 17. Microscopia eletrônica de varredura de Paiwarria venulis. (A) exocório do ovo, (B) detalhe dos escolos dorsais e (C, D) tegumento sobre o segmento A7 com abertura do órgão nectário dorsal (DNO) e órgãos perfurados em forma de cúpula (PCO) . .68 


\section{RESUMO GERAL}

Eumaeini (Lepidoptera, Lycaenidae) é uma tribo rica em espécies de borboletas na região Neotropical. A coloração críptica e interações simbióticas com formigas são atributos ecológicos de defesa das lagartas desses lepidópteros. Contudo, sabe-se pouco da história de vida e da relação entre recursos, abundância e interações desses licenídeos. Os objetivos desse estudo foram avaliar os efeitos da diversidade e abundância dos recursos (inflorescências) e a presença de formigas sobre a abundância de imaturos de Eumaeini; fornecer informações sobre a história natural e características morfológicas de Paiwarria venulius (Cramer) e Paiwarria aphaca (Hewitson) comparando-as com lagartas aposemáticas de Parides Hübner (Papilionidae), sugeridas como possíveis modelos miméticos, e apresentar a biologia e morfologia dos imaturos de Strymon crambusa (Hewitson), uma espécie rara em levantamentos. As amostragens ocorreram em mata de galeria, cerrado sensu stricto e campo sujo. Os resultados indicaram que a abundância de inflorescências afetou positivamente a abundância dos licenídeos, mas a composição de espécies não foi afetada pela composição florística. A presença de formigas no total das plantas também exibiu efeito sobre a abundância dos imaturos. Lagartas das duas espécies de Paiwarria apresentam escolos e coloração conspícua sobre folhas das plantas hospedeiras. $P$. venulius possui órgão nectário dorsal enquanto $P$. aphaca não, além disso, o padrão de coloração da primeira exibe maior convergência fenotípica com o encontrado nas lagartas de Parides spp.. P. venulius é registrada também em áreas de mata, enquanto $P$. aphaca ocorre em áreas de cerrado. As diferenças morfológicas entre elas podem estar relacionadas aos caracteres adaptativos na transição do ambiente de mata para o savânico ou vice versa. Lagartas de S. crambusa são crípticas e são localmente especializadas em Oxalidaceae. Esta tese fornece informações inéditas sobre padrões e processos ecológicos e evolutivos que podem estar atuando em diferentes escalas nas comunidades de Lycaenidae no Cerrado.

Palavras-chave: licenídeos; planta hospedeira; lagartas; fenótipo; mimetismo; Parides 


\section{ABSTRACT}

In the Neotropics Eumaeini (Lycaenidae) is a very species rich tribe. Their caterpillar cryptic coloration and symbiotic interactions with ants (myrmecophily) are ecological attributes recognized as defense strategies. Little is known about the life history and the relation between resources, abundance and interactions of these lepidopterans. The objectives of this study were to evaluate the effects of diversity and abundance of inflorescences and the presence of ants on the plants on the abundance of immature stages of Eumaeini, furnish informations on the natural history and morphological characteristics of Paiwarria venulius (Cramer) and Paiwarria aphaca (Hewitson), making comparisons with aposematic caterpillars of Parides Hübner (Papilionidae), suggested as possible mimetic models, also presents the biology and morphology of immatures Strymon crambusa (Hewitson), a species that is infrequently registered. Sampling was conducted in gallery forest, cerrado sensu stricto and campo sujo. The results indicated that the abundance of inflorescences positively affected the abundance of Eumaeini immatures, but the species composition were not affect by floristic composition. The presence of ants on the plants also had an effect on the immatures abundance. Caterpillar of both species of Paiwarria have scoli and a conspicuous coloration on the leaves of their food plants. P. venulius presents the dorsal nectary organ while $P$. aphaca does not, and the first has a higher phenotypic convergence with caterpillars of Parides spp.. P. aphaca occurs in savanna areas, while $P$. venulius is also in forest areas. Morphological differences between the two species of Paiwarria may be relate to adaptive characteristics in the transition from the gallery forest to the cerrado or vice versa. S. crambusa have cryptic caterpillars and are locally specialized in Oxalidaceae. This thesis provides new information on patterns and ecological and evolutionary processes that may be acting in different scales in communities of Lycaenidae in the Cerrado.

Key words: lycaenids; food plants; caterpillars; phenotype; mimetism; Parides 


\section{INTRODUÇÃO GERAL}

A abundância de insetos herbívoros pode ser influenciada pelas variações temporais e espaciais na qualidade e na composição da vegetação. Estas variações afetam as interações entre os organismos, ocasionando diferentes adaptações fisiológicas, morfológicas e comportamentais devido, em grande parte, à resposta aos constituintes da planta hospedeira e às pressões sofridas por determinados inimigos naturais. A ordem Lepidoptera com sua megadiversidade de táxons apresenta cerca de 20.000 espécies de borboletas distribuídas mundialmente (Lewinsohn \& Prado 2002), constituindo um dos principais grupos de insetos herbívoros estudados quanto às relações ecológicas (Zalucki et al. 2002, Greeney et al. 2012). No entanto, dentre a diversidade de borboletas, a família Lycaenidae se destaca pelas lacunas de informações biológicas, ecológicas e, consequentemente, de adequadas associações filogenéticas (Lamas 2008, Pierce et al. 2002).

Na região Neotropical, Lycaenidae é representada por três subfamílias, Lycaeninae, Polyommatinae e Theclinae, com cerca de 1.200 espécies (Robbins 2004). A tribo Eumaeini (Theclinae) apresenta a maior riqueza e é amplamente distribuída nessa região, onde as informações sobre os imaturos são mais fragmentadas e escassas. Lagartas de Eumaeini exibem características que podem ser consideradas comuns entre as espécies, são solitárias e várias espécies se alimentam de botões florais, flores, folhas e frutos (Robbins \& Aiello 1982, Monteiro 1990, Calvo 1998), mas existem aquelas que consomem vegetais em decomposição (Duarte \& Robbins 2010). Em geral, são crípticas sobre as plantas hospedeiras, com a coloração variando de acordo com o alimento consumido (Monteiro 1991). Assim como na família Riodinidae, as lagartas de Lycaenidae podem exibir associação com formigas (Pierce et al. 2002).

Entre os Lycaenidae, a associação mutualista com formigas pode ser obrigatória, onde as formigas estão constantemente atendendo as lagartas e essas tem dependência da interação ou facultativa, onde as formigas podem ou não antenar as lagartas, que é o mais comum para os Eumaeini neotropicais (Monteiro 1990, Fiedler 1991, Pierce et al. 2002, Kaminski \& Freitas 2010). Para esta tribo, são reconhecidos dois principais órgãos relacionados à mirmecofilia (Malicky 1970), além de cerdas especializadas (dendríticas) (Ballmer \& Pratt 1988). O órgão nectário dorsal (DNO) que deve estar presente a partir do terceiro ínstar e, se funcional, quando estimulado secreta um fluido rico em carboidratos e aminoácidos que é oferecido às formigas pela defesa contra 
predadores e parasitoides (Pierce \& Mead 1981, Robbins 1991); função análoga a dos nectários extraflorais e aos exsudados de hemípteros (Oliveira \& Del-Claro 2005). E os órgãos perfurados em forma de cúpula (PCOs) que são pequenas glândulas distribuídas pelo tegumento das lagartas e pupas, e são considerados os mais importantes, pois liberam substâncias capazes de acalmar o comportamento agressivo das formigas (Malicky 1970, Pierce et al. 2002). PCOs, aparentemente, estão presentes em todos os ínstares, mesmo em espécies consideradas não mirmecófilas (Ballmer \& Pratt 1992, Kaminski \& Freitas 2010). Desta forma, a associação com formigas é vista como mediadora da ampliação da dieta, com fêmeas procurando ovipor em plantas com a presença de formigas, mesmo em relações facultativas (Atsatt 1981, Wagner \& Kurina 1997, Kaminski et al. 2010).

O Cerrado, com sua alta diversidade, heterogeneidade topográfica e fitofisionomica (Ribeiro \& Walter 2008), pode propiciar uma grande diversidade de interações e de adaptações destes organismos (Marquis et al. 2002). Nos últimos anos, pesquisas para o conhecimento dos imaturos de Eumaeini no Cerrado têm sido realizadas (Silva et al. 2011, Bächtold \& Alves-Silva 2012). Nestas pesquisas foram divulgadas informações sobre a preferência de muitas espécies por estruturas reprodutivas das plantas hospedeiras (Robbins \& Aiello 1982, Morais et al. 2009, Silva et al. 2011) e revelado alguns aspectos da morfologia e de estratégias de defesa das lagartas nesse bioma. Por exemplo, comportamento de saltar em fio de seda (Silva et al. 2014) incomum em licenídeos, e a obtenção de um espaço livre de inimigos a partir da presença de hemípteros trofobiontes (Oliveira \& Del-Claro 2005, Kaminski et al. 2010). Desta forma, este estudo foi proposto com intuito de obter informações sobre a biologia e ecologia dos imaturos e contribuir para o entendimento dos aspectos morfológicos e evolutivos dos Eumaeini Neotropicais.

A presente tese está dividida em três capítulos, os quais abordam aspectos relativamente diferentes. O Capítulo I - Efeitos da abundância e diversidade de recursos florais e formigas mutualistas em uma comunidade de lagartas florívoras (Lepidoptera: Lycaenidae) - trata-se de um estudo de ecologia de comunidades, onde a abundância de imaturos foi avaliada em relação à diversidade e disponibilidade de recursos (inflorescências e presença de formigas nas plantas) em áreas de campo sujo na Fazenda Água Limpa/DF. Esse trabalho, concomitantemente, fornece informações sobre as plantas hospedeiras e os estágios imaturos das espécies de Eumaeini encontrados no campo. O Capítulo II - História natural e morfologia dos estágios 


\section{imaturos de duas espécies de Paiwarria (Eumaeini) com notas sobre mimetismo}

larval- refere-se aos aspectos biológicos e morfológicos de imaturos de duas espécies de Paiwarria Kaye. Neste capítulo são comparados o comportamento e a morfologia entre as duas espécies, entre aquelas que coocorrem nas mesmas plantas hospedeiras, e com Parides Hübner (Papilionidae, Troidini) que ocorrem no mesmo hábitat, e são sugeridas como possiveis modelos miméticos para Paiwarria. No Capítulo IIIBiologia dos estágios imaturos de Strymon crambusa (Lycaenidae: Theclinae) em Oxalidaceae -é apresentada a biologia e a morfologia dos estágios imaturos de Strymon crambusa (Hewitson) e sua relação com a família das plantas hospedeiras é discutida. Esse último capítulo já se encontra publicado em revista científica na versão em inglês, desta forma, é apresentado aqui como anexo no formato da publicacação da revista.

\section{REFERÊNCIAS BIBLIOGRÁFICAS}

Atsatt, P.R. 1981. Ant-dependent food plant selection by the mistletoe butterfly Ogyris amaryllis (Lycaenidae). Oecologia, 48: 60-63.

Bächtold, A. \& Alves-Silva, E. 2012. Behavioral strategy of a lycaenid (Lepidoptera) caterpillar against aggressive ants in a Brazilian savana. Acta Ethologica DOI 10.1007/s10211-012-0140-2.

Ballmer, G.R. \& Pratt, G.F. 1988. A survey of the last instar larvae of the Lycaenidae of California. Journal of Research on the Lepidoptera, 27(1): 1-81.

Ballmer, G.R. \& Pratt, G.F. 1992. Loranthomitoura, a new genus of Eumaeini (Lepidoptera: Lycaenidae: Theclinae).Tropical Lepidoptera, 3(1): 37-46.

Calvo, R. 1998. Reprodución de Oenomaus ortignus (Lepidoptera: Lycaenidae) en Barva, Heredia, Costa Rica. Revista de Biologia Tropical, 46(1): 101-104.

Duarte, M. \& Robbins, R.K. 2010. Description and phylogenetic analysis of the Calycopidina (Lepidoptera, Lycaenidae, Theclinae, Eumaeini): a subtribe of detritivores. Revista Brasileira de Entomologia, 54(1): 45-65.

Fiedler, K. 1991. Systematic, evolutionary, and ecological implications of myrmecophily within the Lycaenidae (Insecta: Lepidoptera: Papilionoidea). Bonner Zoologische Monographien, 31: 1-210.

Greeney, H.F.; Dyer, L.A. \& Smilanich, A.M. 2012. Feeding by lepidopteran larvae is dangerous: A review of caterpillars' chemical, physiological, morphological, and behavioral defenses against natural enemies. Invertebrate Survival Journal, 9: 7-34.

Kaminski, L.A. \& Freitas, A.V.L. 2010. Natural history and morphology of immature stages of the butterfly Allosmaitia strophius (Godart) (Lepidoptera: Lycaenidae) on flower buds of Malpighiaceae. Studies on Neotropical Fauna and Environment, 45: 11-19. 
Kaminski, L.A., Freitas A.V.L., Oliveira P.S. 2010. Interaction between mutualisms: ant-tended butterflies exploit enemy-free space provided by ant-treehopper associations. The American Naturalist, 176(3): 322-334.

Lamas, G. 2008. La sistemática sobre mariposas (Lepidoptera: Hesperioidea y Papilionoidea) en el mundo: Estado actual y perspectivas futuras. In: Contribuciones taxonómicas en órdenes de insectos hiperdiversos. LlorenteBousquets, J. \& A. Lanteri (eds.). Las Prensas de Ciencias, UNAM. México D. F. pp. 57-70.

Lewinsohn, T.M. \& Prado, P.I. 2002. Biodiversidade brasileira: síntese do estado atual do conhecimento. São Paulo: Editora Contexto.

Malicky, H. 1970. New aspects of the association between lycaenid larvae (Lycaenidae) and ants (Formicidae, Hymenoptera). Journal of the Lepidopteristis' Society, 24: 190-202.

Marquis, R. J.; H. C. Morais \& I. R. Diniz. 2002. Interactions among Cerrado plants and their herbivores: unique or typical. In: The Cerrados of Brazil - Ecology and Natural History of a Neotropical Savanna. Oliveira, P.S. \& Marquis, R.J. (eds). Columbia University Press, pp. 306-328.

Monteiro, R.F. 1990. Aspectos ecológicos de teclíneos (Lepidoptera: Lycaenidae) com especial referência à coloração críptica de duas espécies de Rekoa Kaye. Doutorado em Ecologia, Universidade Estadual de Campinas, Campinas, SP, Brasil.

Monteiro, R.F. 1991. Cryptic larval polychromatism in Rekoa marius Lucas and $R$. palegon Cramer (Lycaenidae: Theclinae). Journal of Research on the Lepidoptera, 29: 77-84.

Morais, H.C.; Hay, J.D.V. \& Diniz, I.R. 2009. Brazilian cerrado folivore and florivore caterpillars: how different are they? Biotropica, 41(4): 401-405.

Oliveira, P.S. \& Del-Claro, K. 2005. Multitrophic interactions in a neotropical savanna: ant-hemipteran systems, associated insect herbivores and a host plant. In: D.F.R.P. Burslem, M.A. Pinard \& S.E. Hartley (eds.). Biotic interactions in the tropics: their role in maintenance of species diversity. Cambridge, Cambridge University Press, pp. 414-438.

Pierce, N.E. \& Mead, P.S. 1981 Parasitoids as selective agents in the symbiosis between lycenid butterfly caterpillars and ants. Science, 211: 1185-1187.

Pierce, N.E.; Braby, M.F.; Heath, A.; Lohman, D.J.; Mathew, J.; Rand D.B. \& Travassos, M.A. 2002. The ecology and evolution of ant association in the Lycaenidae (Lepidoptera). Annual Review of Entomology, 47: 733-771.

Ribeiro, J.F. \& Walter, B.M.T. 2008. As principais fitofisionomias do Bioma Cerrado. In: Sano, S.M.; Almeida, S.P. \& Ribeiro, J.F. (eds.). Cerrado: ecologia e flora. Vol. 1. Embrapa Informação Tecnológica, Brasília/DF, pp. 153-212.

Robbins, R.K. 1991. Cost and evolution of a facultative mutualism between ants and lycaenid larvae (Lepidoptera). Oikos, 62: 363-369.

Robbins, R.K. 2004. Introduction to the checklist of Eumaeini (Lycaenidae). In: Lamas G, editor. Checklist: Part 4A. Hesperioidea - Papilionoidea. In: J.B. Heppner (ed.). Atlas of Neotropical Lepidoptera. Volume 5A. Association for Tropical Lepidoptera, Gainesville, pp. xxiv-xxx.

Robbins R.K. \& Aiello A. 1982. Foodplant and oviposition records for Panamanian Lycaenidae and Riodinidae. Journal of the Lepidopterist Society, 36:65-75.

Silva, N.A.P.; Duarte, M.; Araujo, E.B. \& Morais, H.C. 2014. Larval biology of anthophagous Eumaeini (Lepidoptera: Lycaenidae, Theclinae) in the Cerrado of central Brazil. Journal of Insect Science, 14(184). DOI: 10.1093/jisesa/ieu046. 
Silva, N.A.P.; Duarte, M.; Diniz, I.R. \& Morais, H.C. 2011. Host plants of Lycaenidae on inflorescences in central Brazilian cerrado. Journal of Research on the Lepidoptera, 44: 95-105.

Wagner, D. \& Kurina, L. 1997. The influence of ants and water availability on oviposition behaviour and survivorship of a facultatively ant-tended herbivore. Ecological Entomology, 22 (3): 352-360.

Zalucki, M.P.; Clarke, A.R. \& Malcolm, S.B. 2002. Ecology and behavior of first instar larval Lepidoptera. Annual Review of Entomology, 47: 361-393. 


\section{CAPÍTULO I}

Efeitos da abundância e diversidade de recursos florais e formigas mutualistas em uma comunidade de lagartas florívoras (Lepidoptera: Lycaenidae)

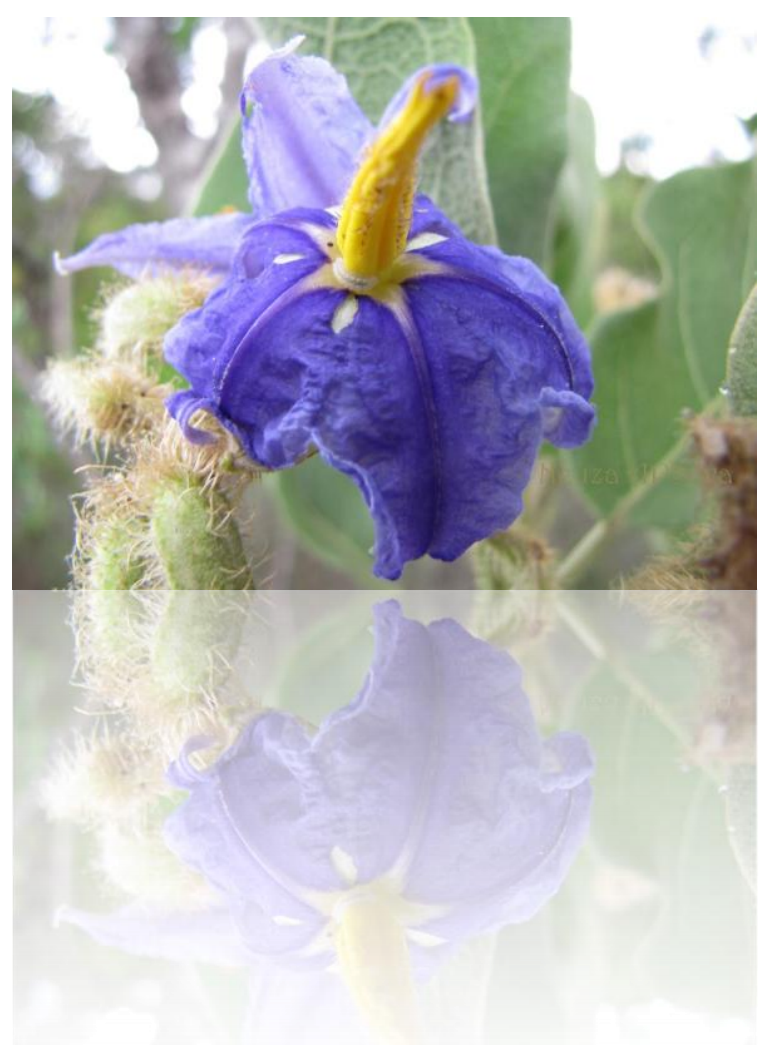




\subsection{INTRODUÇÃO}

A diversidade e abundância dos insetos fitófagos podem ser afetadas pelas variações espaciais e temporais na composição da vegetação, nas formas de crescimento e na qualidade nutricional das plantas (Fernandes \& Price 1992, Kelly \& Southwood 1999, Pais \& Varanda 2003, Oliveira 2008, Silva et al. 2011a).

A hipótese da abundância do recurso pressupõe que as plantas que apresentam mais recursos têm o potencial para sustentar mais espécies e maiores abundâncias de insetos herbívoros, enquanto que a hipótese da concentração dos recursos prediz que as plantas que ocorrem em maior densidade são mais facilmente encontradas pelos herbívoros (Ohgushi 1992, Hunter 1992, Kelly \& Southwood 1999). A complexidade estrutural das plantas (por ex. tamanho) também é importante para a diversidade de herbívoros, pois plantas mais altas são de fácil localização e fornecem diferentes estratos para abrigos e alimentação (Lawton 1983, Costa et al. 2011). A abundância de recursos vegetais disponíveis pode ser medida de diferentes formas como a sincronia de folhas novas sendo produzidas, biomassa ou partes das plantas (por ex. folhas, inflorescências, frutos) ou o indivíduo inteiro (Thomson 1981, Hill 1992, Marques et al. 2000, Kursar et al. 2006, Varanda \& Pais 2006).

Para os lepidópteros herbívoros, a escolha do local para oviposição e alimentação pode ser consequência de restrições filogenéticas, da história de vida do inseto e da acessibilidade ao potencial hospedeiro e depende das características morfológicas (morfologia floral ou foliar) e dos compostos químicos produzidos pelas plantas (Kelly \& Southwood 1999, Forister 2005, Hopkins et al. 2009, Rodrigues et al. 2010). Desta forma, insetos que se especializam em determinadas espécies, ou tecidos vegetais, são mais eficientes na localização e na utilização do seu recurso (Forister 2004, Stefanescu et al. 2006). Entretanto, variações espaciais e sazonais na composição química e na fenologia das plantas hospedeiras podem afetar a abundância dos insetos e suas interações com competidores e inimigos naturais (Coley et al. 1985, Hughes 2000, Kursar et al. 2006, Elzinga et al. 2007, Gingras et al. 2008, Costa et al. 2011).

Por exemplo, estudos com insetos galhadores no Cerrado revelaram uma maior abundância e diversidade desses organismos localizadas em habitats mais xéricos do que aqueles próximos a fontes de água (Fernandes \& Price 1992). A preferência das fêmeas de galhadores em ovipor em plantas com relativo déficit hídrico, esclerofilas, 
pode ser consequência de um conjunto de fatores, e pode incluir um espaço livre de inimigos naturais (Fernandes \& Price 1992; Fernandes et al. 1997).

A variação na qualidade e na disponibilidade de recursos faz com que espécies de lepidópteros que utilizam recursos efêmeros, como inflorescências e folhas novas, sejam capazes de sincronizar seu ciclo de vida com o da planta hospedeira ou usar esse recurso de forma sequencial, o que favorece a diversificação da dieta (Thompson 1983, Fiedler 1995b, Morais et al. 2009). A sincronia com a floração da planta hospedeira é muito importante para especialistas florívoros, pois implica na densidade de ovos e na sobrevivência das lagartas (Rodriguez et al. 1994). Por outro lado, para os insetos herbívoros generalistas, o efeito da abundância do recurso deve ser maior para aqueles capazes de escolher as espécies de plantas com mais recursos disponíveis, contribuindo para a maior abundância em um local (Quinn et al. 1998, Hughes 2000, Marques et al. 2000, Costa et al. 2011).

Para lagartas de borboletas da família Lycaenidae com ampla distribuição e riqueza de espécies na região Neotropical (Brown Jr. 1993), a presença de formigas em um habitat também pode ter efeitos significativos sobre a abundância relativa das espécies. Estudos têm mostrado que a oviposição de licenídeos fitófagos pode ser guiada pela presença de formigas nas plantas, utilizadas como um recurso de defesa contra predadores e parasitoides (Atsatt 1981, Seufert \& Fiedler 1999, revisão em Pierce et al. 2002). Este comportamento (mirmecofilia) é mantido por órgãos especializados nas lagartas, que secretam voláteis e substâncias nutritivas que servem de alimento para as formigas (Malicky 1970). A tendência das fêmeas utilizarem formigas como pistas na seleção da planta hospedeira tem sido considerada importante na evolução da polifagia de muitos desses lepidópteros, envolvendo tanto plantas com maior disponibilidade de recursos (nitrogênio) para lagartas, como plantas com maior atratividade para formigas (nectários extraflorais e hemípteros trofobiontes) (Baylis \& Pierce 1991, Fiedler 1995a, Kaminski et al. 2010).

Interações entre lagartas de borboletas e formigas podem ser classificadas em diferentes graus de dependência, em um gradiente desde associações obrigatórias a facultativas. Para Plejebus argus L. (Lycaenidae, Polyommatinae), por exemplo, uma espécie europeia com mirmecofilia obrigatória, a presença de ovos é maior em locais com maior frequência da formiga associada, no entanto, Seymour et al. (2003) argumentam que a presença da formiga especifica está relacionada a solos mais úmidos, assim $P$. argus poderia usar estas pistas do habitat para localizar e reconhecer as 
manchas de suas parceiras (Seymour et al. 2003). Para os Lycaenidae da região Neotropical são conhecidas apenas espécies com mirmecofilia facultativa (DeVries 1991, Kaminski et al. 2012). Os fatores que influenciam a variação nesta interação ainda não são bem entendidos (Peterson 1995, Kaminski \& Freitas 2010). Na verdade, as interações facultativas são condicionais e os custos e benefícios das interações dependem de muitos fatores. Por exemplo, Burghardt \& Fiedler (1996) mostraram que lagartas de um licenídeo com mirmecofilia facultativa e que se alimentam em plantas com estresse nutricional, podem ser menos visitadas pelas formigas devido à baixa qualidade da recompensa oferecida. O melhor desempenho das lagartas, tanto em desenvolvimento quanto nas interações, corresponde ao maior conteúdo de nitrogênio e água presente nas inflorescências do que sobre as folhas (Burghardt \& Fiedler 1996).

A maioria dos Lycaenidae Neotropicais pertence a tribo Eumaeini (Theclinae), uma linhagem monofilética com grande riqueza (Robbins 2004). Espécies desta tribo utilizam, comumente, botões florais e flores como recurso alimentar, mas podem ser encontradas, também, em folhas jovens, flores caídas e frutos (Fiedler 1995b, Calvo 1998, Silva et al. 2011b). Alguns estudos indicam maior diversidade de certos gêneros em ambientes xéricos da América Central à América do Sul (Robbins \& Nicolay 2001, Robbins 2010) e de espécies restritas a áreas do Cerrado no Brasil Central (Brown Jr. 1993).

Levantamentos em áreas do Cerrado no Distrito Federal (DF) registraram pelo menos 112 espécies de Lycaenidae das quais 76 ocorrem na Área de Proteção Ambiental (APA) Gama e Cabeça de Veado (Emery et al. 2006, Pinheiro \& Emery 2006, Silva et al. 2011b). A APA possui diversos tipos de vegetação do Cerrado, desde áreas de campos a matas de galeria (Ratter 1980, Munhoz \& Felfili 2005). Campo sujo, por exemplo, é uma fitofisionomia tipicamente arbustivo-herbácea, com cobertura arbórea menor que $5 \%$ e onde espécies que ocorrem também no cerrado sensu stricto são menos desenvolvidas (Ribeiro \& Walter 2008). Campo sujo pode ser encontrado desde áreas mais elevadas sobre pequenos afloramentos rochosos a áreas mais baixas, variando em solos com diferentes condições de drenagem e disponibilidade de nutrientes, o que contribui para a diferenciação da composição e da riqueza florística (Munhoz \& Felfili 2006, Ribeiro \& Walter 2008). As peculiaridades dos campos sujos tornam esses locais mais propensos a ter espécies endêmicas (Ribeiro \& Fernandes 2000). 
Pouco é conhecido a respeito da disponibilidade dos recursos e a relação na abundância e interações das espécies de Lycaenidae (Hill 1992), principalmente em fitofisionomias do Cerrado. Este estudo explora a influência da abundância e disponibilidade de recursos, aqui tratados como o número de inflorescências e presença de formigas nas plantas, sobre os imaturos de licenídeos em áreas de campo sujo no DF. A especialização em um tecido vegetal conspícuo como as inflorescências torna os licenídeos, particularmente os Eumaeini, um grupo interessante para o desenvolvimento desse tipo de estudo, pois a fonte de erro tende a ser reduzida na detecção do recurso disponível. E também, de um modo geral, o Cerrado oferece uma diversidade de espécies de plantas que florescem ao mesmo tempo, e apresenta uma rica fauna de formigas e interações mirmecófilas (Oliveira \& Freitas 2004). Além disso, lagartas de licenídeos possuem baixa mobilidade e não costumam mudar de inflorescências, completam seu desenvolvimento em uma única planta e o deslocamento da planta pode ocorrer somente no momento da empupação.

Desta forma, o objetivo geral deste estudo foi avaliar a diversidade e a variação na disponibilidade de recursos (inflorescências, presença de formigas) e a ocorrência de imaturos (ovos e lagartas) de Lycaenidae em áreas de campo sujo. A pesquisa foi desenvolvida partindo do pressuposto de que existe uma relação positiva entre a abundância de recursos e a abundância dos florívoros. Assim, foi verificado se (1) a variação na abundância de inflorescências afeta a abundância de imaturos de Lycaenidae; se (2) a variação da composição florística difere entre as áreas e se esta diferença afeta a composição de espécies de Lycaenidae e se (3) a abundância de plantas com presença de formigas tem relação com a abundância das lagartas florívoras, tendo em vista que espécies de Eumaeini, mesmo com mirmecofilia facultativa, utilizam a presença de formigas para guiar a oviposição. 


\subsection{METODOLOGIA}

\section{Local do estudo}

O estudo foi realizado em áreas de campo sujo na Fazenda Água Limpa (FAL) (Figura 1), fazenda experimental da Universidade de Brasília, com uma área de aproximadamente 4.300 ha e que faz parte da Área de Proteção Ambiental Gama e Cabeça de Veado, no Distrito Federal. O clima da região é sazonal, com o verão chuvoso (outubro a abril) e o inverno seco (maio a setembro). A precipitação média no período de coletas, de janeiro a abril de 2014, foi de $188,8 \mathrm{~mm}$, a temperatura média $22,5^{\circ} \mathrm{C}$, e a umidade relativa média $76 \%$ (RECOR 2014).

\section{Período de coletas e áreas amostradas}

A avaliação da diversidade e abundância de recursos (inflorescências e presença de formigas) e dos imaturos (ovos e lagartas) de Lycaenidae foi realizada entre os meses de janeiro e abril de 2014. Esse período foi selecionado porque a floração em áreas de campo ocorre o ano todo, no entanto, uma maior concentração de espécies em florescimento tende a ser encontrada do meio para o final da estação chuvosa (Munhoz \& Felfili 2005). Além disso, a riqueza florística do estrato arbustivo-herbáceo de campo sujo também varia espacialmente (Munhoz \& Felfili 2005, Munhoz \& Felfili 2006). Desta forma, foram selecionadas quatro áreas de campo sujo na FAL. Duas localizadas em pontos mais elevados na Fazenda, mais distantes de fonte de água, e aparentemente com aspecto mais seco e duas em campos sujos de baixada, mais próximos às matas de galeria dos córregos Gama e Taquara (Tabela 1 e Figura 1). Para facilitar a leitura no decorrer do texto aqui serão utilizadas as abreviações A1E e A3E correspondendo às áreas mais elevadas (E), mais distantes de córregos na FAL e A2B e A4B correspondendo às áreas de baixada (B), mais próximas aos córregos. Esses locais são distantes em, pelo menos, um quilometro para prevenir pseudoreplicações. 
Tabela 1. Referências da localização das quatro áreas de campo sujo com inflorescências coletadas nas parcelas e examinadas em busca de imaturos de Lycaenidae na Fazenda Água Limpa/DF entre janeiro e abril de 2014. Número de parcelas e total $\left(\mathrm{m}^{2}\right)$ das áreas amostradas nos campos sujos. A1E-A3E= Elevadas, áreas distantes de córregos e A2B-A4B =Baixada, áreas próximas a córregos. As parcelas são consideradas replicas das áreas.

\begin{tabular}{|c|c|c|c|c|c|}
\hline Áreas & Ref. na FAL & Coordenadas & $\begin{array}{l}\text { Altitude } \\
\text { média }\end{array}$ & $\begin{array}{c}\text { n. parcelas } \\
\left(4 \mathbf{m}^{2}\right)\end{array}$ & $\begin{array}{l}\text { Área } \\
\text { total }\end{array}$ \\
\hline A1E & $\begin{array}{l}\text { Mirante (próx. a } \\
\text { BR 251) }\end{array}$ & $\begin{array}{l}15^{\circ} 58^{\prime}, 542^{\prime \prime} \mathrm{S} \\
47^{\circ} 56^{\prime} 889^{\prime \prime} \mathrm{O}\end{array}$ & $1.195 \mathrm{~m}$ & 50 & $200 \mathrm{~m}^{2}$ \\
\hline A2B & $\begin{array}{l}\text { Próx. ao córrego } \\
\text { Gama }\end{array}$ & $\begin{array}{l}15^{\circ} 57^{\prime} 177^{\prime \prime} \mathrm{S} \\
47^{\circ} 57^{\prime} 661, ' \mathrm{O}\end{array}$ & $1.090 \mathrm{~m}$ & 50 & $200 \mathrm{~m}^{2}$ \\
\hline A3E & $\begin{array}{l}\text { Acima do córrego } \\
\text { Capetinga }\end{array}$ & $\begin{array}{l}15^{\circ} 57^{\prime} 771^{\prime \prime} \mathrm{S} \\
47^{\circ} 57^{\prime} 320^{\prime \prime} \mathrm{O}\end{array}$ & $1.140 \mathrm{~m}$ & 50 & $200 \mathrm{~m}^{2}$ \\
\hline$A 4 B$ & $\begin{array}{l}\text { Próx. ao córrego } \\
\text { Taquara }\end{array}$ & $\begin{array}{l}15^{\circ} 56^{\prime} 200^{\prime \prime} \mathrm{S} \\
47^{\circ} 54^{\prime} 239^{\prime \prime} \mathrm{O}\end{array}$ & $1.074 \mathrm{~m}$ & 50 & $200 \mathrm{~m}^{2}$ \\
\hline Total & & & & 200 & $800 \mathrm{~m}^{2}$ \\
\hline
\end{tabular}

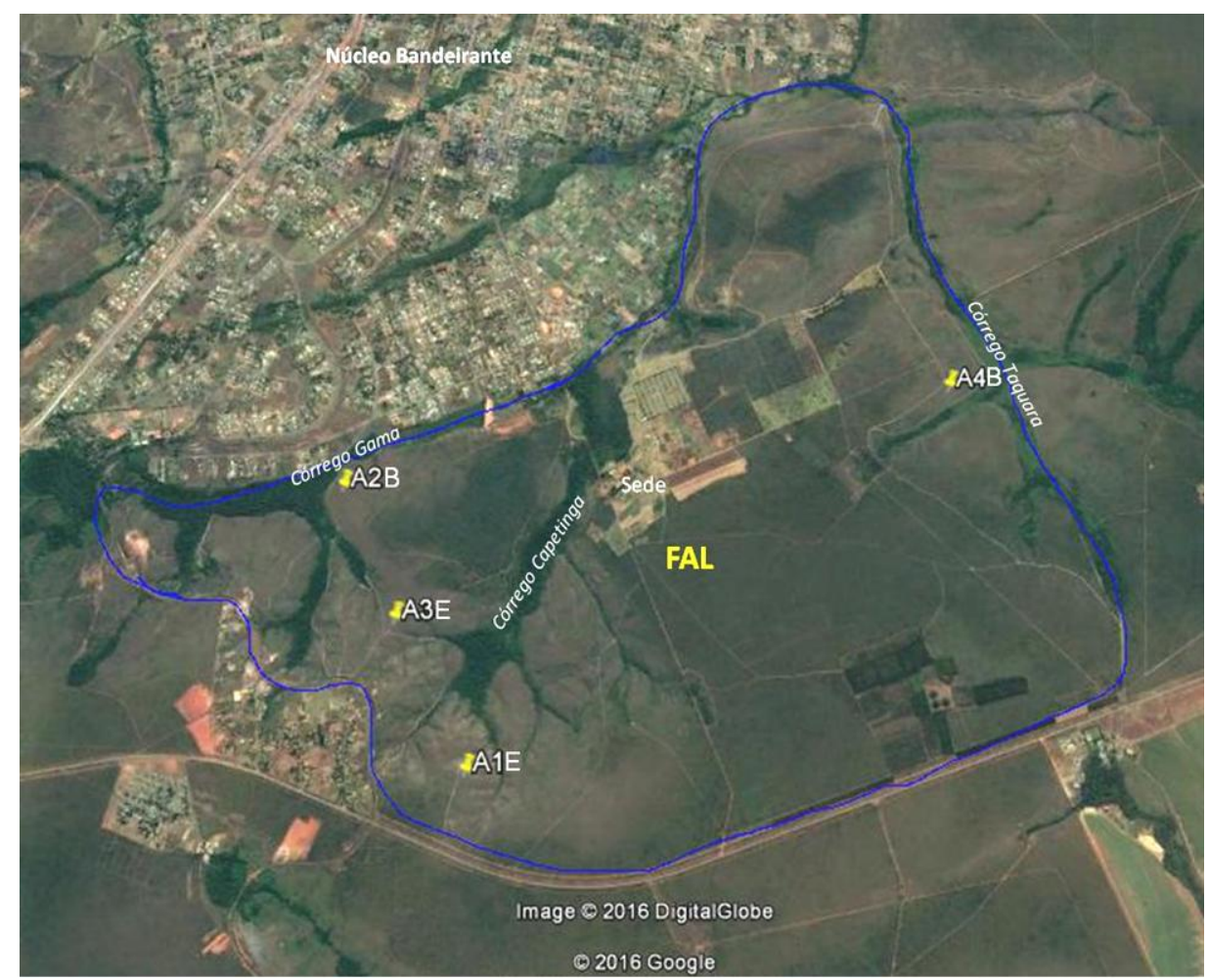

Figura 1. Localização das quatro áreas de campo sujo onde foram feitas parcelas para coleta e vistoria de inflorescências em busca de imaturos de Lycaenidae na Fazenda Água Limpa (FAL), DF, entre janeiro e abril de 2014. Áreas A1E e A3E=Elevadas, campos sujos mais distantes de córregos e A2B e A4B=Baixada, campos sujos próximos aos córregos Gama e Taquara. 


\section{Trabalho de campo e laboratório}

Semanalmente foram amostradas duas áreas, uma em campo mais distante da fonte de água (A1E ou A3E) e outra de baixada, próxima a córrego (A2B ou A4B) (Figura 1). No início e ao final de cada amostragem foi feita uma marcação do ponto com GPS (Garmin Etrex $\left.{ }^{\circledR} \mathrm{H}\right)$ e com fita colorida, com o intuito de ter a altitude média da área percorrida (Tabela 1) e para evitar a repetição dos espécimes de plantas. Para cada área foram marcadas 10 parcelas temporárias de $2 \times 2 \mathrm{~m}\left(4 \mathrm{~m}^{2}\right)$, totalizando $40 \mathrm{~m}^{2}$ de área amostrada a cada dia de campo. Ao menos uma planta com inflorescência deveria estar presente para a marcação da parcela. $O$ trajeto para as coletas foi percorrido, preferencialmente, em linha reta e com distância de até 5 metros entre parcelas. Ao longo do período de coletas (janeiro a abril), foram examinadas 50 parcelas em cada área $\left(200 \mathrm{~m}^{2}\right)$ quanto à abundância de inflorescências, imaturos de licenídeos e a presença de formigas (total de 200 parcelas de $4 \mathrm{~m}^{2}=800 \mathrm{~m}^{2}$ ). O levantamento foi feito por coleta manual e quantificação de todas as inflorescências encontradas (exceto gramíneas) dentro das parcelas.

No campo, as inflorescências foram primeiramente examinadas quanto à presença de formigas que, quando presentes, foram capturadas e conservadas em frascos contendo álcool a 70\%. Em seguida, as inflorescências foram coletadas individualmente em sacos plásticos, e encaminhadas ao laboratório. Em laboratório, as vistorias das inflorescências eram iniciadas no mesmo dia da coleta, no entanto, devido ao grande volume de amostras, primeiro foram vistoriadas aquelas inflorescências com maior risco de deteriorização, por exemplo, com flores maiores (p. ex. Arrabidaea brachypoda (DC.), Bignoniaceae) ou com aglomerados de botões florais. Desta forma, algumas inflorescências permaneciam nos sacos plásticos por até dois dias para a vistoria. Nesse intervalo os sacos plásticos contendo as amostras eram mantidos dependurados e, enventualmente, eram abertos para troca gasosa, ou enxugados em seu interior se necessário, de forma a prevenir o acúmulo de umidade pela transpiração do vegetal, o que poderia acarrretar no afogamento dos insetos, além no risco de contaminação por fungos. As inflorescências foram minuciosamente examinadas quanto à presença de ovos e lagartas. Lagartas de licenídeos comumente adquirem à coloração da inflorescência consumida que aliada à morfologia as tornam altamente crípticas no substrato (Monteiro 1991, Silva et al. 2014), desta forma a vistoria em laboratório foi importante, pois permitiu manusear com segurança ramos com aglomerados florais e 
utilizar lupa estereoscópica, o que facilita também o encontro das lagartas em primeiro ínstar.

Os ovos e lagartas encontrados foram mantidos individualmente sobre inflorescência da espécie de planta hospedeira, sem controle de luz e temperatura, em potes plásticos de 120 e $300 \mathrm{ml}$ protegidos com tecido tipo filó e/ou com plástico preso com elástico. Os recipientes foram inspecionados com intervalo de dois a três dias para limpeza e reposição do alimento. O suprimento de inflorescências foi mantido sob refrigeração e renovado semanalmente com novas coletas. O desenvolvimento dos lepidópteros foi acompanhado até a emergência do adulto. Observações quanto ao desenvolvimento e o comportamento das lagartas sobre a inflorescência em laboratório foram registrados e todos os estágios foram fotografados.

\section{Identificação das plantas e dos licenídeos}

Amostras das espécies de plantas que não puderam ser reconhecidas no campo foram coletadas, herborizadas e encaminhadas para identificação botânica junto a especialistas no Herbário da Universidade de Brasília. Ovos não eclodidos e espécimes de lagartas sem exemplar adulto foram comparados com amostras preservadas e considerados como morfoespécies. As borboletas foram identificadas por comparação com exemplares de Lycaenidae da Coleção Entomológica do Departamento de Zoologia da Universidade de Brasília (CEDZ-UnB) e pelo Dr. Marcelo Duarte (Museu de Zoologia da Universidade de São Paulo-MZUSP). Os espécimes imaturos que morreram durante o processo de criação ou separados para estudos futuros foram conservados em solução de Kahle e, assim com as borboletas foram depositadas na CEDZ-UnB. As formigas foram conservadas em álcool a $70 \%$ e separadas para a identificação por especialistas e, posteriormente também serão depositados na CEDZUnB.

\section{Análise dos dados}

A riqueza e a abundância das espécies, tanto dos imaturos quanto das plantas e inflorescências, bem como a presença de formigas, foram calculadas para cada área separadamente e em conjunto considerando a localização das áreas na FAL, ou seja, mais distantes de córregos (A1E+A3E) e mais próximas aos córregos (A2B+A4B). As 
riquezas, tanto de plantas como de licenídeos foram comparadas com curvas de rarefação de indivíduos considerando a diferença na abundância de espécies entre as áreas (Magurran 2004).

As medidas de diversidade foram realizadas utilizando o perfil de diversidade de Rényi. Com este método é possível comparar a diversidade entre as áreas com diferentes índices simultaneamente. Ele é considerado conveniente já que elimina a escolha arbitrária de índices e a subjetividade na interpretação dos valores para as comparações (Tóthmérész 1995). Os índices são representados graficamente por parâmetros alfa $(\alpha)$, onde $\alpha=0$ representa a riqueza total de espécies, $\alpha=1$ é equivalente ao índice de Shannon, sensitivo à contribuição de espécies raras para a diversidade, $\alpha=2+$ se comporta como o índice de Simpson, com sensitividade maior para espécies frequentes, neste caso a função converge para abundância relativa das espécies mais comuns (Tóthmérész 1995, Hammer et al. 2001, Magurran 2004). A comparação entre os perfis se dá pela altura da linha correspondente a determinado grupo, linha superior indica maior diversidade em relação aos que estão alinhados abaixo, os perfis onde as linhas se cruzam são "não comparáveis", pois correspondem a resultados que não podem ser ordenados e geram subjetividade segundo Tóthmérész (1995). O perfil de Rényi fornece também informações sobre a riqueza e a uniformidade da distribuição das espécies que são apresentadas em um ranking de abundância, quanto mais horizontal o perfil maior a equabilidade na distribuição das espécies (Magurran 2004, Kindt \& Coe 2005).

A similaridade (ou dissimilaridade) das espécies nas áreas foram medidas com índice Bray-Curtis que leva em consideração a abundância relativa das espécies. Em seguida foi realizada análise de agrupamento, com o método de ligação simples, onde duas amostras mais similares são combinadas e formam um só grupo. Foi utilizado o teste Shapiro-Wilk (p-valor <0.05) para verificar a normalidade dos dados. Todas essas análises foram realizadas utilizando o programa estatístico PAST Version 3.12 (Hammer et al. 2001).

Para verificar os possíveis efeitos da abundância das plantas e inflorescências, bem como da presença de formigas sobre a abundância de ovos e lagartas (imaturos) de licenídeos, foram construídos modelos lineares generalizados (GLM, “generalized linear models"). Por se tratarem de dados de contagem foi utilizada a função de distribuição de Poisson (regressão de Poisson), e corrigidos para quasipoisson quando detectada subdispersão ou sobredispersão dos dados, que é quando a variação observada difere 
daquela assumida pelo modelo (Zuur et al. 2010). Para examinar se a abundância das espécies de plantas tem implicação sobre a abundância das espécies de licenídeos foi realizada análise com distribuição binomial com ajuste quasibinomial quando necessário. Foram feitas análises de comparações múltiplas post hoc, usando o pacote “multcomp" no programa estatístico R (Hothorn et al. 2016) quando apontadas diferenças com efeito significativo entre as áreas. Todas as análises GLM foram realizadas no programa $\mathrm{R}$ ( $\mathrm{R}$ Core Team 2014).

Os resultados estão apresentados inicialmente de maneira a caracterizar a abundância e a diversidade da vegetação nas áreas, em seguida são apresentados os resultados para licenídeos imaturos e subsequentemente para a presença de formigas nas plantas.

\subsection{RESULTADOS}

\section{Plantas e inflorescências: Riqueza, abundância e diversidade}

Foram examinadas 5.964 inflorescências de 1.049 plantas distribuídas em 125 espécies pertencentes a 34 famílias (Tabela 2, Anexos 1 e 2). Sete famílias foram mais representativas, entre elas Asteraceae com maior abundância de espécies $(n=34)$, de indivíduos $(n=442)$ e de inflorescências $(n=2.885)$, seguida de Malpighiaceae $(n=103$ indivíduos) e Acanthaceae ( $\mathrm{n}=102$ indivíduos). Juntas estas três famílias corresponderam a $61,6 \%$ das plantas e 65,5\% (n=3.908) das inflorescências examinadas. Outras quatro famílias, Convolvulaceae, Fabaceae, Rubiaceae e Melastomataceae, representaram $20,7 \%$ das plantas e $18,1 \%$ das inflorescências vistoriadas, as demais famílias $(\mathrm{n}=27)$ contribuíram com menos de $3 \%$ das espécies cada uma, totalizando $17,7 \%$ das plantas. Cinco famílias foram compartilhadas entre as quatro áreas (Asteraceae, Malpighiaceae, Fabaceae, Iridaceae, Lythraceae) (Anexo 1). No entanto, apenas duas compartilharam as mesmas espécies em floração entre todas as áreas (Malpighiaceae: Banisteriopsis campestris (A. Juss.) Little, Byrsonima pachyphylla A. Juss., Asteraceae: Vernonia monocephala Gardner).

A área A1E apresentou a maior abundância de plantas $(29,6 \%)$ e de inflorescências $(28,9 \%)$ devido, principalmente, ao maior número de Asteraceae presentes nesse local. Por outro lado, a área $\mathrm{A} 3 \mathrm{E}$ foi a que apresentou as menores 
abundâncias (Tabela 2, Figura 2). Mas não foram detectadas diferenças significativas entre as abundâncias médias das inflorescências $(\mathrm{F}=0,654 ; \mathrm{P}=0,58)$ e das plantas $\left(\chi^{2}\right.$ =3,19; g.l.= 3; $\mathrm{P}=0,362$ ) nas áreas (Figura 2). Em relação à riqueza de espécies, as curvas de rarefação (Figura 3) revelaram que as áreas próximas aos córregos, A4B e $\mathrm{A} 2 \mathrm{~B}$, foram as que apresentaram maior riqueza de plantas em floração, 59 e 45 espécies sendo 35 e 24 exclusivas, respectivamente. As áreas distantes da fonte de água, A1E e A3E, apresentaram 35 espécies e 15 exclusivas cada uma.

Tabela 2. Riqueza de espécies de plantas, de famílias e total de plantas e inflorescências examinadas em $200 \mathrm{~m}^{2}$ de cada uma das quatro áreas de campo sujo amostradas na Fazenda Água Limpa/DF entre janeiro e abril de 2014. A1E-A3E= Elevadas, áreas distantes de córregos e A2B-A4B =Baixada, áreas próximas córregos.

\begin{tabular}{ccccc}
\hline Áreas & $\begin{array}{c}\text { Riq. espécies } \\
\text { de plantas }\end{array}$ & Riq. de famílias & n. plantas $(\%)$ & n. inflor.(\%) \\
\hline A1E & 35 & 18 & $310(\mathbf{2 9 , 6})$ & $1.721(\mathbf{2 8 , 9 )}$ \\
A2B & 45 & 13 & $265(\mathbf{2 5 , 3})$ & $1.388(\mathbf{2 3 , 3})$ \\
A3E & 35 & 18 & $218(\mathbf{2 0 , 8})$ & $1.387(\mathbf{2 3 , 3})$ \\
A4B & 59 & 18 & $256(\mathbf{2 4 , 4 )}$ & $1.468(\mathbf{2 4 , 6 )}$ \\
\hline Total & $125^{*}$ & $34^{*}$ & $1.049(\mathbf{1 0 0})$ & $5.964(\mathbf{1 0 0})$ \\
\hline
\end{tabular}

*Total se refere à riqueza de espécies/família geral, sem considerar as compartilhadas. 

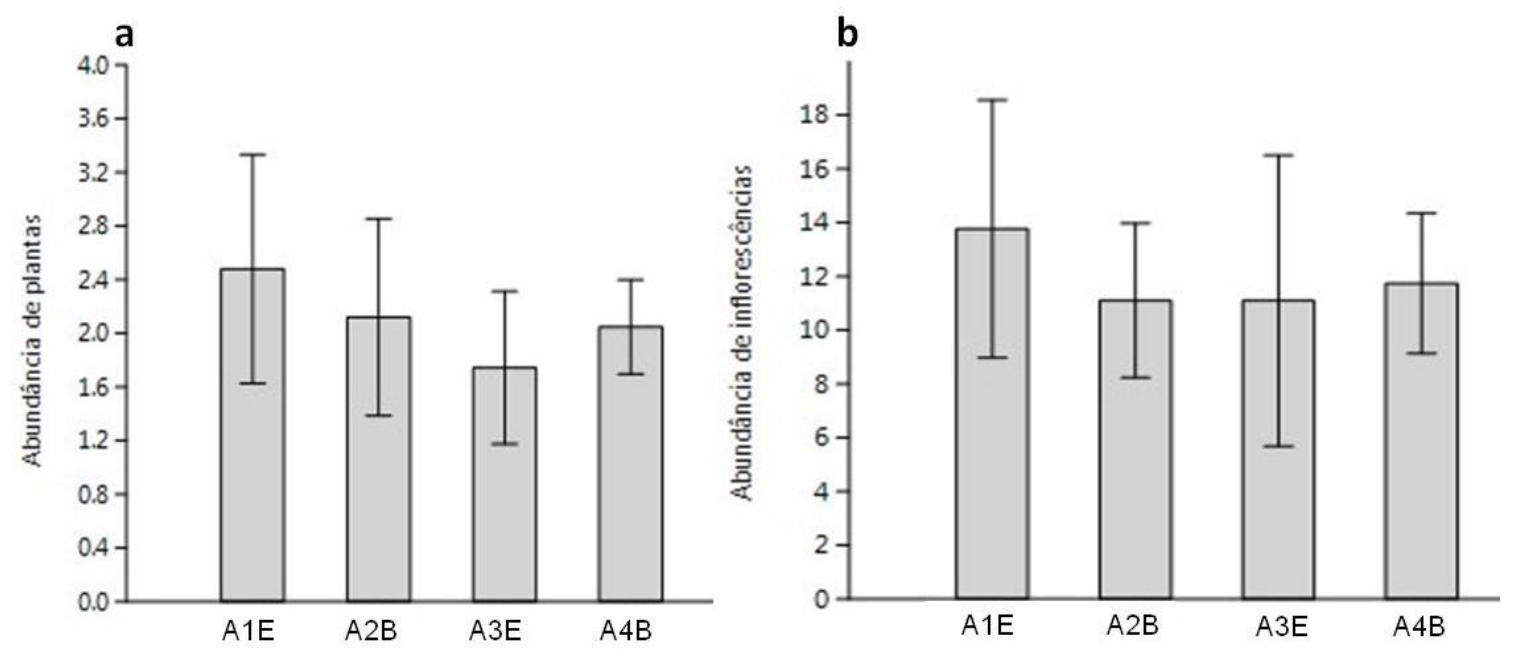

Figura 2. (a) Abundância média (+erro padrão) de plantas e (b) de inflorescências em cada uma das quatro áreas de campo sujo amostradas na Fazenda Água Limpa/DF entre janeiro e abril de 2014. A1E, A3E= Elevadas, áreas distantes de córregos e A2B, $\mathrm{A} 4 \mathrm{~B}=\mathrm{Baixada}$, áreas próximas a córregos.

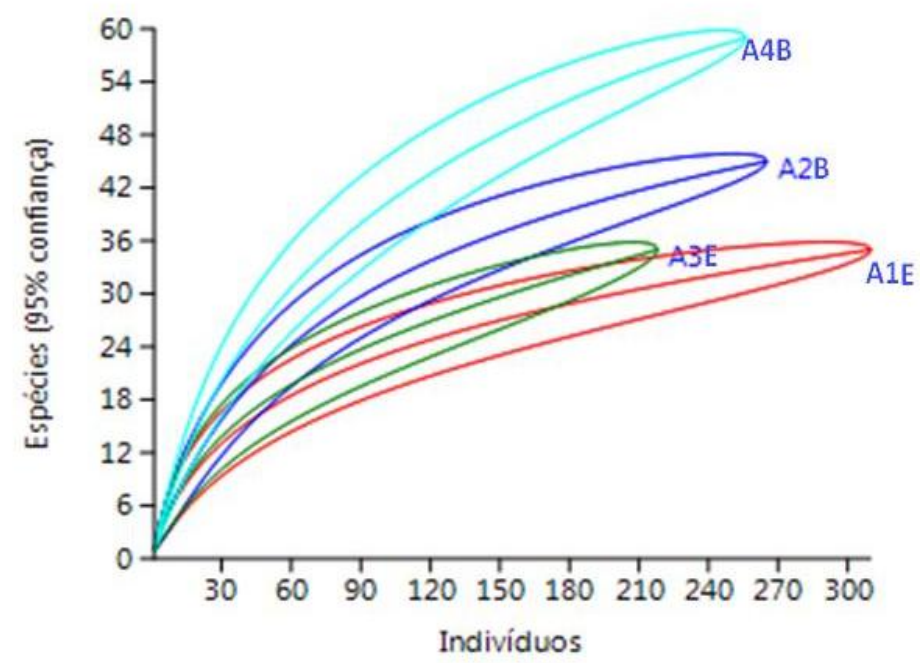

Figura 3. Curvas de rarefação de indivíduos de plantas em floração (com intervalo de 95\% de confiança) examinadas em busca de imaturos de Lycaenidae em quatro áreas de campo sujo amostradas na Fazenda Água Limpa/DF entre janeiro e abril de 2014. A1E, $\mathrm{A} 3 \mathrm{E}=$ Elevadas, áreas distantes de córregos e $\mathrm{A} 2 \mathrm{~B}, \mathrm{~A} 4 \mathrm{~B}=$ Baixada, áreas próximas a córregos.

A comparação com os perfis de diversidade de Rényi (Figura 4) para as plantas em floração em cada área mostra que a A4B foi a mais diversa em relação às demais. Os 
perfis da $\mathrm{A} 2 \mathrm{~B}$ e das áreas $\mathrm{A} 1 \mathrm{E}$ e $\mathrm{A} 3 \mathrm{E}$ apontam o quanto são diversas, no entanto, o cruzamento entre as linhas faz com que as mesmas sejam não comparáveis. Quando as áreas foram agrupadas considerando a distância em relação à fonte de água, o perfil confirmou maior riqueza e diversidade de plantas nas áreas de baixada, próximas aos córregos (Figura 4b).
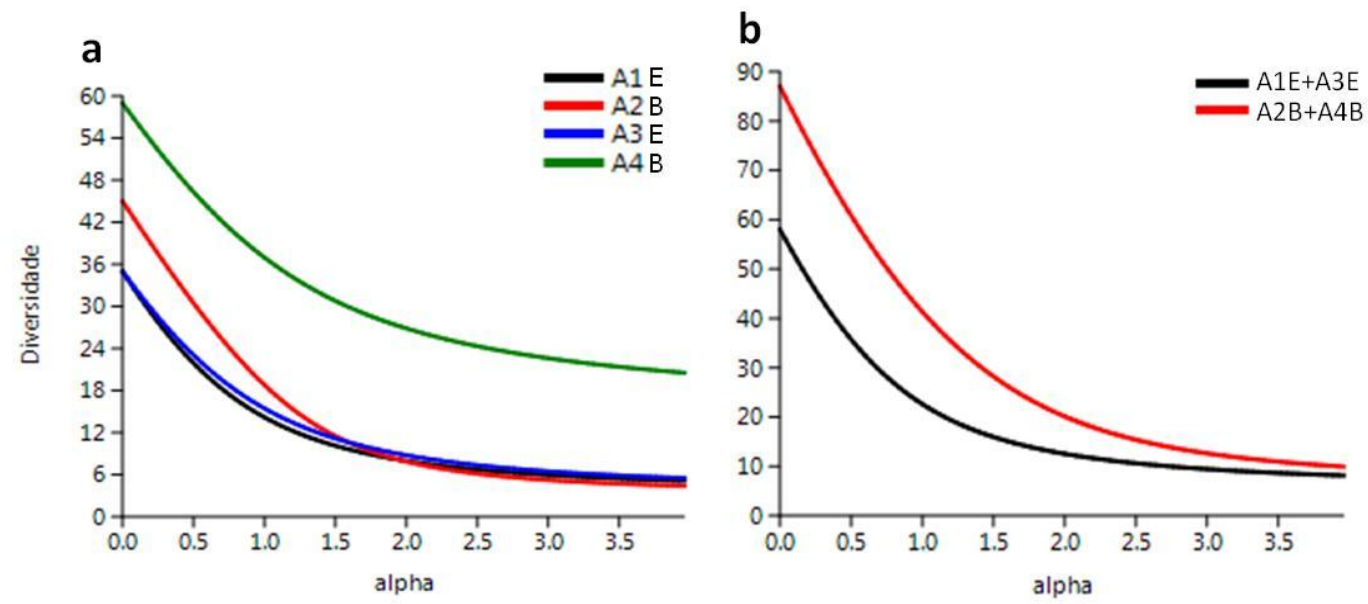

Figura 4. Perfis de diversidade de Rényi das espécies de plantas examinadas em busca de imaturos de Lycaenidae nas quatro áreas de campo sujo amostradas na Fazenda Água Limpa/DF entre janeiro e abril de 2014. (a) Diversidade nas quatro áreas e (b) Diversidade nas áreas agrupadas: $\mathrm{A} 1 \mathrm{E}-\mathrm{A} 3 \mathrm{E}=\mathrm{Elevadas,}$ áreas distantes de córregos e $\mathrm{A} 2 \mathrm{~B}-\mathrm{A} 4 \mathrm{~B}=\mathrm{Baixada}$, áreas próximas a córregos.

\section{Análise de similaridade das plantas em floração entre as áreas de campo sujo}

A avaliação da similaridade da composição de plantas entre as quatro áreas resultou no agrupamento da área $\mathrm{A} 1 \mathrm{E}$ com a $\mathrm{A} 3 \mathrm{E}$ com $19 \%$ de similaridade e $\mathrm{A} 2 \mathrm{~B}$ com a A4B com 22\% (Figura 5). Ou seja, em relação às abundâncias entre as áreas $81 \%$ e $78 \%$ das espécies são dissimilares, o que ressalta a diversidade dos locais examinados. A área A1E e A3E compartilham 12 espécies e 15 espécies são exclusivas de cada area; A2B e A4B compartilham 17 espécies e 35 e 24 são, respectivamente, exclusivas nessas áreas. Quando as áreas foram agrupadas em relação à localização na FAL, distantes $(\mathrm{A} 1 \mathrm{E}+\mathrm{A} 3 \mathrm{E})$ e próximas de córregos (A2B+A4B), o índice Bray-Curtis indicou 20\% de similaridade entre as áreas. 


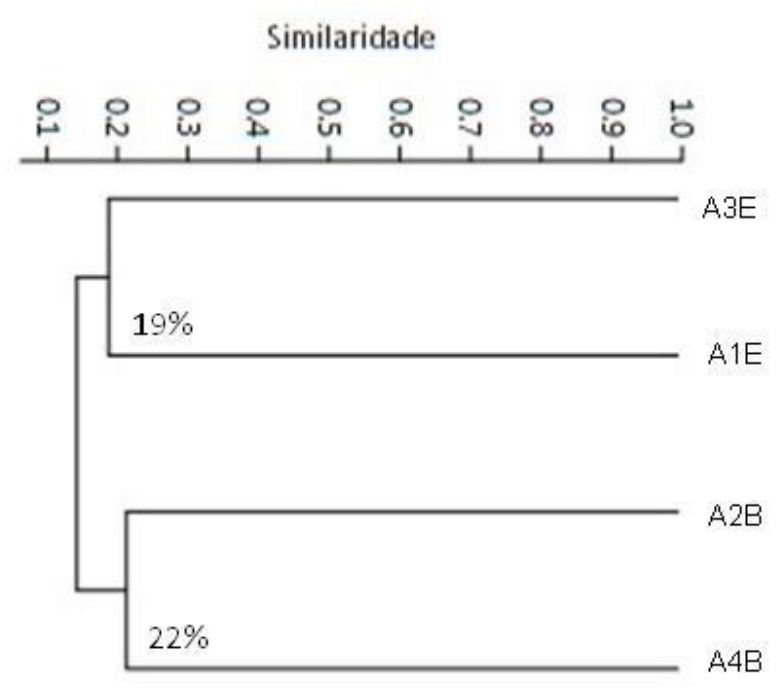

Figura 5. Dendograma de similaridade das espécies de plantas em floração examinadas em busca de imaturos de Lycaenidae nas quatro áreas de campo sujo amostradas na Fazenda Água Limpa/DF entre janeiro e abril de 2014. A1E, A3E= Elevadas, áreas distantes de córregos e $\mathrm{A} 2 \mathrm{~B}, \mathrm{~A} 4 \mathrm{~B}=\mathrm{Baixada}$, áreas próximas a córregos Análise pelo índice de similaridade Bray-Curtis, método de ligação simples.

\section{Imaturos de Lycaenidae: Riqueza, abundância e diversidade}

Foram encontrados 134 imaturos (61 ovos e 73 lagartas) de Lycaenidae em 72 plantas $(6,9 \%)$ com total de 923 inflorescências (15,5\% de 5.964) em 24 espécies $(19,2 \%$ de 125) de 13 famílias $(38,2 \%)$ (Tabela 3). Se for considerado o total de inflorescências vistoriadas $(n=5.964)$, independente da espécie, foram obtidos 2,2 imaturos em cada grupo de cem inflorescências. As famílias de plantas que abrigaram a maior abundância e riqueza de imaturos foram Malpighiaceae $(n=52$ imaturos de oito espécies), Fabaceae ( $n=33$ imaturos, três espécies) e Lytrhaceae ( $n=9$ imaturos de seis espécies) (Tabela 3, Figura 6).

Do total de ovos e lagartas registrados $(n=134), 72$ desenvolveram-se até adultos, 38 morreram por causas desconhecidas e por parasitismo, quatro adultos não emergiram das pupas e o restante foram ovos cujas lagartas não eclodiram $(n=14)$ e amostras preservadas $(n=6)$ para estudos futuros. Os imaturos estavam distribuídos em 22 espécies, sendo duas de Polyommatinae e 20 Theclinae (Eumaeini), não foi possível a identificação específica de sete desses Eumaeini que morreram enquanto lagartas, mas foram mantidos nas análises como morfoespécies (Tabela 4). Três espécies foram mais abundantes: Allosmaitia strophius (Godart) $(\mathrm{n}=29)$ em seis espécies de Malpighiaceae e 
presente nas quatro áreas, Ministrymon azia (Hewitson) $(\mathrm{n}=22)$ em duas espécies de Fabaceae, só não ocorreu na área A1, e Tmolus venustus $(H$. H. Druce) $(\mathrm{n}=15)$ também presente nas quatro áreas, ocorreu em cinco espécies de três famílias, Malpighiaceae, Fabaceae e em Rubiaceae, essa última como novo registro de hospedeira. Parrhasius polibetes (Stoll) presente em duas áreas, e duas morfoespécies ocorreram com sete indivíduos, as demais espécies $(\mathrm{n}=16)$ apresentaram menos de seis indivíduos cada uma (Tabela 4, Anexo 3 para lista de licenídeos e plantas hospedeiras).

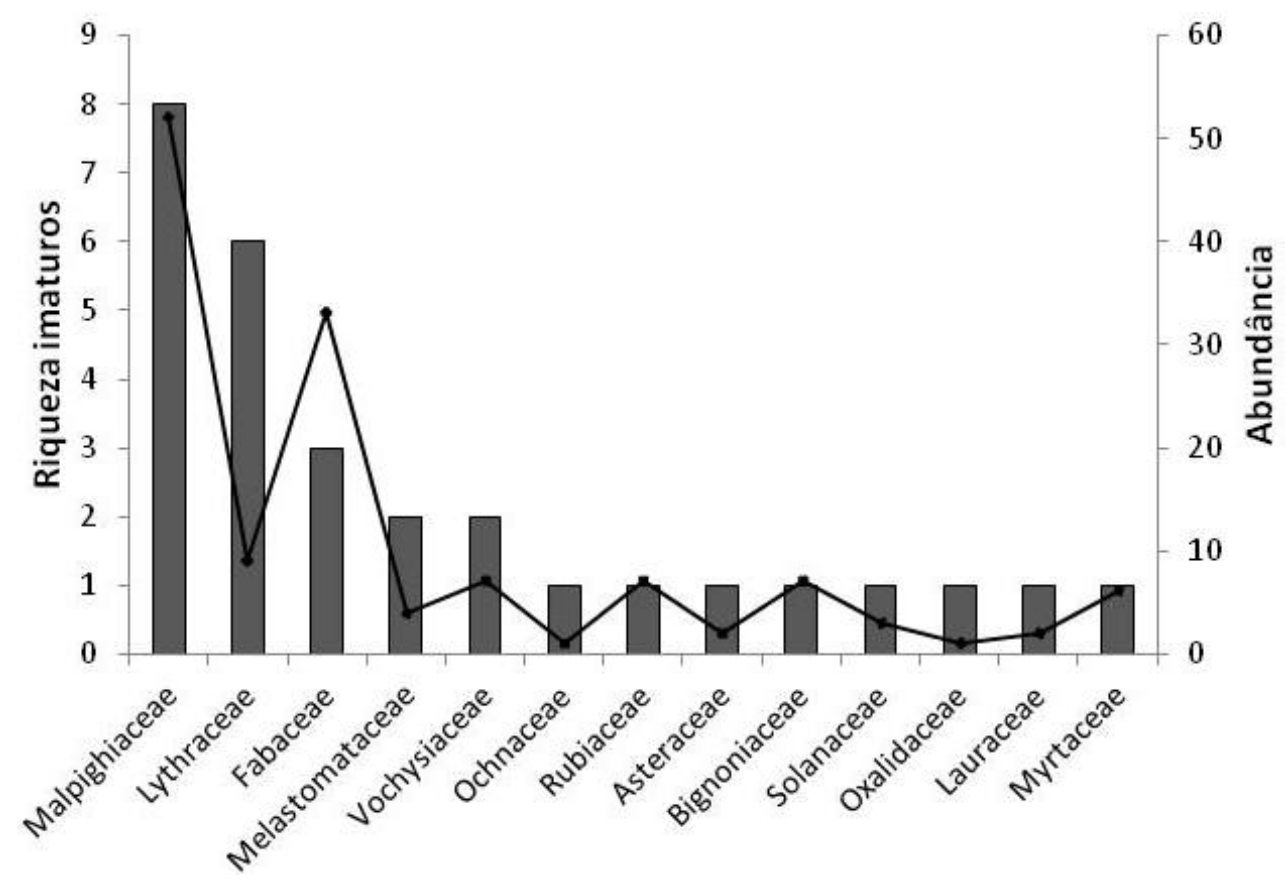

Figura 6. Riqueza (barras) e abundância (linha) de Lycaenidae imaturos em cada família de plantas hospedeiras em quatro áreas de campo sujo amostradas na Fazenda Água Limpa/DF entre janeiro e abril de 2014. 
Tabela 3. Famílias e espécies de plantas com inflorescências utilizadas como recurso pelos Lycaenidae nas quatro áreas de campo sujo amostradas na Fazenda Água Limpa/DF entre janeiro e abril de 2014. Total geral das plantas com inflorescências disponíveis como recurso, número efetivo de plantas utilizadas e de inflorescências presentes nelas; número de imaturos e de espécies de Lycaenidae encontrados.

\begin{tabular}{|c|c|c|c|c|c|c|}
\hline Famílias plantas & $\begin{array}{l}\text { Espécies } \\
\text { de plantas }\end{array}$ & $\begin{array}{c}\text { Total } \\
\text { plantas } \\
\text { disponíveis }\end{array}$ & $\begin{array}{l}\text { n. plantas } \\
\text { utilizadas }\end{array}$ & $\begin{array}{c}\text { n. } \\
\text { inflor. }\end{array}$ & $\stackrel{\mathbf{n} .}{\text { imaturos }}$ & $\begin{array}{c}\text { n. spp. } \\
\text { imaturos }\end{array}$ \\
\hline Asteraceae & Lepidaploa rufogrisea & 53 & 2 & 28 & 2 & 1 \\
\hline Bignoniaceae & Arrabidaea brachypoda & 1 & 1 & 10 & 7 & 1 \\
\hline Fabaceae & Mimosa claussenii & 11 & 3 & 23 & 4 & 1 \\
\hline Fabaceae & Galactia sp. & 7 & 4 & 16 & 5 & 3 \\
\hline Fabaceae & Mimosa foliosa & 7 & 3 & 16 & 18 & 1 \\
\hline Fabaceae & Galactia heringeri & 6 & 4 & 9 & 4 & 1 \\
\hline Fabaceae & Calliandra dysantha & 1 & 1 & 3 & 1 & 1 \\
\hline Fabaceae & Zornia sp. & 1 & 1 & 1 & 1 & 1 \\
\hline Lauraceae & Cassytha filiformis & 10 & 1 & 3 & 2 & 1 \\
\hline Lythraceae & Diplusodon oblongus & 4 & 3 & 174 & 9 & 6 \\
\hline Malpighiaceae & Banisteriopsis megaphylla & 7 & 4 & 165 & 12 & 5 \\
\hline Malpighiaceae & Banisteriopsis argyrophylla & 2 & 1 & 104 & 1 & 1 \\
\hline Malpighiaceae & Byrsonima pachyphylla & 44 & 19 & 86 & 25 & 5 \\
\hline Malpighiaceae & Peixotoa goiana & 4 & 4 & 63 & 5 & 3 \\
\hline Malpighiaceae & Heteropterys pteropetala & 12 & 3 & 26 & 7 & 2 \\
\hline Malpighiaceae & Camarea affinis & 2 & 1 & 2 & 2 & 1 \\
\hline Melastomataceae & Microlicia fulva & 21 & 1 & 28 & 2 & 1 \\
\hline Melastomataceae & Tibouchina sp. & 4 & 1 & 12 & 2 & 1 \\
\hline Myrtaceae & Psidium sp. & 1 & 1 & 1 & 6 & 1 \\
\hline Ochnaceae & Ouratea floribunda & 9 & 1 & 52 & 1 & 1 \\
\hline Oxalidaceae & Oxalis densifolia & 3 & 1 & 4 & 1 & 1 \\
\hline Rubiaceae & Sabicea brasiliensis & 34 & 7 & 49 & 7 & 1 \\
\hline Solanaceae & Solanum lycocarpum & 1 & 1 & 8 & 3 & 1 \\
\hline Vochysiaceae & Vochysia elliptica & 13 & 4 & 40 & 7 & 2 \\
\hline 13 famílias & 24 espécies plantas & 258 & 72 & 923 & 134 & 22 spp. \\
\hline
\end{tabular}


Tabela 4. Espécies de Lycaenidae, abundância de imaturos em cada área e número de espécies de plantas hospedeiras dos licenídeos imaturos encontrados nas quatro áreas de campo sujo amostradas na Fazenda Água Limpa/DF entre janeiro e abril de 2014. A1E, $\mathrm{A} 3 \mathrm{E}=$ Elevadas, áreas distantes de córregos e A2B, A4B =Baixada, áreas próximas a córregos.

\begin{tabular}{|c|c|c|c|c|c|c|}
\hline Espécies Lycaenidae & A1E & A2B & A3E & A4B & $\begin{array}{c}\text { Total } \\
\text { imaturos }\end{array}$ & $\begin{array}{l}\text { n. spp. } \\
\text { plantas }\end{array}$ \\
\hline Allosmaitia strophius (Godart) & 8 & 14 & 2 & 5 & 29 & 6 \\
\hline Arawacus ellida (Hewitson) & 3 & 0 & 0 & 0 & 3 & 1 \\
\hline Cyanophrys herodotus (Fabricius) & 0 & 1 & 0 & 0 & 1 & 1 \\
\hline Kolana ergina (Hewitson) & 1 & 2 & 0 & 0 & 3 & 2 \\
\hline Magnastigma julia Nicolay & 0 & 0 & 2 & 0 & 2 & 1 \\
\hline Ministrymon azia (Hewitson) & 0 & 14 & 7 & 1 & 22 & 2 \\
\hline Eumaeini sp. & 1 & 1 & 1 & 4 & 7 & 3 \\
\hline Eumaeini sp.01 & 0 & 2 & 0 & 0 & 2 & 1 \\
\hline Eumaeini sp.1 & 0 & 1 & 0 & 0 & 1 & 1 \\
\hline Eumaeini sp.2 & 6 & 0 & 0 & 0 & 6 & 1 \\
\hline Eumaeini sp.3 & 0 & 6 & 0 & 0 & 6 & 1 \\
\hline Eumaeini sp.4 & 0 & 7 & 0 & 0 & 7 & 1 \\
\hline Eumaeini sp.5 & 0 & 0 & 2 & 0 & 2 & 1 \\
\hline Nicolaea socia (Hewitson) & 1 & 0 & 0 & 0 & 1 & 1 \\
\hline Parrhasius polibetes (Stoll) & 3 & 4 & 0 & 0 & 7 & 2 \\
\hline Rekoa marius (Lucas) & 0 & 3 & 0 & 1 & 4 & 4 \\
\hline Rekoa palegon (Cramer) & 0 & 0 & 2 & 0 & 2 & 1 \\
\hline Strymon crambusa (Hewitson) & 0 & 0 & 1 & 0 & 1 & 1 \\
\hline Strymon mulucha (Hewitson) & 1 & 1 & 0 & 0 & 2 & 2 \\
\hline Tmolus venustus (H. H. Druce) & 2 & 6 & 5 & 2 & 15 & 5 \\
\hline \multicolumn{7}{|l|}{ Polyommatinae: } \\
\hline Hemiargus hanno (Stoll) & 0 & 0 & 0 & 6 & 6 & 3 \\
\hline Polyommatinae sp. & 2 & 0 & 0 & 3 & 5 & 2 \\
\hline Abundância total & 28 & 62 & 22 & 22 & 134 & -- \\
\hline Riqueza total & 10 & 13 & 8 & 7 & $22 *$ & $24^{*}$ \\
\hline
\end{tabular}

*Total se refere à riqueza sem considerar as espécies compartilhadas. 
De acordo com as curvas de rarefação, a riqueza e a abundância de imaturos apresentaram um padrão semelhante (Figura 7). A maior riqueza de espécies $(n=13)$ e a maior abundância de imaturos $(n=62,46.3 \%)$ ocorreram na área $\mathrm{A} 2 \mathrm{~B}$, com cinco espécies exclusivas e com dominância de A. strophius $(\mathrm{n}=14)$ e M. azia $(\mathrm{n}=14)$. A segunda área mais rica foi a A1E com 10 espécies e 28 indivíduos, A3E com oito e A4B com sete espécies e 22 indivíduos cada uma (Tabela 4, Anexo 1). Houve uma diferença estatística significativa entre a abundância dos imaturos da área $\mathrm{A} 2 \mathrm{~B}$ em relação às demais áreas $\left(\chi^{2}=27,81 ;\right.$ g.1.= $\left.3 ; \mathrm{P}<0,001\right)$ (Figura 8).

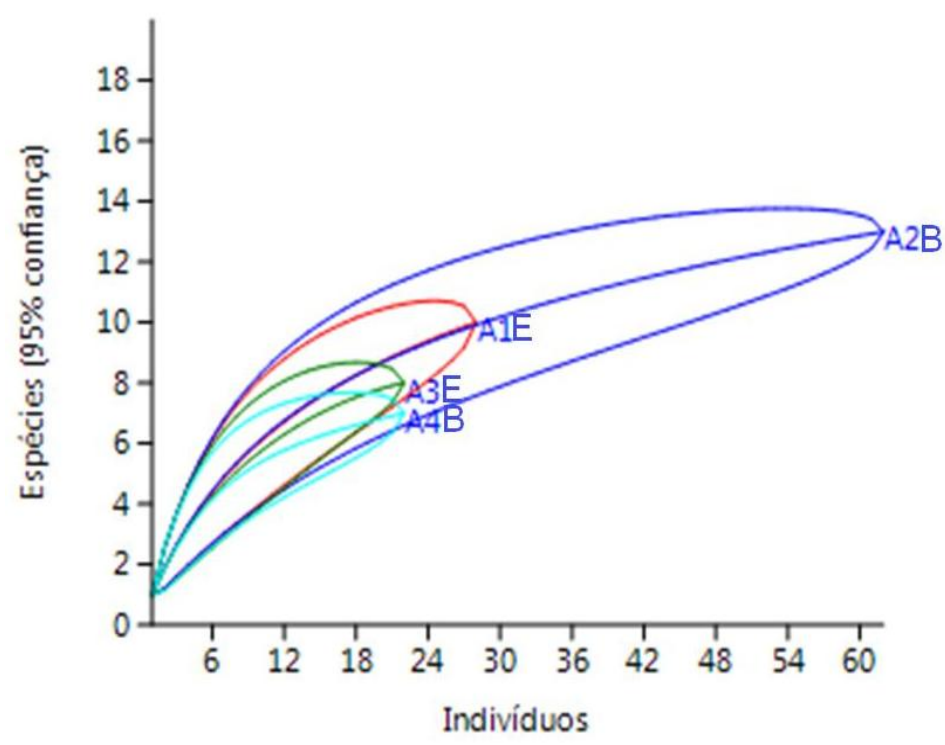

Figura 7: Curva de rarefação individual (com intervalo de $95 \%$ de confiança) de espécies de Lycaenidae nas quatro áreas de campo sujo amostradas na Fazenda Água Limpa/DF entre janeiro e abril de 2014. A1E, A3E= Elevadas, áreas distantes de córregos e A2B, A4B=Baixada, próximas a córregos. 


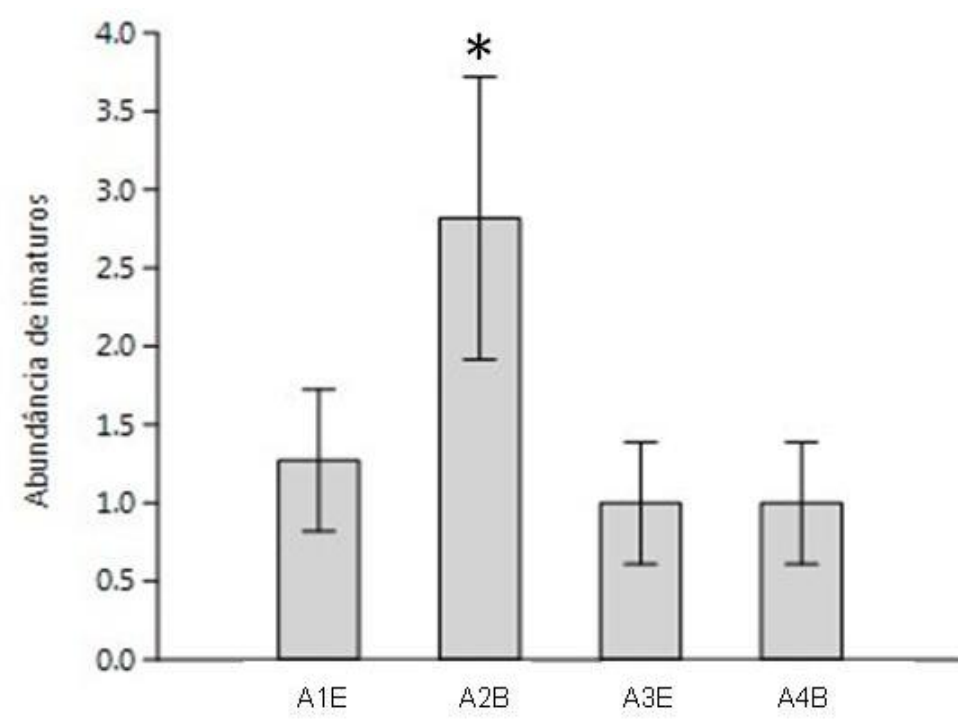

Figura 8. Abundância média (+erro padrão) de imaturos de Lycaenidae nas quatro áreas de campo sujo amostradas na Fazenda Água Limpa/DF entre janeiro e abril de 2014. $\mathrm{A} 1 \mathrm{E}, \mathrm{A} 3 \mathrm{E}=$ Elevadas, áreas distantes de córregos e A2B, A4B=Baixada, áreas próximas a córregos. $\mathrm{O}$ asterisco $(*)$ indica diferença significativa $(\mathrm{P}<0,001)$ em relação às outras áreas.

A comparação dos perfis de diversidade de Rényi (Figura 9) evidenciou a maior diversidade de imaturos na área $\mathrm{A} 2 \mathrm{~B}$, seguida da $\mathrm{A} 1 \mathrm{E}$, as áreas $\mathrm{A} 3 \mathrm{E}$ e $\mathrm{A} 4 \mathrm{~B}$ apresentaram intersecção e são não comparáveis. Quando as áreas foram observa-se que não há diferenças entre a riqueza (15 espécies), mas o perfil indicou maior diversidade nas áreas distantes de córregos, A1E+A3E (Figura 9b). Esses resultados são contrários aos perfis da diversidade para as plantas, onde a maior diversidade foi nas áreas próximas da fonte de água, A2B+A4B (Figura 4). 

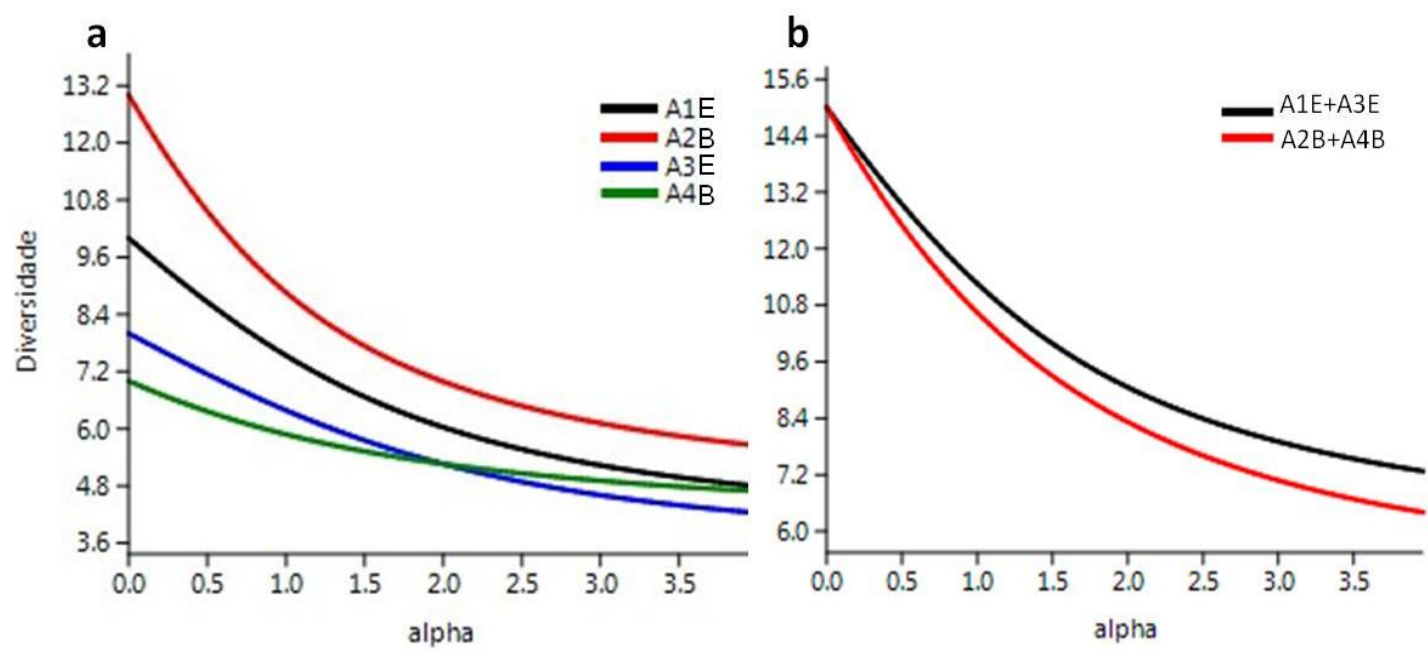

Figura 9. Perfis de diversidade de Rényi para espécies de Lycaenidae em plantas em floração nas quatro áreas de campo sujo amostradas na Fazenda Água Limpa/DF entre janeiro e abril de 2014. (a) Diversidade nas quatro áreas e (b) diversidade nas áreas agrupadas. A1E, A3E= Elevadas, áreas distantes de córregos e A2B, A4B =Baixada, áreas próximas a córregos.

\section{Análise de similaridade das espécies de licenídeos nas áreas}

A composição de imaturos avaliada com o índice Bray-Curtis, resultou no agrupamento das áreas A1E e A4B com 40\% de similaridade e de A2B e A3E com 36\% de similaridade, ambos os pares compartilharam quatro espécies (Figura 10). O resultado do agrupamento foi contrário ao encontrado para a composição florística. Quando as áreas foram agrupadas em relação à localização na FAL, distantes $(\mathrm{A} 1 \mathrm{E}+\mathrm{A} 3 \mathrm{E})$ e próximas de córregos $(\mathrm{A} 2 \mathrm{~B}+\mathrm{A} 4 \mathrm{~B})$, o índice Bray-Curtis indicou 49\% de similaridade entre as áreas. 


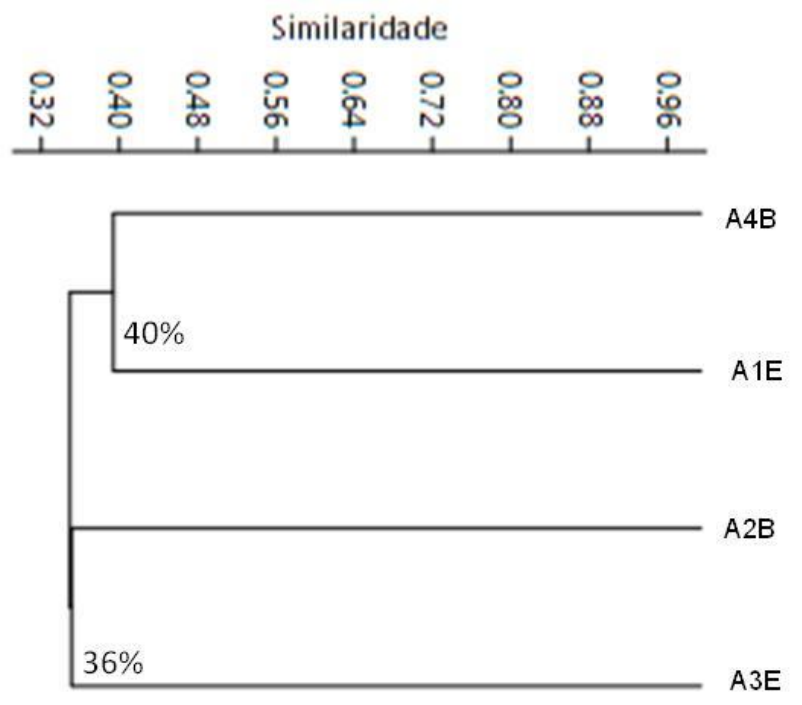

Figura 10. Dendograma de similaridade da composição dos imaturos de Lycaenidae nas quatro áreas de campo sujo amostradas na Fazenda Água Limpa/DF entre janeiro e abril de 2014. A1E, A3E= Elevadas, áreas distantes de córregos e A2B, A4B=Baixada, áreas próximas a córregos. Análise de agrupamento pelo índice Bray-Curtis, método de ligação simples.

\section{Resposta da abundância de imaturos aos recursos vegetais}

De uma forma geral, houve efeito significativo da abundância de inflorescências sobre a abundância dos imaturos $\left(\chi^{2}=58,54\right.$; g.l.= 1; $\mathrm{P}<0,001$; Figura 11). Mas este efeito não apresentou diferenças estatísticas significativas relacionadas às áreas $(\mathrm{P}=0,091)$. A abundância dos imaturos também apresentou variação significativa em relação à abundância total das espécies de plantas $\left(\chi^{2}=549,57 ; \mathrm{g} .1 .=124 ; \mathrm{P}<0,001\right)$ e em relação à abundância das 24 espécies de plantas hospedeiras $\left(\chi^{2}=79,23\right.$; g.l.= 23; $\mathrm{P}<0,001$; Tabela 3, Figuras 12 e 13). 


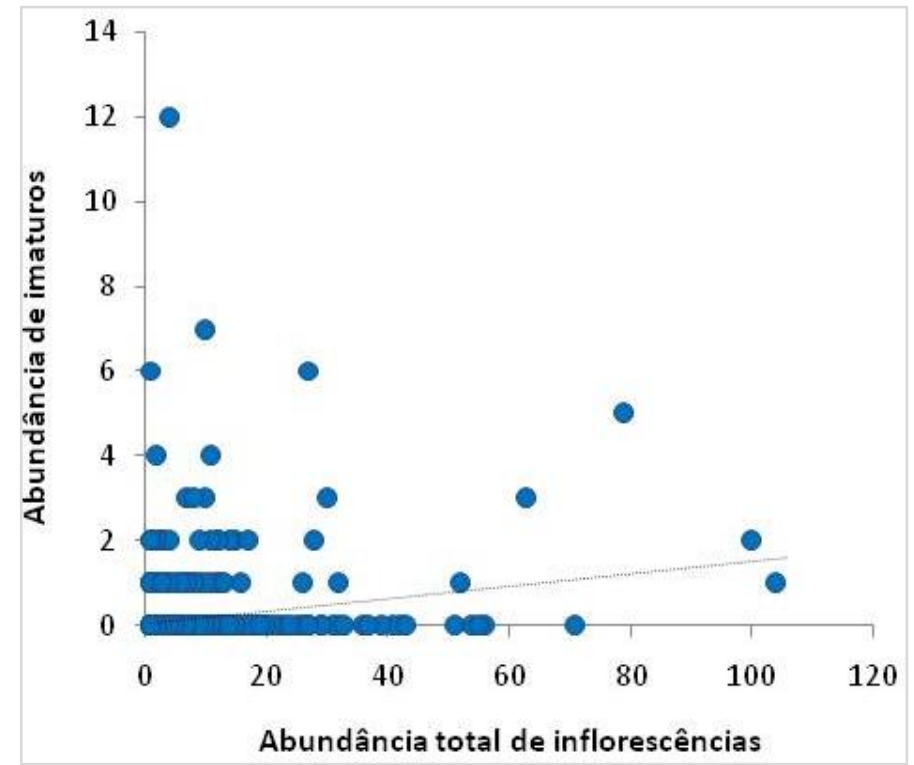

Figura 11: Resposta da abundância de imaturos de Lycaenidae em relação à abundância total de inflorescências examinadas nas áreas de campo sujo amostradas na Fazenda Água Limpa/DF entre janeiro e abril de 2014.
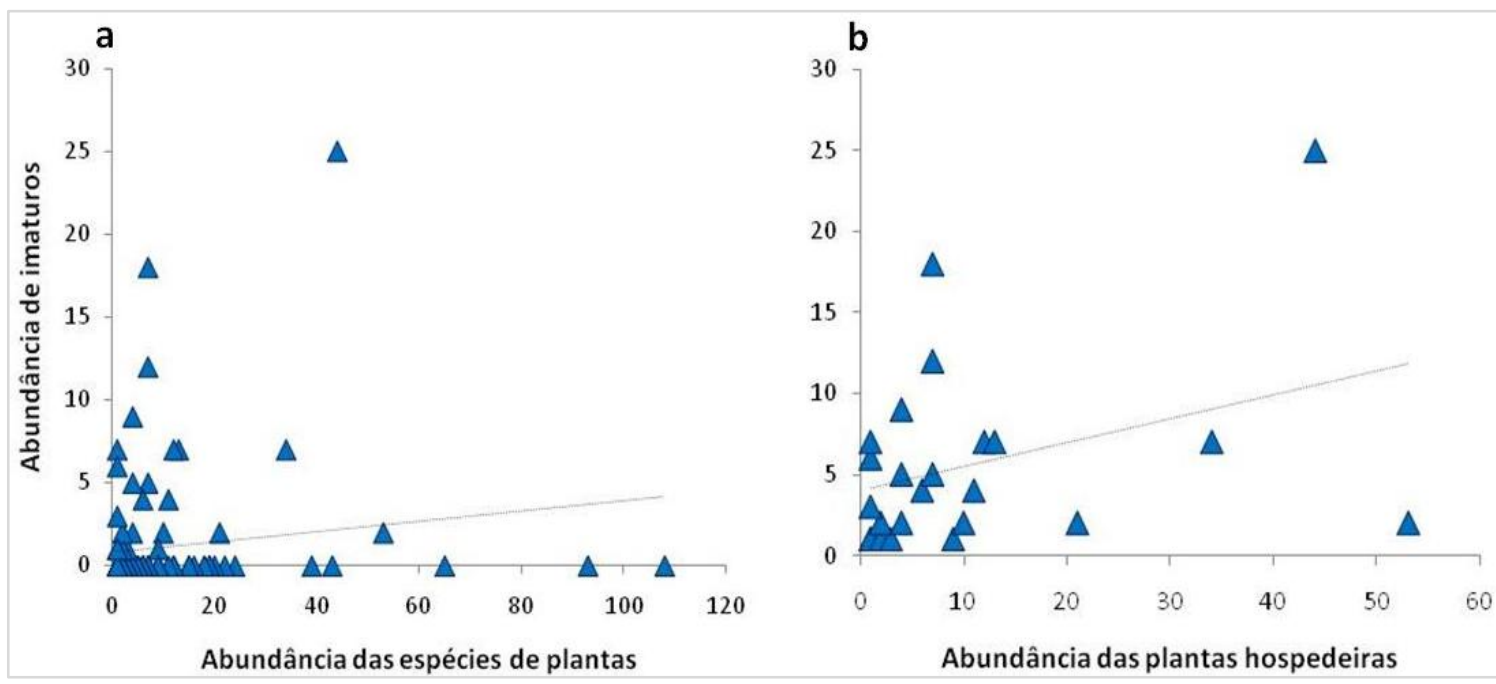

Figura 12. (a) Resposta da abundância de imaturos de Lycaenidae em relação à abundância total das espécies de plantas e (b) abundância de imaturos de Lycaenidae em relação à abundância total das 24 espécies de plantas hospedeiras nas áreas de campo sujo amostradas na Fazenda Água Limpa/DF entre janeiro e abril de 2014. 


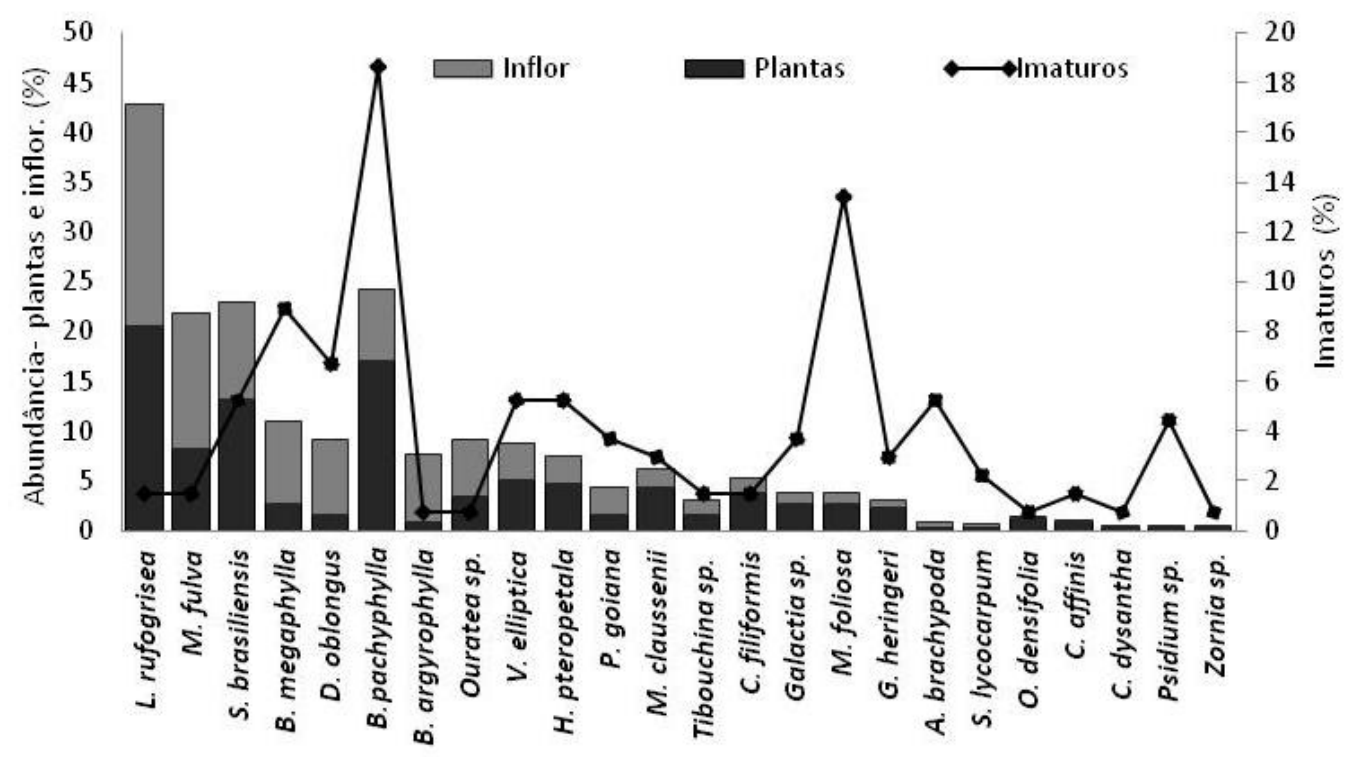

Figura 13. Abundância relativa das espécies de plantas hospedeiras $(n=24)$ e das inflorescências disponíveis ao longo do período de coletas e proporção dos Lycaenidae imaturos encontrados sobre elas nas quatro áreas de campo sujo amostradas na Fazenda Água Limpa/DF entre janeiro e abril de 2014. Ranking da maior para a menor porcentagem de inflorescências por planta.

\section{Abundância de plantas com formigas}

Do total de 1.049 plantas examinadas, 199 (19\%) representadas por 53 espécies de 15 famílias foram registradas com a presença de formigas (Tabela 5, Figura 14). A área A4B correspondeu a 32\% $(\mathrm{n}=64)$ do total geral de plantas registradas com formigas, seguida da área A1E, 25\% (n=49) (Tabela 5). Individualmente, a frequência relativa de plantas com formigas presentes na $\mathrm{A} 4 \mathrm{~B}$ foi de $25 \%$ do número total da área $(\mathrm{n}=256)$. A área A1E apresentou a menor frequência local de plantas com formigas, 16\% $(\mathrm{n}=49)$. Houve diferença estatística significativa entre o número de indivíduos de plantas com formigas entre as áreas $\left(\chi^{2}=9,18\right.$; g.l.= 3; P=0,027) (Figura 14b). Não houve variação significativa da abundância das plantas com presença formigas entre as áreas agrupadas em distantes $(\mathrm{A} 1 \mathrm{E}+\mathrm{A} 3 \mathrm{E})$ e próximas de córregos $(\mathrm{A} 2 \mathrm{~B}+\mathrm{A} 4 \mathrm{~B})\left(\chi^{2}\right.$ $=1,65 ;$ g.l. $=1 ; \mathrm{P}=0,198)$. 
Tabela 5. Total de plantas em cada área, indivíduos de plantas com presença de formigas; número de plantas com formigas e imaturos, número de imaturos em plantas com formigas e número total geral de imaturos nas quatro áreas de campo sujo amostradas na Fazenda Água Limpa/DF entre janeiro e abril de 2014. A1E, A3E= Elevadas, áreas distantes de córregos e A2B, A4B=Baixada, áreas próximas a córregos.

\begin{tabular}{lccccc}
\hline Áreas & Total de plantas & $\begin{array}{c}\text { n. plantas com } \\
\text { presença de } \\
\text { formigas (\%) }\end{array}$ & $\begin{array}{c}\text { n. plantas com } \\
\text { formigas e } \\
\text { imaturos }\end{array}$ & $\begin{array}{c}\text { n. imaturos em } \\
\text { plantas com } \\
\text { formigas }\end{array}$ & $\begin{array}{c}\text { Total de } \\
\text { imaturos }\end{array}$ \\
\hline A1E & 310 & $49(25)$ & 9 & 18 & 28 \\
A2B & 265 & $43(21,5)$ & 11 & 22 & 62 \\
A3E & 218 & $43(21,5)$ & 8 & 9 & 22 \\
A4B & 256 & $64(32)$ & 13 & 15 & 22 \\
\hline Total & 1.049 & $199(100)$ & 41 & 64 & 134 \\
\hline
\end{tabular}
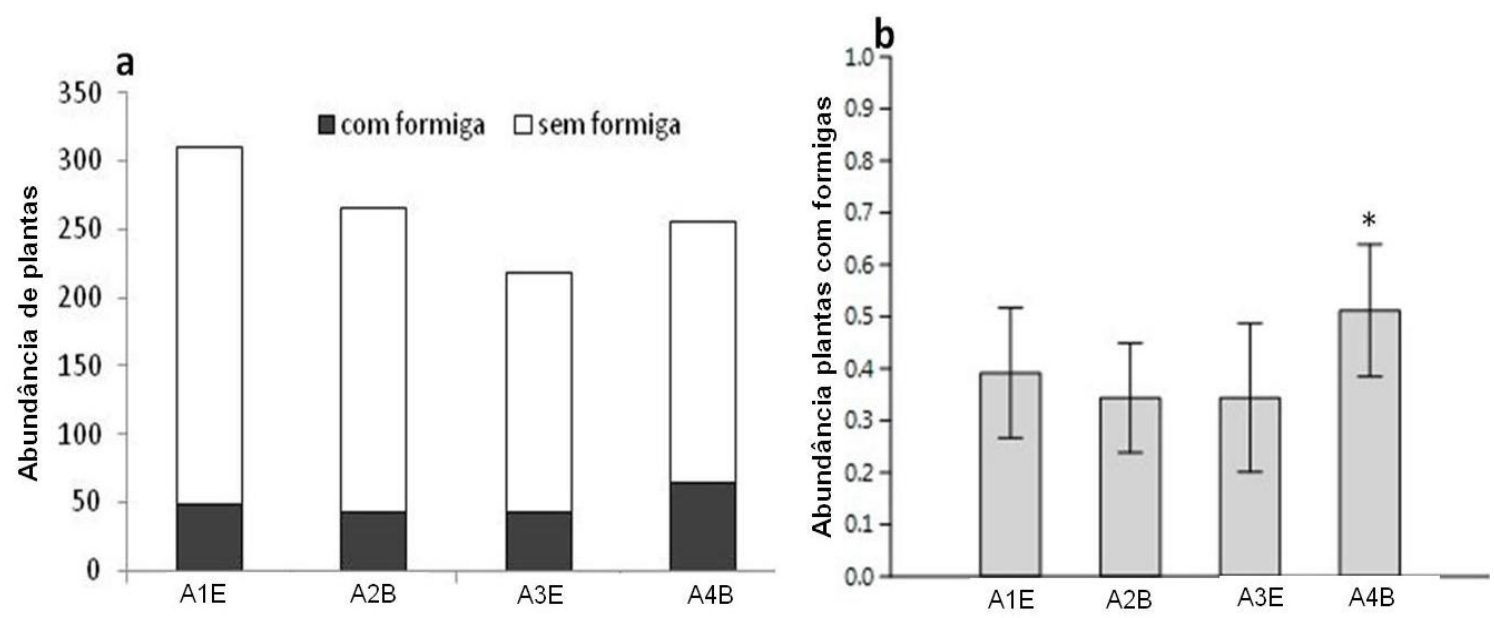

Figura 14. (a) Abundância absoluta de plantas com e sem a presença de formigas nas áreas de campo sujo e (b) abundância média (+erro padrão) de plantas registradas com presença de formigas nas quatro áreas de campo sujo amostradas na Fazenda Água Limpa/DF entre janeiro e abril de 2014. A1E, A3E= Elevadas, áreas distantes de córregos e $\mathrm{A} 2 \mathrm{~B}, \mathrm{~A} 4 \mathrm{~B}=\mathrm{Baixada}$, áreas próximas a córregos. $\mathrm{O}$ asterisco (*) indica diferença significativa da área em relação às demais $(\mathrm{P}<0,05)$.

\section{Ocorrência de imaturos nas plantas com formigas}

Imaturos de Lycaenidae estavam presentes em 41 (20,6\%) dos 199 indivíduos de plantas com formigas (Tabela 5). As plantas com formigas e imaturos estavam distribuídas em 17 espécies vegetais e pelo menos dez dessas apresentam nectários extraflorais (Tabela 6). No total, 47,8\% $(n=64)$ dos ovos e lagartas de 15 espécies foram 
encontrados nessas plantas (Tabelas 5 e 6). A área A4B foi a que apresentou o maior número de plantas com a presença de formigas e presença de imaturos $(n=13), 32 \%$ do total $(n=41)$. Mas foi a área A2B que exibiu a maior abundância de imaturos nas plantas com presença de formigas, 11 plantas com 22 imaturos, correspondendo a 34\% do total de imaturos em plantas com formigas de todas as áreas (n=64) (Tabela 5, Figura 15). Na área $\mathrm{A} 1 \mathrm{E}$ ocorreram nove plantas com 18 imaturos e na $\mathrm{A} 3 \mathrm{E}$ foram oito plantas com presença de formigas e nove imaturos (Tabela 5). Quando se considera o total de imaturos apenas dentro de uma área, a proporção de imaturos em plantas com formigas na área A2B apresentou a menor abundância relativa, $35 \%(n=22$, de 62$)$, enquanto que a área A1E e A4B apresentaram mais de $60 \%$ da abundância de imaturos presentes em plantas com formigas em cada área.

A variação da abundância de imaturos entre as áreas em relação à presença de formigas nas plantas $\left(\chi^{2}=8,62 ;\right.$ g.l. $\left.=3 ; \mathrm{P}=0,034\right)$ indicou que a área $\mathrm{A} 2 \mathrm{~B}$ difere significativamente das demais (Figura 15b). Não houve diferença estatística na abundância dos imaturos em plantas com formigas nas áreas agrupadas em distantes $(\mathrm{A} 1 \mathrm{E}+\mathrm{A} 3 \mathrm{E})$ e próximas de córregos $(\mathrm{A} 2 \mathrm{~B}+\mathrm{A} 4 \mathrm{~B})\left(\chi^{2}=2,83 ; \mathrm{g} .1 .=1 ; \mathrm{P}=0,092\right)$.

No entanto, a análise considerando a abundância total de plantas com e sem a presença de formigas, revelou que existe uma maior abundância de imaturos em plantas com a presença de formigas $\left(\chi^{2}=56,72 ;\right.$ g.l $\left.=1 ; \mathrm{P}<0,001\right)$ (Figura 16).
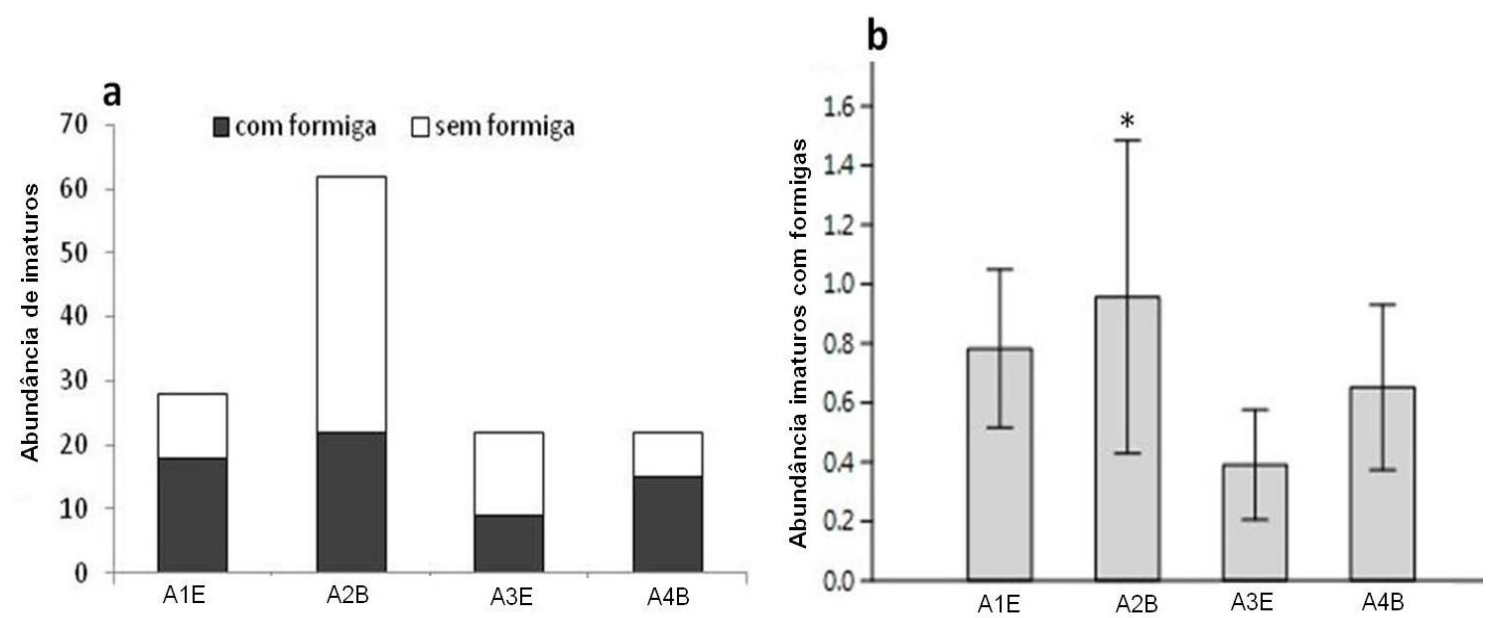

Figura 15. (a) Abundância absoluta de Lycaenidae imaturos registrados nas plantas hospedeiras com e sem a presença de formigas e (b) abundância média (+erro padrão) dos imaturos em plantas com presença de formigas nas quatro áreas de campo sujo amostradas na Fazenda Água Limpa/DF entre janeiro e abril de 2014. A1E, A3E= Elevadas, áreas distantes de córregos e $\mathrm{A} 2 \mathrm{~B}, \mathrm{~A} 4 \mathrm{~B}=\mathrm{B}$ aixada, áreas próximas a córregos. $\mathrm{O}$ asterisco $(*)$ indica diferença significativa da área em relação às demais $(\mathrm{P}<0,05)$. 


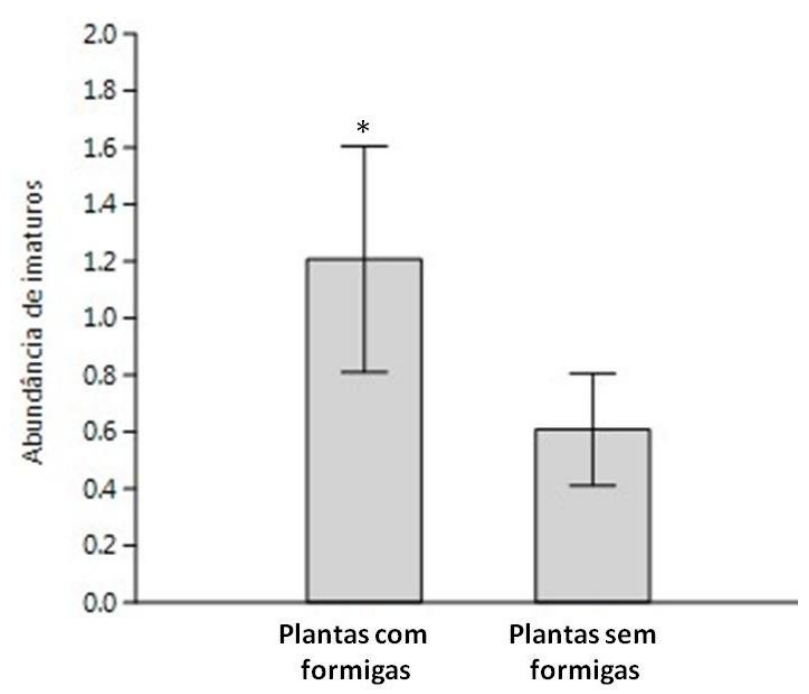

Figura 16. Abundância média (+erro padrão) de Lycaenidae imaturos em plantas com e sem a presença de formigas em todas as áreas de campo sujo amostradas na Fazenda Água Limpa/DF entre janeiro e abril de 2014. O asterisco (*) indica diferença significativa entre os grupos.

Entre as famílias de plantas com indivíduos com formigas e imaturos presentes se destacaram as famílias Fabaceae, com cinco espécies abrigando nove imaturos de quatro espécies e Malpighiaceae com cinco espécies abrigando 31 imaturos de cinco espécies Eumaeini, sendo $B$. pachyphylla a que apresentou o maior número de indivíduos com formigas 34\% ( $\mathrm{n}=14 / 41)$, e imaturos 26.6\% $(\mathrm{n}=17 / 64)$ de quatro espécies de licenídeos (Tabela 6). Com exceção daquelas espécies onde não foi possível a identificação do gênero e Kolana ergina (Hewitson) que não possui orgãos relacionados à mirmecofilia, todas as demais espécies listadas em plantas com formigas (Tabela 6) possuem a abertura do órgão nectário dorsal (Duarte et al. 2001, Silva et al. 2014). Contudo, no campo foram registradas formigas interagindo com lagartas somente em três ocasiões, duas vezes com lagartas de A. strophius, com a formiga antenando sobre o corpo da lagarta e na região do órgão nectarífero, e outra vez com $T$. venustus sobre Sabicea brasiliensis Wernham (Rubiaceae) como primeiro registro em interação com formigas. 
Tabela 6. Famílias e espécies de plantas com presença de formigas e imaturos, com ou sem nectários extraflorais (NEFs); número de plantas e inflorescências, número de imaturos, espécies de licenídeos e número de indivíduos por espécie (n.) que ocorreram nas plantas com formigas nas quatro áreas de campo sujo amostradas na Fazenda Água Limpa/DF entre janeiro e abril de 2014.

\begin{tabular}{|c|c|c|c|c|c|}
\hline Famílias & Espécies de plantas & NEFs & $\begin{array}{l}\text { n. indiv. } \\
\text { plantas } \\
\text { (n. inflor) }\end{array}$ & $\underset{\text { imaturos }}{\text { n. }}$ & Espécies de licenídeos (n) \\
\hline Asteraceae & Lepidaploa rufogrisea & - & $1(16)$ & 1 & R. palegon \\
\hline Bignoniaceae & Arrabidaea brachypoda & $\operatorname{sim}$ & $1(10)$ & 7 & Eumaeini sp.4 \\
\hline Fabaceae & Galactia sp. & $\operatorname{sim}$ & $3(13)$ & 3 & $\begin{array}{l}\text { H. hanno, T.venustus, } \\
\text { Polyommatinae sp. }\end{array}$ \\
\hline Fabaceae & Mimosa claussenii & não & $2(22)$ & 3 & M. azia \\
\hline Fabaceae & Galactia heringeri & sim & $1(3)$ & 1 & H. hanno \\
\hline Fabaceae & Zornia sp. & & $1(1)$ & 1 & H. hanno \\
\hline Lythraceae & Diplusodon oblongus & não & $1(63)$ & 3 & P. polibetes \\
\hline Malpighiaceae & Byrsonima pachyphylla & $\operatorname{sim}$ & $14(67)$ & 17 & $\begin{array}{l}\text { A. strophius (10), } K \text {. } \\
\text { ergina (1), T. venustus } \\
\text { (2), Eumaeini sp.(4) }\end{array}$ \\
\hline Malpighiaceae & Banisteriopsis megaphylla & $\operatorname{sim}$ & $3(135)$ & 9 & $\begin{array}{l}\text { A. strophius (3), } \\
\text { Eumaeini sp. (1), } \\
\text { P. polibetes (3), } \\
\text { T. venustus (2) }\end{array}$ \\
\hline Malpighiaceae & Heteropterys pteropetala & $\operatorname{sim}$ & $1(12)$ & 1 & A. strophius \\
\hline Malpighiaceae & $\begin{array}{l}\text { Banisteriopsis } \\
\text { argyrophylla }\end{array}$ & sim & $1(104)$ & 1 & A. strophius \\
\hline Malpighiaceae & Peixotoa goiana & $\operatorname{sim}$ & $2(40)$ & 3 & A. strophius \\
\hline Ochnaceae & Ouratea floribunda & $\operatorname{sim}$ & $1(52)$ & 1 & R. marius \\
\hline Oxalidaceae & Oxalis densifolia & $\operatorname{sim}$ & $1(4)$ & 1 & S. crambusa \\
\hline Rubiaceae & Sabicea brasiliensis & não & $4(28)$ & 4 & T. venustus \\
\hline Solanaceae & Solanum lycocarpum & não & $1(8)$ & 3 & A. ellida \\
\hline Vochysiaceae & Vochysia elliptica & não & $3(31)$ & 5 & $\begin{array}{l}\text { N. socia (1), } \\
\text { Eumaeini sp.2 (4) }\end{array}$ \\
\hline Total geral & 17 espécies & & $41(609)$ & 64 & 15 espécies \\
\hline
\end{tabular}




\subsection{DISCUSSÃO}

A alta riqueza e diversidade de plantas em floração em áreas de campo sujo na Fazenda Água Limpa foram evidenciadas (Munhoz \& Felfili 2005, 2006). No entanto, apesar da grande disponibilidade dos potenciais recursos alimentares a frequência relativa dos imaturos de licenídeos foi baixa. Este padrão é conhecido para espécies de lepidópteros folívoros no Cerrado (Price et al. 1995, Morais et al. 1996) e essa tendência foi registrada também para licenídeos florívoros no DF (Silva et al. 2011b). Porém, as variações na abundância de indivíduos e de inflorescências por espécie de planta, e especialmente para as espécies hospedeiras, afetaram positivamente a abundância de licenídeos imaturos, sustentando a hipótese da abundância do recurso.

Por outro lado, a composição dos imaturos não foi afetada pela composição florística, apesar da alta heterogeneidade da vegetação entre as áreas de campo sujo. Das famílias de plantas com maior número de espécies e de inflorescências disponíveis apenas Malpighiaceae apresentou maior abundância e riqueza de licenídeos. Sobre a diversidade floral, Fiedler (1995b) comenta que não é um bom preditor da diversidade de borboletas, pois regiões com alta diversidade de plantas podem apresentar uma fauna limitada. De modo geral, habitats com vegetação mais diversa significa menor concentração de recursos alimentares o que tende a dificultar o encontro pelos herbívoros (Andow 1990). Neste estudo, a diversidade dos imaturos nas áreas apresentaram variações contrárias daquelas avaliados para a vegetação, por exemplo, enquanto a maior diversidade de espécies de plantas ocorreu na área $\mathrm{A} 4 \mathrm{~B}$, a maior diversidade e abundância de imaturos ocorreram na área A2B. A diferença na abundância de imaturos nessa área é atribuida a maior presença de espécies de Malpighiaceae, hospedeiras de A. strophius que é oligófaga, se alimenta apenas em inflorescências de espécies dessa família (Kaminski \& Freitas 2010) e Fabaceae, hospedeira de $M$. azia, que pode ser considerada oligófaga a nível local (Silva et al. 2011b).

Investigações sobre fatores que afetam a diversidade de insetos herbívoros englobam uma ampla gama de publicações em ecologia (revisto em Lewinsohn et al. 2005). De uma maneira geral os insetos herbívoros, e em especial as lagartas de Lepidoptera, utilizam uma pequena fração das espécies de plantas disponíveis em um local (Novotny et al. 2002, Morais et al. 2011). Esse padrão se repete aqui, com os imaturos de licenídeos sendo encontrados em apenas 19\% das espécies de plantas 
presentes nas áreas amostradas. Um resultado similar foi obtido para licenídeos em uma área de cerrado em Uberlândia, MG (Bächtold 2014). Nesse grupo a maioria das espécies é localmente oligófaga utilizando espécies de plantas de um mesmo gênero ou de uma mesma família (Silva et al. 2011b). Essa característica, provavelmente, explica a ausência de relação entre a riqueza de espécies de plantas e a de licenídeos nas áreas de estudo.

De certo modo não foi possível interpretar com clareza a relação entre a abundância e a diversidade dos imaturos e a abundância e a diversidade dos recursos alimentares disponíveis. Com uma dieta relativamente restrita era esperado que a abundância de licenídeos estivesse mais diretamente relacionada à abundância do recurso alimentar. Sletvold \& Grindeland (2008) encontraram um padrão semelhante na utilização de inflorescências de uma planta herbácea por uma espécie de lagarta de Geometridae. As lagartas foram encontradas principalmente em flores maiores e em manchas mais densas de inflorescências. Os autores discutem o dilema das plantas em apresentarem atrativos para polinizadores e se tornarem atrativas para herbívoros. Já Stefanescu et al. (2006) registraram que apesar da contradição, a oviposição com mais ovos agrupados pelas fêmeas de um Nymphalinae ocorreu em função da coloração da folha em detrimento daquelas plantas maiores que teoricamente garantiriam mais recursos para a prole. Contudo, neste caso as lagartas tem grande capacidade de locomoção e podem se deslocar em busca de mais suprimentos. Marques et al. (2000) investigaram a disponibilidade de recursos em quatro espécies de Fabaceae e concluíram que a maior abundância dos insetos estava associada a maior abundância do recurso, com biomassa das folhas correspondendo a mais de $50 \%$ da variação dos insetos.

Mas, neste estudo espécies que são relativamente frequentes no cerrado do DF ao longo do ano, altamente polífagas e mirmecófilas facultativas como $P$. polibetes, Rekoa marius (Lucas) e Strymon mulucha (Hewitson) (Monteiro 1991, Kaminski et al. 2012, Silva et al. 2014) foram raras. A amplitude de dieta destas espécies no cerrado da FAL (Silva et al. 2011b) mostra o potencial em avaliar e selecionar as plantas com mais recurso, assim era esperado que esses polífagos respondessem às diferenças na abundância dos recursos disponíveis. Por exemplo, Rekoa palegon (Cramer), costuma se alimentar também de várias espécies de Asteraceae (Monteiro 1991, Silva et al. 2011b), mas apenas dois indivíduos foram registrados, contrariando a hipótese da abundância de recursos. 
De todo modo este estudo, com intuito de abranger um maior número de indivíduos de plantas florescendo, foi realizado em um período específico, do meio para o final da estação chuvosa e é conhecido que há uma variação sazonal, tanto na disponibilidade dos recursos, quanto na abundância dos insetos no Cerrado, com lagartas apresentando picos na estação seca, buscando um espaço livre de inimigos naturais como os parasitóides (Morais et al. 1999, Scherrer et al. 2016). Bächtold (2014) registrou que o número de lagartas de licenídeos florívoros parasitadas tende a aumentar no final da estação seca quando a abundância total das lagartas tende a diminuir. Este comportamento foi verificado inicialmente para espécies folívoras no Cerrado (Morais et al. 1999), onde os autores também observaram que a abundância das lagartas não seguiu a fenologia foliar. Neste sentido, Scherrer et al. (2016) verificaram que lagartas folívoras no cerrado tendem a apresentar uma maior amplitude de plantas consumidas na estação seca quando o recurso é menos abundante, com consequente aumento no grau de especialização ocorrendo na época chuvosa, que provem mais recursos.

Em relação às plantas com formigas, Malpighiaceae também se destacou com o maior número de indivíduos com formigas e imaturos. O licenídeo mais abundante nas plantas com formigas foi a especialista A. strophius que, embora não tenha órgãos mirmecófílicos funcionais, convive com formigas e as fêmeas as utilizam como pistas na seleção das plantas hospedeiras (Kaminski \& Freitas 2010, Bächtold et al. 2014, Silva et al. 2014). P. polibetes espécie já reconhecida com mirmecofilia facultativa (Kaminski et al. 2012) também estava presente em Malpighiaceae. Espécies dessa família de plantas florescem de forma sequencial ao longo do ano e abriga herbívoros continuamente, a presença de nectários extraflorais mantêm o efeito positivo das formigas na redução de certos herbívoros (Vilela et al. 2014). Mas, para várias espécies de licenídeos a frequente disponibilidade das malpighiáceas têm sido um importante recurso, e a presença de formigas nessas plantas pode resultar em benefícios, pois reduz a presença de competidores e dos possíveis predadores (Kaminski \& Freitas 2010, Alves-Silva et al. 2013, Bächtold et al. 2013, Bächtold et al. 2016).

Apesar de ter sido avaliada a presença de formiga na planta individual, foi possível observar que formigas estavam forrageando em plantas com maior densidade de inflorescências, o que provêm uma maior fonte de recurso. Wagner \& Kurina (1997) encontraram uma resposta positiva do número de ovos em relação à presença de formigas e ao maior número de inflorescências associadas com formigas. As interações entre formigas, plantas e herbívoros são complexas e podem ser influenciadas por uma 
variedade de fatores, além da presença e funcionalidade dos nectários extraflorais (Oliveira \& Del-Claro 2005, Delgado 2011). Então, ainda que ocorra um trade-off entre os mutualistas, polinizadores e formigas guardas, e a planta sincronize a floração com liberação de néctar extrafloral (revisão em Elzinga et al. 2007), nas plantas a simples presença das inflorescências pode indicar previsão de néctar para forrageadoras. Além disso, as associações variam com a espécie e no espaço e no tempo, e podem ser singulares no Cerrado, por exemplo, a frequência de $P$. polibetes em associação recorrente com membracídeos no cerrado de São Paulo (Oliveira \& Del-Claro 2005, Kaminski et al. 2010) não é observada no cerrado do DF (N.A.P.Silva observ. pessoal).

Os resultados deste estudo fornecem informações biológicas importantes das espécies de Eumaeini. Por exemplo, a coleta de ovos resultou em primeiros registros para espécies de licenídeos que ainda não se tinha informações como K. ergina; também foi registrada Sabicea brasiliensis como planta hospedeira para T. venustus, e o aumento de quatro espécies em Lythraceae, além dos registros anteriores (Silva et al. 2011b). Além disso, o encontro de mais de uma espécie na mesma planta mostra que as fêmeas não discriminam as inflorescências ocupadas por outras espécies, ou isso pode não ser relevante dado a qualidade e quantidade do recurso disponível (Shapiro 1984) e alerta para subamostragens com metodologia de vistoria ou coleta parcial das inflorescências.

Este estudo foi uma tentativa de entender a associação das lagartas florívoras de licenídeos e a abundância de seus recursos no Cerrado. A heterogeneidade dos recursos no habitat e a dieta restrita desses lepidópteros não apresentaram associação clara, fatores outros devem estar envolvidos na seleção do recurso frente à diversidade disponível. Uma alternativa para entender e visualizar algum padrão específico é acompanhar um grupo ou uma planta hospedeira em particular, como vem sendo realizado com Malpighiaceae (Vilela et al. 2014, Bächtold et al. 2016) com extensão para outros locais que possibilite comparações mais específicas das interações e dos fatores envolvidos. Por outro lado, nosso estudo pôde detectar padrões importantes como a relação entre abundância de inflorescências e presença de formigas que foram revelados nas comparações gerais. Nesse sentido, tais padrões emergem como grandes preditores da abundância de lagartas de Lycaenidae em escalas maiores dentro do Cerrado. 


\subsection{REFERÊNCIAS BIBLIOGRÁFICAS}

Alves-Silva, E.; Bächtold A.; Barônio G.J.; Del-Claro K. 2013. Influence of Camponotus blandus (Formicinae) and flower buds on the occurrence of Parrhasius polibetes (Lepidoptera: Lycaenidae) in Banisteriopsis malifolia (Malpighiaceae). Sociobiology, 60(1): 30-34.

Andow, D.A. 1990. Population dynamics of an insect herbivore in simple and diverse habitats. Ecology, 71(3): 1006-1017.

Atsatt, P.R. 1981. Ant-dependent food plant selection by the mistletoe butterfly Ogyris amaryllis (Lycaenidae). Oecologia, 48: 60-63.

Bächtold, A. 2014. "A comunidade de licenídeos de uma área de cerrado: especificidade de dieta, interações ecológicas e seleção de plantas hospedeiras". Tese de doutorado. Faculdade de Filosofia, Ciênciais e Letras de Ribeirão Preto, Universidade de São Paulo, Ribeirão Preto, SP.

Bächtold, A.; Alves-Silva, E. \& Del-Claro K. 2013. Lycaenidae larvae feeding on Peixotoa parviflora (Malpighiaceae) in a semi-deciduous forest in Southeastern Brazil. Journal of the Lepidopterists' Society, 67(1): 65-67.

Bächtold, A.; Alves-Silva, E. \& Del-Claro, K. 2016. Ants, plant characteristics and habitat conservation status affect the occurrence of myrmecophilous butterflies on an extrafloral nectaried Malpighiaceae. Studies on Neotropical Fauna and Environment, DOI: 10.1080/01650521.2016.1198192

Baylis, M. \& Pierce, N.E. 1991. The effect of host-plant quality on the survival of larvae and oviposition by adults of an ant-tended lycaenid butterfly, Jalmenus evagoras. Ecological Entomology, 16:1-9.

Brown Jr., K. S. 1993. Neotropical Lycaenidae : an overview, p. 45-61; Selected Neotropical species, p. 146-149; Theclinae endemic to the Cerrado vegetation (central Brazil), p.152. In: T. R. New (Ed.). Conservation biology of Lycaenidae (Butterflies). IUCN, Gland, Switzerland.

Burghardt, F. \& Fiedler, K. 1996. The influence of diet on growth and secretion behaviour of mirmecophilous Polyommatus icarus caterpillars (Lepidoptera: Lycaenidae. Ecological Entomology, 21: 1-8.

Calvo, R. 1998. Reprodución de Oenomaus ortignus (Lepidoptera: Lycaenidae) en Barva, Heredia, Costa Rica. Revista de Biologia Tropical, 46(1): 101-104.

Coley, P.D.; Bryant, J.P. \& Chapin, F.S. 1985. Resource availability and plant antiherbivore defense. Science, 230: 895-899.

Costa, F.V.; Neves, F.S.; Silva, J.O. \& Fagundes, M. 2011. Relationship between plant development, tannin concentration and insects associated with Copaifera langsdorffi (Fabaceae). Arthropod-Plant Interactions, 5: 9-18.

Delgado, M.N. 2011. Variações Fenotípicas nas Defesas Anti-Herbivoria de Espécies de Cerrado: Efeitos de Diferentes Condições Ambientais. Tese Doutorado. Universidade Brasilia, Brasília, DF.

DeVries, P.J. 1991. Mutualism between Thisbe irenea butterflies and ants, and the role of ant ecology in the evolution of larval-ant associations. Biological Journal of the Linnean Society, 43: 179-195.

Duarte, M.; Almeida, G.L.; Casagrande, M.M. \& Mielke, O.H.H. 2001. Notes on the last instar and pupa of Hemiargus hanno (Stoll) (Lepidoptera, Lycaenidae, Polyommatinae). Revista Brasileira de Zoologia, 18: 1097-1105. 
Elzinga, J.A.; Atlan, A.; Biere, A.; Gigord, L.; Weis, A.E. \& Bernasconi, G. 2007. Time after time: Flowering phenology and biotic interactions. Trends in Ecology \& Evolution, 22: 432-439.

Emery, E.O.; Brown Jr K.S. \& Pinheiro, C.E.G. 2006. As borboletas (Lepidoptera, Papilionoidea) do Distrito Federal, Brasil. Revista Brasileira de Entomologia, 50: 85-92.

Fernandes, G.W. \& Price, P.W. 1992. The adaptive significance of insect gall distribution: survivorship of species in xeric and mesic habitats. Oecologia, 90: 14-20.

Fernandes, G.W.; Araújo, R.C.; Araújo, S.C.; Lombardi, J. A.; Paula, A. S.; Loyola Jr., R. \& Cornelissen, T.G. 1997. Insect galls from savanna and rocky fields of the Jequitinhonha Valley, Minas Gerais, Brasil. Naturalia, 22: 221-224.

Fiedler, K. 1995a. Lycaenid butterflies and plants: is myrmecophily associated with particular hostplant preferences? Ethology Ecology \& Evolution, 7: 107-132

Fiedler, K. 1995b. Lycaenid butterfles and plants: hostplant relationships, tropical versus temperate. Ecotropica 1: 51-58.

Forister, M.L. 2004. Oviposition preference and larval performance within a diverging lineage of lycaenid butterflies. Ecological Entomology, 29: 264-272.

Forister, M.L. 2005. Influence of host plant phenology on Mitoura nelsoni (Lepidoptera: Lycaenidae). Annals of the Entomological Society of America, 98(3): 295-301.

Gingras, D.; Dutilleul, P. \& Boivin, G. 2008. Effect of plant structure on searching strategy and searching efficiency of Trichogramma turkestanica. Journal of Insect Science, 8(28): 1-9.

Hammer, Ø.; Harper, D.A.T. \& Ryan, P.D. 2001. PAST: Paleontological statistics software package for education and data analysis. Palaeontologia Electronica 4(1): 9pp. < http://palaeo-electronica.org/2001_1/past/issue1_01.htm>.

Hill, C.J. 1992. Temporal changes in abundance of two lycaenid butterflies (Lycaenidae) in relation to adult food resources. Journal of the Lepidopterists' Society, 46(3): 173-181.

Hopkins, R.J.; van Dam, N.M. \& van Loon, J.J.A. 2009. Role of glucosinolates in insect-plant relationships and multitrophic interactions. Annual. Review of Entomology, 54: 57-83.

Hothorn, T.; Bretz, F.; Westfall, P.; Heiberger, R.M.; Schuetzenmeister, A. \& Scheibe, S. 2016. Package 'multcomp'. Disponível em http://multcomp.R-forge.Rproject.org.

Hunter, M.D. 1992. Interactions within herbivore communities mediated by the host plant: the keystone herbivore concept. In: M. D. Hunter, T. Ohgushi, and P. W. Price [eds.], Effects of resource distribution on animal-plant interactions. Academic, New York. pp. 287-325.

Hughes, J.B. 2000. The scale of resource specialization and the distribution and abundance of lycaenid butterflies. Oecologia, 123: 375-383.

Kaminski, L.A. \& Freitas, A.V.L. 2010. Natural history and morphology of immature stages of the butterfly Allosmaitia strophius (Godart) (Lepidoptera: Lycaenidae) on flower buds of Malpighiaceae. Studies on Neotropical Fauna and Environment, 45: 1119.

Kaminski, L.A.; Freitas A.V.L. \& Oliveira P.S. 2010. Interaction between mutualisms: ant-tended butterflies exploit enemy-free space provided by ant-treehopper associations. The American Naturalist, 176(3): 322-334. 
Kaminski, L.A.; Rodrigues, D. \& Freitas, A.V.L. 2012. Immature stages of Parrhasius polibetes (Lepidoptera: Lycaenidae): host plants, tending ants, natural enemies and morphology. Journal of Natural History, 46: 11-12.

Kelly, C.K. \& Southwood, T.R.E.1999. Species richness and resource availability: A phylogenetic analysis of insects associated with trees. Proceedings of the National Academy of Sciences, USA, 96: 8013-8016

Kindt R. \& Coe, R. 2005. Tree diversity analysis. A manual and software for common statistical methods for ecological and biodiversity studies. Nairobi: World Agroforestry Centre (ICRAF).

Kursar, T.A.; Wolfe, B.T.; Epps, M.J.\& Coley, P.D. 2006. Food quality, competition, and parasitism influence feeding preference in a Neotropical lepidopteran. Ecology, 87(12): 3058-3069.

Lawton, J. H. 1983. Plant architecture and the diversity of phytophagous insects. Annual Review of Entomology, 28: 23-29.

Lewinsohn, T. M.; Novotny, V. \& Basset, Y. 2005. Insects on plants: diversity of herbivore assemblages revisited. Annual Review of Ecology, Evolution, and Systematics, 36: 597-620.

Magurran, A. E. 2004. Measuring biological diversity. Blackwell Science, Oxford, UK.

Malicky, H. 1970. New aspects of the association between lycaenid larvae (Lycaenidae) and ants (Formicidae, Hymenoptera). Journal of the Lepidopteristis' Society, 24: 190-202.

Marques, E.S.A.; Price, P.W. \& Cobb, N.S. 2000. Resource abundance and insect herbivore diversity on woody fabaceous desert plants. Environmental Entomology, 29(4): 696-703.

Monteiro, R.F. 1991. Cryptic larval polychromatism in Rekoa marius Lucas and $R$. palegon Cramer (Lycaenidae: Theclinae). Journal of Research on the Lepidoptera, 29: 77-84.

Morais, H.C.; Diniz, I.R. \& Silva, D.M.S. 1999. Caterpillar seasonality in a central Brazilian cerrado. Revista de Biología Tropical., 47: 1025-1033.

Morais, H.C.; Hay, J.D.V. \& Diniz, I.R. 2009. Brazilian cerrado folivore and florivore caterpillars: how different are they? Biotropica, 41(4): 401-405.

Morais, H.C.; Sujii, E.R.; Almeida-Neto, M.; De-Carvalho, P.S.; Hay, J.D.V. \& Diniz, I.R. 2011. Host plant specialization and species turnover of aaterpillars among hosts in the Brazilian Cerrado. Biotropica, 43(4): 467-472.

Munhoz, C.B.R. \& Felfili, J.M. 2005. Fenologia do estrato herbáceo-subarbustivo de uma comunidade de campo sujo na Fazenda Água Limpa no Distrito Federal, Brasil. Acta Botanica Brasilica, 19(4): 979-988.

Munhoz, C.B.R. \& Felfili, J.M. 2006. Fitossociologia do estrato herbáceo-subarbustivo de uma área de campo sujo no Distrito Federal, Brasil. Acta Botanica Brasilica, 20(3): 671-685.

Novotny, V.; Basset, Y.; Miller, S. E.; Drozd, P. \& Cizek, L. 2002. Host specialization of leaf chewing insects in a New Guinea rainforest. Journal of Animal Ecology. 71: 400-412.

Ohgushi, T. 1992. Resource limitation on insect herbivore populations. In: Hunter, M.D. Ohgushi, T. \& Price, P.W. (Eds.). Effects of resource distribution on animalplant interactions. Academic, New York. pp. 287-325.

Oliveira, P.E. A.M. 2008. Fenologia e biologia reprodutiva das espécies de Cerrado. In: Sano, S.M.; Almeida, S.P. \& Ribeiro, J.F. (eds.). Cerrado: ecologia e flora. Vol. 1. Embrapa Informação Tecnológica, Brasília/DF. pp. 273-290. 
Oliveira, P.S. \& Del-Claro, K. 2005. Multitrophic interactions in a neotropical savanna: ant-hemipteran systems, associated insect herbivores and a host plant. In: Burslem, D.F.R.P.; Pinard, M.A. \& Hartley, S.E. (Eds.). Biotic interactions in the tropics: their role in maintenance of s pecies diversity. Cambridge, Cambridge University Press. pp. 414-438.

Oliveira, P.S. \& Freitas, A.V.L. 2004. Ant-plantherbivore interactions in the neotropical cerrado savanna. Naturwissenschaften, 91: 557-570.

Pais, M.P. \& Varanda, E.M. 2003. Variation in plant defenses of Didymopanax vinosum (Cham. \& Schltdl.) Seem. (Apiaceae) across a vegetation gradient in a Brazilian Cerrado. Acta Botanica Brasilica, 17(3): 395-403.

Peterson, M.A. 1995. Unpredictability in the facultative association between larvae of Euphilotes enoptes (Lepidoptera: Lycaenidae) and ants. Biological Journal of the Linnean Society, 55: 209-223.

Pierce, N.E.; Braby, M.F.; Heath, A.; Lohman, D.J.; Mathew, J.; Rand D.B. \& Travassos, M.A. 2002. The ecology and evolution of ant association in the Lycaenidae (Lepidoptera). Annual Review of Entomology, 47: 733-771.

Pinheiro, C.E.G. \& Emery, E.O. 2006. As borboletas (Lepidoptera: Papilionoidea e Hesperioidea) da Área de Proteção Ambiental do Gama e Cabeça de Veado (Distrito Federal, Brasil). Biota Neotropica, 6(3): 1-15.

Price, P.W.; Diniz, I.R.; Morais, H.C. \& Marques, E.S.A. 1995. The abundance of insect herbivore species in the tropics: the high local richness of rare species. Biotropica, 27: 468-478.

Quinn, R.M.; Gaston, K,J. \& Roy, D.B. 1988. Coincidence in the distribution of butterflies and their foodplants. Ecography, 21: 279-288.

R Development Core Team. 2014. R: A language and environment for statistical computing. R Foundation for Statistical Computing. Online: www.R-project.org.

Ratter, J.A. 1980. Notes on the vegetation of Fazenda Água Limpa (Brasília, DF, Brazil), Royal Botanic Garden, Edinburgh, 111p.

RECOR-Reserva Ecológica do IBGE. 2014. Dados meteorológicos. Disponível em http://www.recor.org.br/cid360/download/17-dados-meteorol\%C3\%B3gicos. html (acessado 05.07.2014).

Ribeiro, S.P. \& Fernandes, G.W. 2000. Interações entre insetos e plantas no cerrado: teoria e hipóteses de trabalho. In: Martins, R.P.; Lewinsohn, T.M. \& Barbeitos, M.S. (Eds). Ecologia e comportamento de insetos. Série Oecologia Brasiliensis, vol. VIII. PPGE-UFRJ. Rio de Janeiro, Brasil. pp. 299-320.

Ribeiro, J.F. \& Walter, B.M.T. 2008. As principais fitofisionomias do Bioma Cerrado. In: Sano, S.M.; Almeida, S.P. \& Ribeiro, J.F. (Eds.). Cerrado: ecologia e flora. Vol. 1. Embrapa Informação Tecnológica, Brasília/DF. pp. 153-212.

Robbins, R.K. 2004. Introduction to the checklist of Eumaeini (Lycaenidae). In: Lamas G., (Ed). Checklist: Part 4A. Hesperioidea - Papilionoidea. In: Heppner, J.B. (Ed.). Atlas of Neotropical Lepidoptera. Volume 5A. Association for Tropical Lepidoptera, Gainesville, pp. xxiv-xxx.

Robbins, R.K. \& Nicolay, S.S. 2001. An overview of Strymon Hübner (Lycaenidae: Theclinae: Eumaeini). Journal of the Lepidopterists' Society, 55: 85-100.

Robbins, R.K. 2010. The "upside down" systematics of hairstreak butterflies (Lycaenidae) that eat pineapple and other Bromeliaceae. Studies on Neotropical Fauna and Environment, 45(1): 21-37.

Rodrigues, D.; Kaminski, L.A.; Freitas, A.V.L. \& Oliveira, P.S. 2010. Trade-offs underlying polyphagy in a facultative ant-tended forivorous butterfly: the role of host plant quality and enemy-free space. Oecologia, 163: 719-728. 
Rodriguez, J.; Jordano, D. \& Fernandez, J.H. 1994. Spatial heterogeneity in a butterflyhost plant interaction. Journal of Animal Ecology, 63(1): 31-38.

Seufert, P. \& Fiedler, K. 1999. Myrmecophily and parasitoid infestation of south-east Asian Lycaenidae butterfly larvae. Ecotropica, 5: 59-64.

Seymour, A.S.; Gutiérrez, D. \& Jordano, D. 2003. Dispersal of the lycaenid Plebejus argus in response to patches of its mutualist ant Lasius niger. Oikos, 103(1): 162174.

Scherrer, S.; Lepesqueur, C.; Vieira, M. C.; Almeida-Neto, M.; Dyer, L.; Forister, M. \& Diniz, I. R. 2016. Seasonal variation in diet breadth of folivorous Lepidoptera in the Brazilian cerrado. Biotropica, 48(4): 491-498.

Silva, N.A. P. 2011. Biologia de lagartas de Lycaenidae em inflorescências de plantas no cerrado do Brasil Central. Dissertação de Mestrado em Ecologia, Universidade de Brasília.

Silva, N.A.P.; Duarte, M.; Araujo, E.B. \& Morais, H.C. 2014. Larval biology of anthophagous Eumaeini (Lepidoptera: Lycaenidae, Theclinae) in the Cerrado of central Brazil. Journal Insect of Science, 14(184). DOI: 10.1093/jisesa/ieu046

Silva, N.A.P.; Frizzas, M.R. \& Oliveira, C.M. 2011a. Seasonality in insect abundance in the "Cerrado" of Goiás State, Brazil. Revista Brasileira de Entomologia, 55(1): 7987.

Silva, N.A.P.; Duarte, M.; Diniz, I.R. \& Morais, H.C. 2011b. Host plants of Lycaenidae on inflorescences in central Brazilian cerrado. Journal of Research on the Lepidoptera, 44: 95-105.

Sletvold, N.; Grindeland, J.M. 2008. Floral herbivory increases with inflorescence size and local plant density in Digitalis purpurea. Acta Oecologica, 34: 21-25.

Shapiro, A.M. 1984. "Edge effect" in oviposition behavior: a natural experiment with Euchloe ausonides (Pieridae). Journal of the Lepidopterists' Society, 38(3): 242245.

Stefanescu, C.; Peñuelas, J.; Sardans, J. \& Filella, I. 2006. Females of the specialist butterfly Euphydryas aurinia (Lepidoptera: Nymphalinae: Melitaeini) select the greenest leaves of Lonicera implexa (Caprifoliaceae) for oviposition. European Journal of Entomology, 103: 569-574.

Thomson, J.D. 1981. Spatial and temporal components of resource assessment by flower-feeding insects. Journal of Animal Ecology, 50: 49-59.

Thompson, J.N. 1983. Selection pressures on phytophagous insects feeding on small host plants. Oikos, 40: 438-444.

Tóthmérész, B. 1995. Comparison of different methods for diversity ordering. Journal of Vegetation Science, 6: 283-290.

Varanda, E.M. \& Pais, M.P. 2006. Insect folivory in Didymopanax vinosum (Apiaceae) in a vegetation mosaic of brazilian cerrado. Brazilian Journal of Biology, 66(2B): 671-680.

Vilela, A.A.; Torezan-Silingardi, H.M. \& Del-Claro, K. 2014. Conditional outcomes in ant-plant-herbivore interactions influenced by sequential flowering. Flora, 209(7): 359-366. http://dx.doi.org/10.1016/j.flora.2014.04.004

Wagner, D.; Kurina, L. 1997. The influence of ants and water availability on oviposition behaviour and survivorship of a facultatively ant-tended herbivore. Ecological Entomology, 22(3): 352-360.

Zuur, A.F.; Ieno, E.N.; Elphick, C.S. 2010. A protocol for data exploration to avoid common statistical problems. Methods in Ecology \& Evolution, 1: 3-14. 


\subsection{ANEXOS}

Anexo 1: Famílias, número de espécies (n.) e de indivíduos de plantas e total de espécies por família (n.), abundância absoluta e porcentagem de indivíduos de plantas e inflorescências nas quatro áreas de campo sujo amostradas na Fazenda Água Limpa/DF, Brasil, entre janeiro e abril de 2014. A1E, A3E= Elevadas, áreas distantes de córregos e $\mathrm{A} 2 \mathrm{~B}, \mathrm{~A} 4 \mathrm{~B}=\mathrm{Baixada}$, áreas próximas a córregos. Lista organizada a partir da maior abundância de inflorescências por família.

\begin{tabular}{|c|c|c|c|c|c|c|}
\hline Famílias de plantas & A1E & A2B & $\mathbf{A 3 E}$ & A4B & $\begin{array}{l}\text { (riq.) Total } \\
\text { plantas }(\%)\end{array}$ & $\begin{array}{c}\text { Total } \\
\text { infloresc. }(\%)\end{array}$ \\
\hline Asteraceae & (9) 196 & (16) 64 & (7) 99 & (18) 83 & (34) 442 (42.1) & $2885(48.4)$ \\
\hline Malpighiaceae & (6) 34 & (7) 40 & (3) 4 & (6) 25 & (11) 103 (9.8) & $724(12.1)$ \\
\hline Melastomataceae & (2) 22 & & (3) 11 & (3) 7 & (5) 40 (3.8) & 394 (6.6) \\
\hline Acanthaceae & & (2) 96 & & (1) 6 & (2) 102 (9.7) & $299(5)$ \\
\hline Rubiaceae & & (2) 14 & (2) 23 & (4) 15 & (5) $52(5)$ & $270(4.5)$ \\
\hline Lythraceae & (1) 1 & (4) 8 & (1) 1 & (1) 2 & (5) $12(1.1)$ & $249(4.2)$ \\
\hline Fabaceae & (2) 5 & (5) 15 & (3) 13 & (7) 26 & (13) 59 (5.6) & $216(3.6)$ \\
\hline Convolvulaceae & & (3) 19 & (2) 25 & (4) 22 & (5) $66(6.3)$ & $202(3.4)$ \\
\hline Ochnaceae & & & & (1) 9 & $9(0.9)$ & $129(2.2)$ \\
\hline Lamiaceae & (1) 10 & & (1) 1 & (4) 17 & (5) 28 (2.7) & $93(1.6)$ \\
\hline Iridaceae & (1) 3 & (1) 2 & (2) 2 & (1) 16 & (2) 23 (2.2) & $87(1.5)$ \\
\hline Vochysiaceae & (1) 13 & & & & $13(1.2)$ & $84(1.4)$ \\
\hline Gentianaceae & & & (1) 7 & & $7(0.7)$ & $52(0.9)$ \\
\hline Orobachanceae & & & (1) 12 & (1) 3 & (2) $15(1.4)$ & $51(0.9)$ \\
\hline Salicaceae & (1) 1 & & (1) 1 & & (1) $2(0.2)$ & $47(0.8)$ \\
\hline Xyridaceae & (1) 5 & & & (1) 13 & (1) 18 (1.7) & $40(0.7)$ \\
\hline Lauraceae & (1) 6 & & (1) 4 & & (1) 10 (1) & $34(0.6)$ \\
\hline Eriocaulaceae & (1) 6 & & & & $6(0.6)$ & $22(0.4)$ \\
\hline Polygalaceae & & & (3) 8 & (3) 3 & (2) $11(1)$ & $19(0.3)$ \\
\hline Malvaceae & (2) 3 & & & & $3(0.2)$ & $11(0.2)$ \\
\hline
\end{tabular}


Anexo 1, continuação:

\begin{tabular}{|c|c|c|c|c|c|c|}
\hline Famílias de plantas & A1E & A2B & A3E & A4B & $\begin{array}{l}\text { (riq.) Total } \\
\text { plantas (\%) }\end{array}$ & $\begin{array}{c}\text { Total } \\
\text { infloresc. }(\%)\end{array}$ \\
\hline Oxalidaceae & & (1) 3 & (1) 3 & & (2) $6(0.6)$ & $10(0.2)$ \\
\hline Bignoniaceae & & (1) 1 & & & $1(0.1)$ & $10(0.2)$ \\
\hline Solanaceae & (1) 1 & & & & $1(0.1)$ & $8(0.1)$ \\
\hline Apocynaceae & & (1) 1 & (1) 2 & & (2) $3(0.3)$ & $7(0.1)$ \\
\hline Erythroxylaceae & & & & (1) 4 & $4(0.4)$ & $5(0.1)$ \\
\hline Boraginaceae & & & & (1) 2 & $2(0.2)$ & $4(0.1)$ \\
\hline Euphorbiaceae & & & & (1) 2 & $2(0.2)$ & $3(0.1)$ \\
\hline Myrtaceae & (1) 1 & (1) 1 & & & (2) $2(0.2)$ & $2(0)$ \\
\hline Orchidaceae & $(1) 1$ & & (1) 1 & & (1) $2(0.2)$ & $2(0)$ \\
\hline Família não ident. & & & (1) 1 & & $1(0.1)$ & 1 \\
\hline Gesneriaceae & & & & (1) 1 & $1(0.1)$ & 1 \\
\hline Turneraceae & (1) 1 & & & & $1(0.1)$ & 1 \\
\hline Velloziaceae & & (1) 1 & & & $1(0.1)$ & 1 \\
\hline Verbenaceae & (1) 1 & & & & $1(0.1)$ & 1 \\
\hline Total geral & (34) 310 & (45) 265 & (38) 218 & (59) 256 & $1049(100 \%)$ & $5964(100 \%)$ \\
\hline
\end{tabular}


Anexo 2: Famílias e espécies de plantas, número total de indivíduos e inflorescências e número de Lycaenidae imaturos registrados nas quatro áreas de campo sujo amostradas na Fazenda Água Limpa/DF, Brasil, entre janeiro e abril de 2014.

\begin{tabular}{|c|c|c|c|c|}
\hline Famílias & Espécies de plantas & n. plantas & n. inflor. & n. imaturos \\
\hline \multirow[t]{2}{*}{ Acanthaceae } & Justicia pycnophylla & 93 & 278 & 0 \\
\hline & Ruellia sp. & 9 & 21 & 0 \\
\hline \multirow[t]{2}{*}{ Apocynaceae } & Macrosiphonia velame & 1 & 2 & 0 \\
\hline & Minaria cordata & 2 & 5 & 0 \\
\hline \multirow[t]{28}{*}{ Asteraceae } & Achyrocline satureoides & 1 & 2 & 0 \\
\hline & Ageratum fastigiatum & 65 & 685 & 0 \\
\hline & Aldama bracteata & 19 & 210 & 0 \\
\hline & Aspilia sp. & 11 & 40 & 0 \\
\hline & Aspilia foliacea & 7 & 45 & 0 \\
\hline & Asteraceae spp. (3 espécies) & 2 & 47 & 0 \\
\hline & Ayapana amygdalina & 6 & 28 & 0 \\
\hline & Baccharis dracunculifolia & 2 & 33 & 0 \\
\hline & Baccharis subdentata & 1 & 9 & 0 \\
\hline & Calea hymenolepis & 1 & 71 & 0 \\
\hline & Calea quadrifolia & 20 & 178 & 0 \\
\hline & Calea sickii & 2 & 29 & 0 \\
\hline & Chromolaena spp. (2 espécies) & 10 & 101 & 0 \\
\hline & Elephantopus micropappus & 18 & 35 & 0 \\
\hline & Elephantopus sp. & 5 & 46 & 0 \\
\hline & Eremanthus goyazensis & 5 & 57 & 0 \\
\hline & Eremanthus mollis & 15 & 53 & 0 \\
\hline & Lepidaploa aurea & 108 & 383 & 0 \\
\hline & Lepidaploa rufogrisea & 53 & 511 & 2 \\
\hline & Pseudobrickelia sp. & 2 & 9 & 0 \\
\hline & Riencourtia oblongifolia & 15 & 78 & 0 \\
\hline & Stevia sp. & 2 & 7 & 0 \\
\hline & Trichogonia spp. (3 espécies) & 15 & 52 & 0 \\
\hline & Trixis nobilis & 2 & 12 & 0 \\
\hline & Vernonanthura spp. (2 espécies) & 3 & 16 & 0 \\
\hline & Vernonia bardanoides & 9 & 54 & 0 \\
\hline & Vernonia megapotamica & 2 & 10 & 0 \\
\hline & Vernonia monocephala & 39 & 55 & 0 \\
\hline Bignoniaceae & Arrabidaea brachypoda & 1 & 10 & 7 \\
\hline Boraginaceae & Heliotropium salicioides & 2 & 4 & 0 \\
\hline \multirow[t]{5}{*}{ Convolvulaceae } & Convolvulaceae spp. (3 espécies) & 4 & 17 & 0 \\
\hline & Evolvulus pterygophyllus & 16 & 25 & 0 \\
\hline & Ipomoea procurrens & 1 & 1 & 0 \\
\hline & Ipomoea sp. & 2 & 2 & 0 \\
\hline & Merremia tomentosa & 43 & 157 & 0 \\
\hline Eriocaulaceae & Paepalanthus sp. & 6 & 22 & 0 \\
\hline
\end{tabular}


Anexo 2, continuação:

Famílias

Erythroxylaceae

Euphorbiaceae

Fabaceae

Família não identificada

Gentianaceae

Gesneriaceae

Iridaceae

Lamiaceae

\section{Lauraceae}

Lythraceae

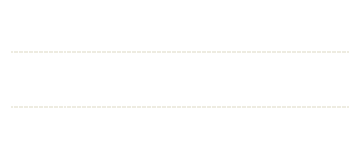

Malpighiaceae

\section{Espécies de plantas}

Erythroxylum campestre

Dalechampia caperonioides

Calliandra dysantha

Chamaecrista adenophora

Chamaecrista desvauxii

Crotalaria spp. (2 espécies)

Eriosema glabrum

Galactia heringeri

Galactia sp.

Mimosa claussenii

Mimosa foliosa

Mimosa radula

Mimosa sp.

Periandra mediterranea

Zornia sp.

Msp..

Gentianaceae sp.

Sinningia allagophylla

Sisyrinchium vaginatum

Trimezia sp.

Cyanocephalus peduncularis

Hyptis linarioides

Hyptis nudicaulis

Hyptis villosa

Lamiaceae sp.

Cassytha filiformis

Cuphea micrantha

Cuphea sp.

Cuphea spermacoce

Diplusodon oblongus

Lythraceae sp.

Banisteriopsis argyrophylla

Banisteriopsis campestris

Banisteriopsis megaphylla

Banisteriopsis oxyclada

Banisteriopsis sp.

Byrsonima coccolobifolia

Byrsonima pachyphylla

Camarea affinis

Heteropterys pteropetala

Peixotoa goiana

Pterandra pyroidea n. plantas n. inflor. n. imaturos

\begin{tabular}{ccc}
4 & 5 & 0 \\
2 & 3 & 0 \\
1 & 3 & 1 \\
1 & 2 & 0 \\
5 & 15 & 0 \\
3 & 7 & 0 \\
6 & 33 & 0 \\
6 & 15 & 4 \\
7 & 26 & 5 \\
11 & 44 & 4 \\
7 & 23 & 18 \\
\hline 3 & 4 & 0 \\
\hline 6 & 41 & 0 \\
\hline 2 & 2 & 0 \\
1 & 1 & 1 \\
1 & 1 & 0 \\
7 & 52 & 0 \\
\hline
\end{tabular}

$1 \quad 1 \quad 0$

$19 \quad 83 \quad 0$

$4 \quad 4 \quad 0$

$22 \quad 74 \quad 0$

140

$1 \quad 1 \quad 0$

$3 \quad 11 \quad 0$

$1 \quad 3 \quad 0$

$\begin{array}{lll}10 & 34 & 2\end{array}$

360

$2 \quad 14 \quad 0$

$2 \quad 3 \quad 0$

$4 \quad 175 \quad 9$

$1 \quad 51 \quad 0$

$2 \quad 159 \quad 1$

$24 \quad 41 \quad 0$

$\begin{array}{lll}7 & 188 & 12\end{array}$

3230

100

260

$44 \quad 166 \quad 25$

$2 \quad 4 \quad 2$

$\begin{array}{lll}12 & 63 & 7\end{array}$

$4 \quad 63 \quad 5$

$2 \quad 2$


Anexo 2, continuação:

\begin{tabular}{|c|c|c|c|c|}
\hline Famílias & Espécies de plantas & n. plantas & n. inflor. & n. imaturos \\
\hline \multirow[t]{2}{*}{ Malvaceae } & Malvaceae spp. (2 espécies) & 2 & 3 & 0 \\
\hline & Sida rhombifolia & 1 & 8 & 0 \\
\hline \multirow[t]{5}{*}{ Melastomataceae } & Miconia albicans & 1 & 13 & 0 \\
\hline & Microlicia fulva & 21 & 314 & 2 \\
\hline & Siphanthera cordata & 1 & 2 & 0 \\
\hline & Tibouchina spp. (3 espécies) & 13 & 29 & 0 \\
\hline & Tibouchina sp3 & 4 & 36 & 2 \\
\hline \multirow[t]{2}{*}{ Myrtaceae } & Myrcia sp. & 1 & 1 & 0 \\
\hline & Psidium sp. & 1 & 1 & 6 \\
\hline Ochnaceae & Ouratea floribunda & 9 & 129 & 1 \\
\hline Orchidaceae & Habenaria sp. & 2 & 2 & 0 \\
\hline \multirow[t]{2}{*}{ Orobachanceae } & Buchnera sp. & 3 & 6 & 0 \\
\hline & Esterhazya splendida & 12 & 45 & 0 \\
\hline \multirow[t]{2}{*}{ Oxalidaceae } & Oxalis cordata & 3 & 3 & 0 \\
\hline & Oxalis densifolia & 3 & 7 & 1 \\
\hline \multirow[t]{2}{*}{ Polygalaceae } & Polygala longicaulis & 7 & 8 & 0 \\
\hline & Polygala spp. (3 espécies) & 4 & 11 & 0 \\
\hline \multirow[t]{5}{*}{ Rubiaceae } & Borreria suaveolens & 3 & 10 & 0 \\
\hline & Galianthe grandifolia & 1 & 8 & 0 \\
\hline & Palicourea squarrosa & 9 & 12 & 0 \\
\hline & Sabicea brasiliensis & 34 & 223 & 7 \\
\hline & Sipanea hispida & 5 & 17 & 0 \\
\hline Salicaceae & Casearia sylvestris & 2 & 47 & 0 \\
\hline Solanaceae & Solanum lycocarpum & 1 & 8 & 3 \\
\hline Turneraceae & Turneraceae sp. & 1 & 1 & 0 \\
\hline Velloziaceae & Vellozia squamata & 1 & 1 & 0 \\
\hline Verbenaceae & Stachytarpheta longispicata & 1 & 1 & 0 \\
\hline Vochysiaceae & Vochysia elliptica & 13 & 84 & 7 \\
\hline Xyridaceae & Xyris sp. & 18 & 40 & 0 \\
\hline Total geral 34 & 125 espécies & 1.049 & 5.964 & 134 \\
\hline
\end{tabular}


Anexo 3. Espécies de Lycaenidae, número de indivíduos imaturos e espécies de plantas e famílias hospedeiras registradas nas quatro áreas de campo sujo amostradas na Fazenda Água Limpa/DF, Brasil, entre janeiro e abril de 2014.

\section{Espécies Lycaenidae}

n. imaturos

Plantas hospedeiras

Eumaeini:

Allosmaitia strophius

Arawacus ellida

Cyanophrys herodotus

Kolana ergina

Magnastigma julia

Ministrymon azia

Eumaeini sp.

Eumaeini sp.01

Eumaeini sp.1

Eumaeini sp.2

Eumaeini sp. 3

Eumaeini sp.4

Eumaeini sp.5

Nicolaea socia

Parrhasius polibetes

Rekoa marius

Rekoa palegon

Strymon crambusa

Strymon mulucha

Tmolus venustus

Polyommatinae:

Hemiargus hanno

Polyommatinae sp.
Banisteriopsis argyrophylla, Banisteriopsis

29 megaphylla, Byrsonima pachyphylla, Camarea affinis, Heteropterys pteropetala, Peixotoa goiana (Malpighiaceae)

3 Solanum lycocarpum (Solananceae)

1 Diplusodon oblongus (Lythraceae)*

3 Byrsonima pachyphylla (Malpighiaceae)

Diplusodon oblongus (Lythraceae)*

2 Cassytha filiformis (Lauraceae)

22 Mimosa claussenii, Mimosa foliosa (Fabaceae)

Banisteriopsis megaphylla, Byrsonima

7 pachyphylla, Heteropterys pteropetala (Malpighiaceae)

2 Byrsonima pachyphylla (Malpighiaceae)

1 Diplusodon oblongus (Lythraceae)

6 Vochysia elliptica (Vochysiaceae)

6 Psidium sp. (Myrtaceae)

7 Arrabidaea brachypoda (Bignoniaceae)

2 Tibouchina sp3. (Melastomataceae)

1 Vochysia elliptica (Vochysiaceae)

7 Banisteriopsis megaphylla (Malpighiaceae)

Diplusodon oblongus (Lythraceae)

Banisteriopsis megaphylla (Malpighiaceae)

$4 \quad$ Calliandra dysantha (Fabaceae)

Diplusodon oblongus (Lythraceae)*

Ouratea floribunda (Ochnaceae)

2 Lepidaploa rufogrisea (Asteraceae)

1 Oxalis densifolia (Oxalidaceae)

2 Diplusodon oblongus (Lythraceae)*

Peixotoa goiana (Malpighiaceae)

Banisteriopsis megaphylla, Byrsonima

15 pachyphylla, Peixotoa goiana (Malpighiaceae),

Galactia sp. (Fabaceae), Sabicea brasiliensis

(Rubiaceae)* $^{*}$

6

Galactia heringeri, Galactia sp., Zornia sp.

(Fabaceae)

$5 \quad$ Galactia sp. (Fabaceae)

Microlicia fulva (Melastomataceae)

*Novo registro de família de planta hospedeira neste estudo. 


\section{CAPÍTULO II}

História natural e morfologia dos estágios imaturos de duas espécies de Paiwarria (Eumaeini) com notas sobre mimetismo larval

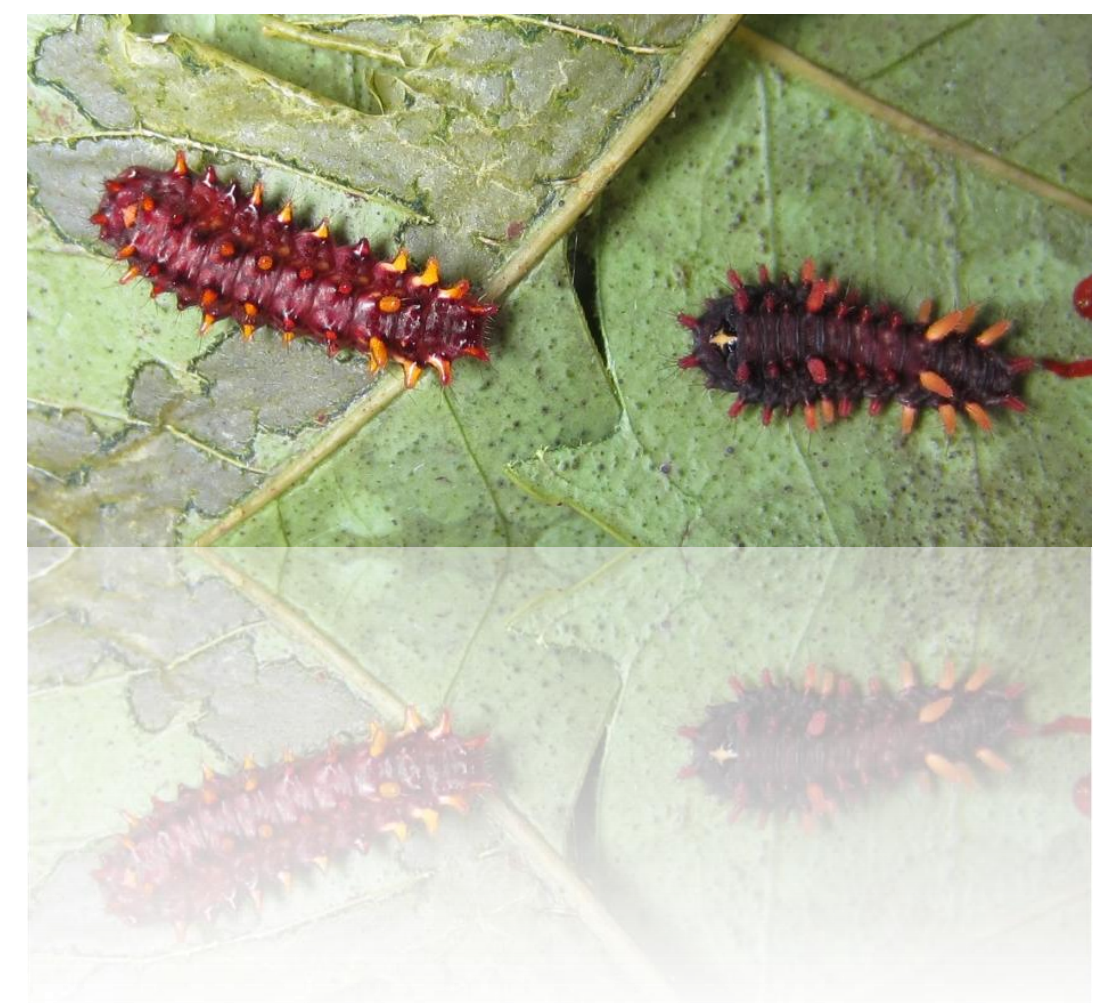




\subsection{INTRODUÇÃO}

A América do Sul se destaca como um dos locais com maior diversidade de borboletas (Lamas 2008). Lycaenidae está entre os principais táxons de Lepidoptera e é uma família composta na sua maioria pela tribo Eumaeini (Theclinae), com 1.130 espécies já reconhecidas (Robbins 2004a). Os Eumaeini são uma linhagem monofilética que passou por uma radiação adaptativa recente na região neotropical (Quental 2008). Por ser um grupo diverso, é também pouco conhecido e apresenta uma grande complexidade taxonômica. $\mathrm{O}$ conhecimento dessa tribo tem avançado nos últimos anos e informações sobre a distribuição, plantas hospedeiras e características dos imaturos têm sido consideradas como importantes complementos para o esclarecimento das relações filogenéticas (Ballmer \& Pratt 1992a, Robbins \& Nicolay 2001, Duarte et al. 2005, Robbins \& Busby 2008, Duarte \& Robbins 2010, Robbins 2010, Silva et al. 2011). As lagartas de Eumaeini, de um modo geral, são solitárias, apresentam corpo onisciforme (sem cerdas longas ou escolos), se alimentam de botões, flores e eventualmente de folhas e frutos; tendem a ser crípticas sobre as plantas hospedeiras e várias espécies podem apresentar interações simbióticas com formigas (mirmecofilia) mediadas por órgãos especializados presentes no tegumento (Robbins \& Aiello 1982, Ballmer \& Pratt 1988, 1992b, Monteiro 1990, Fiedler 1991, Calvo 1998, Kaminski et al. 2012, Silva et al. 2014).

Dentre os órgãos relacionados a mirmecofilia se destaca o órgão nectário dorsal (DNO) que secreta recompensas calóricas que servem de alimento para as formigas em troca de uma suposta defesa (Pierce et al. 2002). A mirmecofilia e a presença de DNO são apresentadas como uma condição ancestral em Lycaenidae de modo que a falta de interação e não funcionalidade ou ausência de DNO é considerada uma redução secundária e ocorreu em várias linhagens (Malicky 1970, Fiedler 1991). Outros órgãos larvais importantes são os órgãos perfurados em forma de cúpula (PCOs), glândulas epidérmicas unicelulares cuja função tem sido associada com a liberação de substâncias que apaziguam o comportamento agressivo das formigas (Pierce et al. 2002). Adaptações morfológicas e comportamentais tais como a cutícula espessa e o hábito alimentar endófago, geralmente nos primeiros ínstares, também têm sido relacionadas com a mirmecofilia em Theclinae e são apresentados como os principais mecanismos de defesas (Malicky 1970, Ballmer \& Pratt 1992a, Monteiro 1990, Bächtold \& Alves-Silva 
2012). Além disso, sinais sonoros emitidos através do substrato por lagartas e pupas de algumas espécies também podem funcionar repelindo predadores ou como alerta para atrair formigas atendentes (Downey 1966, DeVries 1990, Travassos \& Pierce 2000).

Como outros sistemas mutualistas, os benefícios da interação com as formigas são condicionais, ou seja, podem variar espacialmente e temporalmente em função de variáveis ambientais ou presença de outras espécies. Para os insetos herbívoros, em geral, as propriedades da planta hospedeira, e a pressão dos inimigos naturais, atuam de diferentes formas na evolução dos atributos das lagartas e as espécies apresentam diferentes estratégias de defesa dependendo de sua distribuição e tipos de hábitat (Ehrlich \& Raven 1964, Stamp 1986, Tyler et al. 1994, Price 2002). Isto envolve adaptações químicas, morfológicas e comportamentais. Entre as diversas táticas de defesa está a capacidade de construir abrigos (Costa \& Varanda 2002, Diniz et al. 2012), de sintetizar suas próprias toxinas (Rettenmeyer 1970, Bowers 1993) ou de adquiri-las a partir dos compostos secundários presentes em suas plantas hospedeiras (Ehrlich \& Raven 1964), o que parece ser mais comum entre os especialistas do que em espécies generalistas (Price et al. 1980, Dyer 1995, Camara 1997, Diamond \& Kingsolver 2011). Diversos táxons de lepidópteros apresentam coloração que pode atuar advertindo o predador quanto à sua toxicidade (Grant 2007, Canfield et al. 2009, Massuda \& Trigo 2009) ou mimetizando as espécies quimicamente defendidas (Owen 1980, Tyler et al. 1994). A coloração é um mecanismo defensivo primário entre os animais e entre as lagartas de lepidópteros as defesas secundárias são representadas por movimentos de levantar o tórax e abdome (beat reflex), saltar em fio de seda, morder, regurgitar, irritar com as estruturas urticantes (cerdas e espinhos), exibir odor e paladar desagradável (Owen 1980, Bowers 1993, Zalucki et al. 2002, Grant 2007). Em resumo, a manutenção ou perda da mirmecofilia nas lagartas está relacionada ao balanço entre custos e benefícios, entre defesas bióticas praticadas pelas formigas e outros tipos de defesa direta, como aqueles oriundos de compostos secundários das plantas hospedeiras.

Nesse sentido, Eumaeini constitui um bom modelo para entender estas transições, pois várias linhagens mostram variação no grau de mirmecofilia e tendência à redução e perda da mirmecofilia (p. ex. Kaminski \& Freitas 2010). Um sistema promissor é composto pelas espécies Paiwarria aphaca (Hewitson) e Paiwarria venulius (Cramer) (Theclinae: Eumaeini) que ocorrem no cerrado do Distrito Federal (DF) (Emery et al. 2006) e que foram o foco do presente estudo. 
O gênero Paiwarria Kaye corresponde, atualmente, a sete espécies neotropicais (Robbins 2004b, Hall \& Willmott 2005). Os limites geográficos não são bem conhecidos, mas é registrado em localidades entre o México e a Argentina (Robbins \& Small 1981, D’Abrera 1995, Robbins 2004b, Hall \& Willmott 2005, Núñez Bustos 2009). P. aphaca é registrada em áreas do Cerrado, em floresta de montanha em altitudes moderadas e ocorre no Paraguai e Brasil (Mato Grosso, Mato Grosso do Sul, Goiás, Tocantins, Minas Gerais, Rio de Janeiro, São Paulo, Rio Grande do Sul e Distrito Federal). E $P$. venulius é registrada em planícies de floresta decídua e áreas abertas próximas à floresta úmida e ocorre na Guiana Francesa, Suriname, Guiana, Trinidad, Venezuela, Equador, Peru e Brazil (Pará, Mato Grosso, Mato Grosso do Sul, Goiás, Tocantins, Maranhão, Minas Gerais, Rio de Janeiro, São Paulo e Distrito Federal) (R.K.Robbins com. pess). Essas duas espécies são reconhecidas apenas pela descrição dos adultos (Figura 1) e como para outros gêneros de Eumaeini, a posição filogenética de Paiwarria ainda não está clara (Bálint \& Salazar 2003, Robbins 2004a, Hall \& Willmott 2005, Quental 2008). Aspectos superficiais da morfologia das lagartas dessas duas espécies são apresentados pela primeira vez por Silva et al. (2014). Não há outros registros de imaturos de Paiwarria na literatura, exceto para Paiwarria umbratus (Geyer) ilustrado por Janzen \& Hallwachs (2013) sobre Sapotaceae na Costa Rica.

Curiosamente, ao contrário de P. umbratus, $P$. aphaca e $P$. venulius, além de apresentarem escolos com espinhos possuem coloração conspícua sobre as folhas das plantas hospedeiras (Silva et al. 2014). Ambas as espécies se alimentam de plantas da família Celastraceae, sendo que $P$. venulius foi registrada posteriormente à $P$. aphaca sobre as mesmas espécies de plantas na Fazenda Água Limpa/DF (Diniz \& Morais 1995, Silva et al. 2011, 2014). O registro de Bignoniaceae em Beccaloni et al. (2008) para $P$. venulius, é um erro na identificação da planta (A.V.L. Freitas com. pess.).

A família Celastraceae é amplamente distribuída nos trópicos e é representada por árvores, arbustos e lianas (Lombardi 2009, Stevens 2012). Hippocratea volubilis L., e Peritassa laevigata (Hoffmanns. ex Link) A.C.Sm., por exemplo, são espécies de lianas com ampla distribuição no Cerrado. Na Área de Proteção Ambiental Gama e Cabeça de Veado/DF ocorrem ao menos sete gêneros, sendo as arbustivas Salacia crassifolia (Mart. ex Shult.) G. Dom., Peritassa campestris (Cambess.) A.C. Sm. e Plenckia polpunea Reissek as mais comuns em áreas de cerrado sensu stricto e campo sujo, Cheiloclinium cognatum (Miers) A. C.Sm. é uma árvore frequente em matas de galeria (Cavalcanti \& Ramos 2001, Felfili et al. 2004). 
Celastráceas podem exibir uma variedade de compostos secundários. Estudos fitoquímicos têm atribuído potencial farmacológico das espécies à presença de flavonoides, alcaloides, e outros compostos denominados de celastroloides, que são derivativos de metabolitos secundários restritos a esse grupo vegetal (Corsino 2000, Lião et al. 2002, Magalhães et al. 2011). Diversos compostos com propriedades químicas citotóxica e antioxidantes já foram extraídos de hospedeiras de Paiwarria no Cerrado, por exemplo, de Maytenus salicifolia Reissek, S. crassifolia e P. campestris (citada como Salacia sp. em Silva et al. 2011) (Corsino et al. 2009, Magalhães et al. 2011, Oliveira et al. 2012).

As lagartas de Paiwarria encontradas nas celastráceas, principalmente $P$. venulius, apresentam semelhanças com lagartas aposemáticas de Parides Hübner (Papilionidae, Troidini). Lagartas de Parides se alimentam de Aristolochia spp. (Aristolochiaceae) e sequestram compostos do metabolismo secundário de suas plantas para defesa, participando como modelo de vários complexos miméticos neotropicais (Tyler et al. 1994). Embora o mimetismo batesiano e mülleriano sejam amplamente conhecidos e estudados em borboletas, é considerado raro em lagartas e tem sido pouco estudado (Berenbaum 1995, revisão em Willmott et al. 2011). Assim, caso seja confirmado o mimetismo, Paiwarria pode constituir um modelo para estudos de mimetismo larval. Contudo, as interações entre os organismos envolvem uma ampla gama de aspectos bióticos e abióticos, de tal forma que qualquer comparação só poderá ser aferida após o conhecimento detalhado da morfologia, comportamento e biologia da espécie.

Desta forma, os objetivos deste estudo foram: obter informações sobre a história natural e descrever a morfologia dos estágios imaturos de Paiwarria aphaca e $P$. venulius, avaliar se há variação de coloração das lagartas em relação à estrutura consumida (folha e inflorescência) e verificar a semelhança das lagartas de Paiwarria com lagartas de espécies simpátricas de Parides. São fornecidas ilustrações dessas e de outras espécies de lagartas que coocorrem nas mesmas plantas hospedeiras de Paiwarria. 


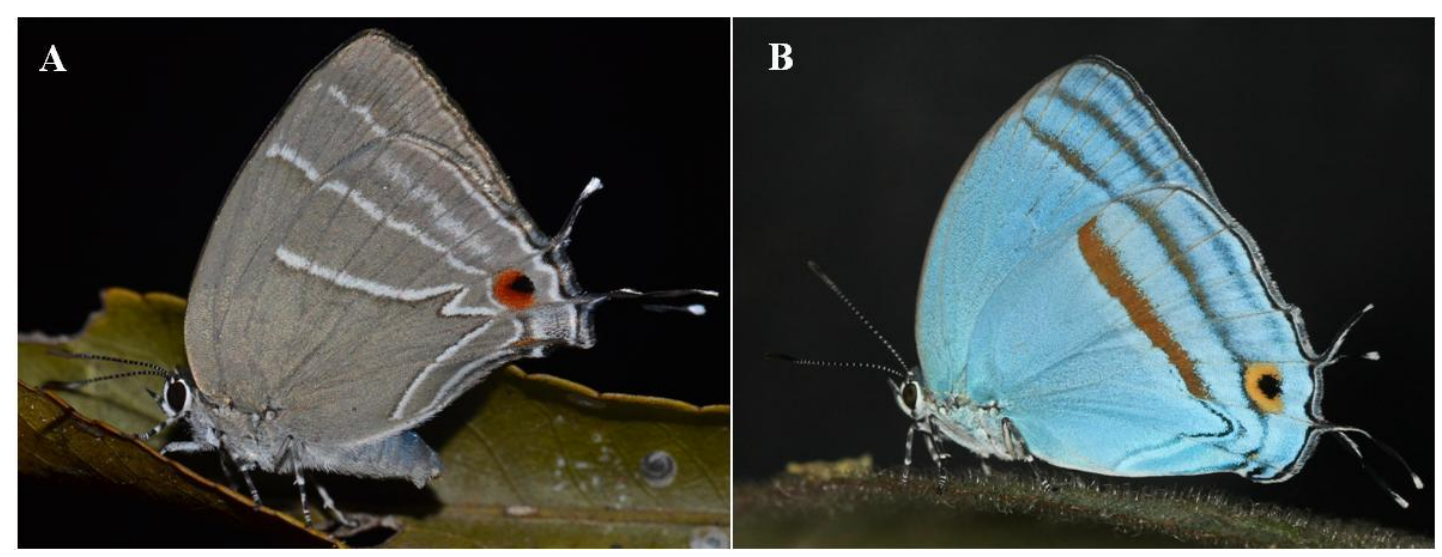

Figura 1. Adultos de (A) Paiwarria aphaca e (B) P. venulius (Lycaenidae, Theclinae, Eumaeini). (Fotos L. Kaminski).

\subsection{METODOLOGIA}

\section{Áreas de estudo}

As buscas por plantas hospedeiras com imaturos tanto das espécies de Paiwarria como de Parides spp. foram realizadas semanalmente entre janeiro de 2015 e maio de 2016 em áreas de cerrado sensu stricto, campo sujo e mata de galeria, principalmente na Fazenda Água Limpa (FAL) $\left(15^{\circ} 55^{\prime} \mathrm{S}-47^{\circ} 55^{\prime} \mathrm{W}\right)$, mas com coletas também no Jardim Botânico de Brasília (JBB), $\left(15^{\circ} 55^{\prime} \mathrm{S}, 47^{\circ} 55^{\prime} \mathrm{W}\right)$, na Reserva Ecológica do IBGE (RECOR- $15^{\circ} 56^{\prime} \mathrm{S}-47^{\circ} 53^{\prime} \mathrm{W}$ ) e no Parque Nacional de Brasília (PNB) (15º 47' S - $47^{\circ} 56^{\prime}$ W). FAL, JBB e IBGE fazem parte da APA Gama e Cabeça de Veado. As quatro áreas são de preservação e localizadas próximo a Brasília/DF. Buscas por plantas hospedeiras foram realizadas também em mata ciliar na Fazenda Grotão 15³3' 35'S, $47^{\circ} 45^{\prime} 53^{\prime \prime} \mathrm{W}$, próximo a Planaltina/DF e na mata do Santuário de Vida Silvestre Vagafogo $15^{\circ} 49^{\prime} 21^{\prime \prime} \mathrm{S}, 48^{\circ} 59^{\prime} 42^{\prime \prime W}$, em Pirenópolis/GO. A sazonalidade climática é marcante em toda essa região com o verão chuvoso (outubro a abril) e o inverno seco (maio a setembro).

\section{Plantas hospedeiras}

Para os imaturos de Paiwarria foram inspecionadas folhas e inflorescências de espécies de Celastraceae. Atualmente, Hippocrateaceae é tratada como sinônimo de Celastraceae e Hippocrateoideae e Salacioideae são incluídas como subfamílias 
(Lombardi 2009, Stevens 2012). Neste estudo, as espécies de plantas serão tratadas como pertencentes à Celastraceae seguindo a disposição dos táxons proposta no Angiosperm Phylogeny Website (http://www.mobot.org/MOBOT/research/APweb/) (Stevens 2012). Para o registro das lagartas de Parides spp. foram examinadas folhas de espécies de Aristolochiaceae presentes nas áreas de estudo.

\section{Coletas de campo, criação e analise morfológica dos imaturos}

Ovos e lagartas encontrados nas plantas foram coletados e transportados em sacos plásticos ao laboratório onde foram mantidos individualmente em recipientes plásticos, sem controle de luz e umidade. As lagartas foram supridas ad libitum com a estrutura da espécie de planta correspondente, e no caso de Paiwarria algumas com flor ou com folha para verificar variação no padrão da coloração dependente da dieta. Os potes de criação foram inspecionados diariamente, para limpeza e reposição do alimento. Todos os estágios imaturos foram fotografados com câmeras digitais Canon ${ }^{\circledR}$ Powershot SX20 e Powershot ELPH 300HS acoplada a estereomicroscopio. As imagens foram utilizadas para acompanhar alterações morfológicas entre os ínstares e comparar morfologia geral das lagartas de Paiwarria e Parides. A cada ecdise as cápsulas cefálicas foram separadas e conservadas a seco. As medidas foram realizadas com auxilio de estereomicroscopios Bresser ${ }^{\circledR}$ Researcher ICD e Leica ${ }^{\circledR}$ S8 APO equipado com escala micrométrica. Amostras de imaturos das duas espécies de Paiwarria foram preparadas para microscopia eletrônica de varredura (MEV) seguindo protocolo de procedimentos do Laboratório de Microscopia da Universidade de Brasília (UnB): primeiro foram fixadas em solução de Kahle, e para o processo de desidratação para MEV ficaram imersas por trinta minutos de cada vez em diferentes concentrações de acetona (50, 70, 90 e 2x100\%). A desidratação a ponto crítico foi realizada em um aparelho Balzers® - CPD 030, em seguida as amostras foram montadas sobre fita dupla face em suporte metálico e metalizadas no aparelho Balzers® - SCD 050. As imagens foram feitas em microscópio JEOL® JSM 7001F.

Os parasitoides de ovos, lagartas e pupas que emergiram no recipiente de criação foram conservados em álcool a 70\%. Adultos foram montados em alfinetes entomológicos. Os estágios imaturos de Paiwarria aphaca e $P$. venulius são descritos separadamente e comparadas também entre espécies. Os dados morfométricos são fornecidos nos valores mínimos e máximos. Para a descrição dos estágios imaturos das 
duas espécies foram utilizadas apenas lagartas que se alimentaram de folhas, o que foi mais frequentemente encontrado no campo. Foi utilizada a terminologia de Downey \& Allyn (1981) para a descrição do estágio de ovo, Stehr (1987), Ballmer \& Pratt (1988), Kaminski et al. (2012), para cerdas, tórax e abdome das lagartas. Material testemunho dos insetos foi depositado na Coleção Entomológica do Departamento de Zoologia da Universidade de Brasília, DF.

\subsection{RESULTADOS}

\section{História natural de Paiwarria aphaca e $P$. venulius}

Foram examinadas pelo menos 1.200 plantas de seis espécies de Celastraceae, Hippocratea volubilis, Peritassa laevigata, Peritassa campestris e Plenckia polpunea. Ovos e lagartas de $P$. aphaca foram registrados ao longo do ano, principalmente sobre folhas de $P$. polpunea (13 imaturos) e mais frequentemente em $P$. campestris (78 imaturos) em áreas de cerrado sensu stricto e próximas ou na borda das estradas de terra. Imaturos de $P$. venulius $(\mathrm{n}=29)$ também foram encontrados nessas duas espécies de plantas na FAL, entre os meses de maio e outubro. As buscas em áreas de mata, entre novembro e maio, em $C$. cognata $(\mathrm{n}=150$ plantas) e $H$. volubilis e P. laevigata $(\mathrm{n}=21$ plantas), resultaram apenas no encontro de ovos já eclodidos $(n=9)$ ou que não eclodiram em laboratório $(n=2)$ o que impossibilitou a identificação correta, mas presume-se que sejam de $P$. venulius que é registrada com maior frequência nesse ambiente a partir da coleta de adultos (L.A. Kaminski com. pess., dados de coleta em coleção). Um adulto de P. venulius foi observado em voo aproximadamente às 15:00 horas em fevereiro de 2016 na mata do PNB.

Uma fêmea de P. aphaca foi vista no cerrado em comportamento de oviposição, caminhando e tocando com o final do abdome entre o pecíolo das folhas e o caule de $P$. campestris, ao meio dia, mas somente um ovo foi encontrado na planta. Ambas as espécies colocam os ovos isoladamente no pecíolo das folhas e no caule próximo as gemas reprodutivas e sobre inflorescências (Figura 2). Não foi possível diferenciar os ovos das duas espécies no campo. Até sete ovos foram encontrados em uma mesma planta, as lagartas têm hábito solitário em todos os ínstares. Uma fêmea adulta de $P$. aphaca, oriunda da lagarta em criação, foi confinada em gaiola mantida em laboratório 
e resultou na postura de sete ovos, apesar da presença de um macho os ovos não estavam fecundados. Fêmea de $P$. venulius criada em laboratório não foi capaz de ovipor confinada.
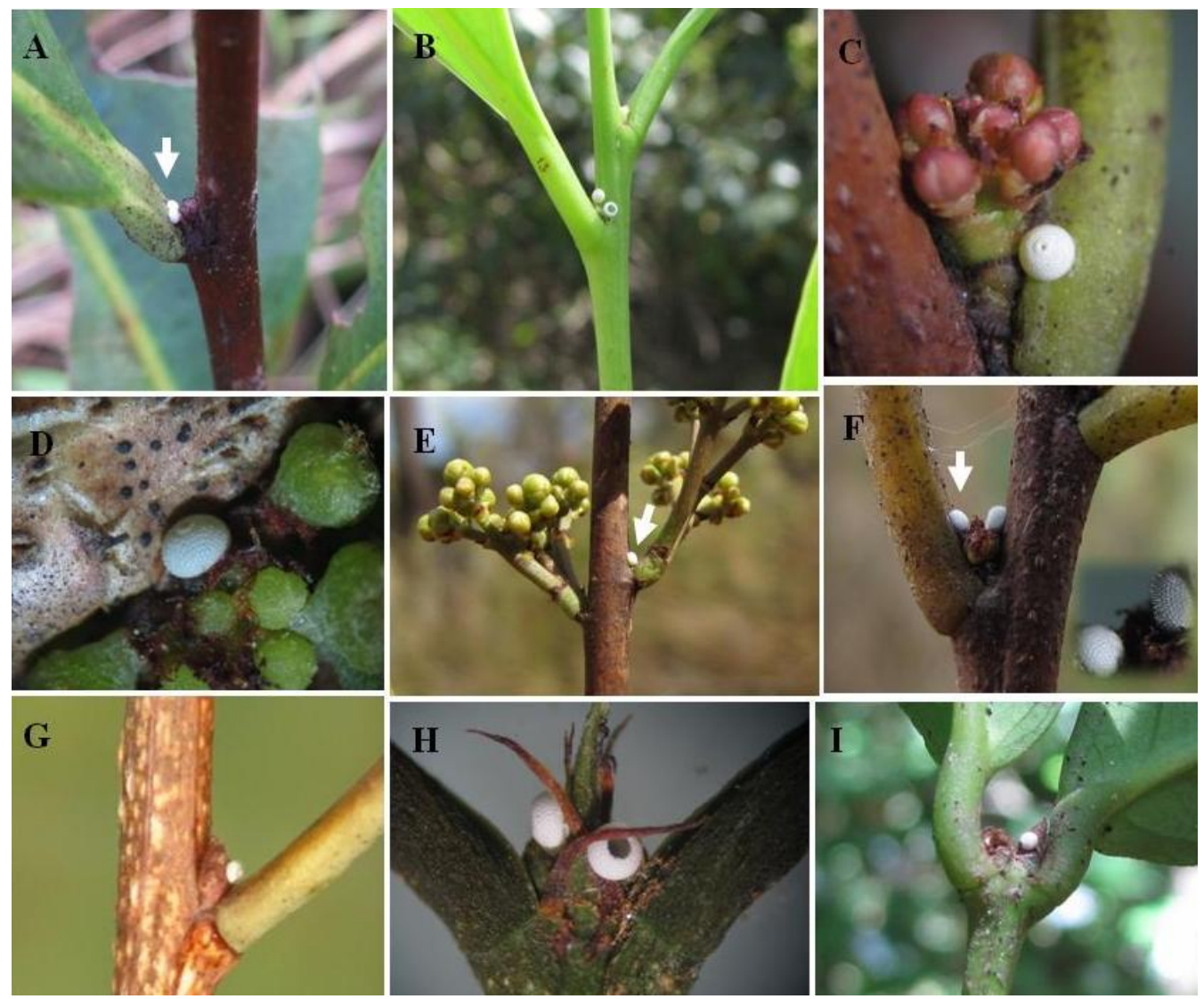

Figura 2. Localização dos ovos (setas) de Paiwarria aphaca e $P$. venulius nas espécies de Celastraceae. (F) detalhe à direita mostrando ovo de Emesis russula Stichel (Riodinidae) ao lado de ovo de Paiwarria (seta). (Fotos: Neuza Silva).

A duração do desenvolvimento desde a eclosão da lagarta do ovo até a emergência do adulto, de ambas as espécies, é de 30 a 45 dias. As lagartas completam o ciclo com quatro ínstares larvais (L1-L4) e ao final de cada ecdise podem consumir toda a exúvia, inclusive a cápsula cefálica. Assim, algumas vezes é necessário verificar vestígios nas fezes para acompanhar as mudanças de ínstar. Logo após a ecdise, as lagartas surgem com cores mais vibrantes e conspícuas sobre a folha (Figura 3); a cápsula cefálica e a placa protorácica de coloração pálida escurecem em pouco tempo (Figura 3A, B, D). 

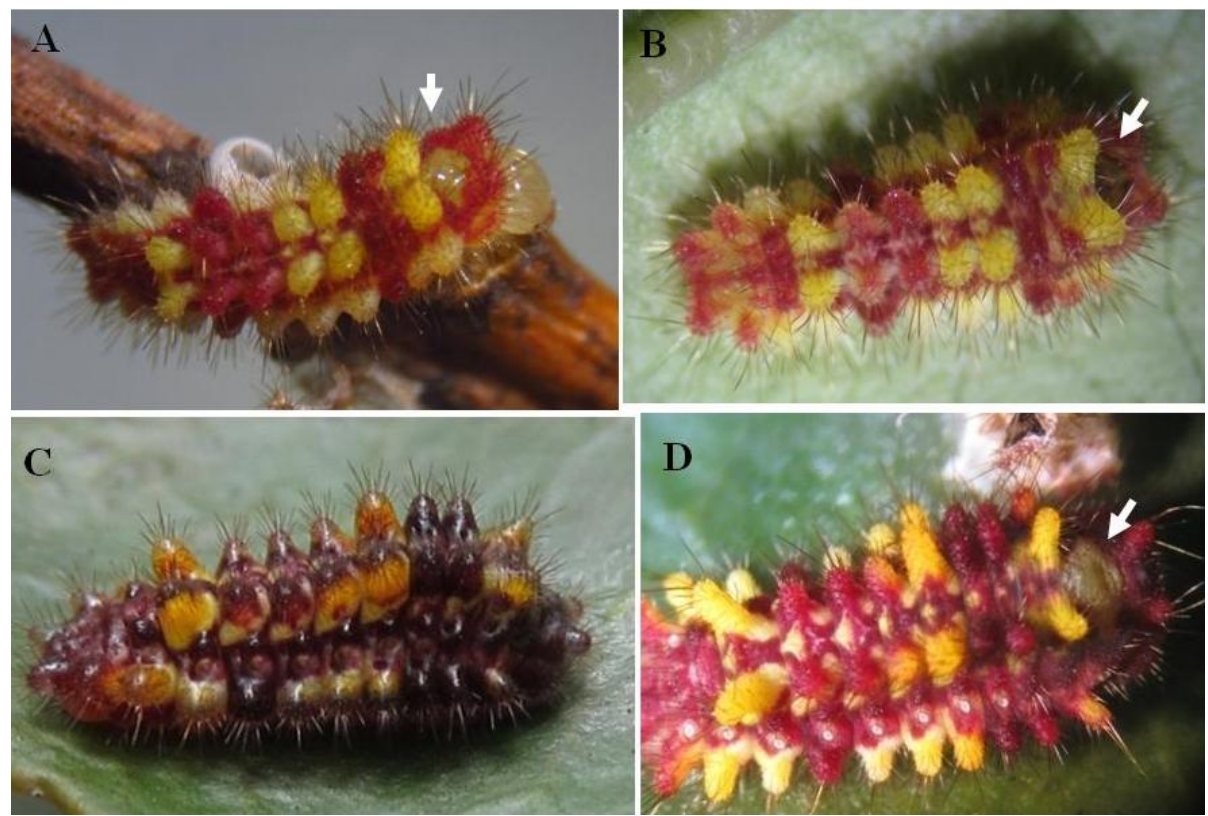

Figura 3. (A, B) Paiwarria aphaca, lagarta de segundo ínstar logo após a ecdise, setas indicam a placa protorácica; (C) lagarta de terceiro ínstar imóvel, em fase de ecdise, e (D) imediatamente após a liberação da exúvia. (Fotos: Neuza Silva).

Em laboratório a formação da pupa ocorreu no pote de criação e sobre a folha. Duas pupas de $P$. aphaca foram encontradas no campo atadas sobre a superfície adaxial da folha da planta hospedeira e outras duas estavam em plantas vizinhas, uma em uma espécie de Myrtaceae (Figura 4) e outra sobre Croton goyazensis Müll.Arg. (Euphorbiaceae) (coleta C. Lepesqueur). As lagartas em ínstares iniciais se alimentam de folhas raspando a parte abaxial (5A), de flores e de botões florais (5B, C) onde consomem o interior introduzindo a cabeça e deixando o resto do corpo exposto, imóvel (Figura 5C). A partir do terceiro ínstar tendem a se alimentar nas bordas das folhas, justo quando adquirem coloração mais avermelhada com amarelo e tornam-se conspícuas sobre o substrato (Figura 5D, E). 


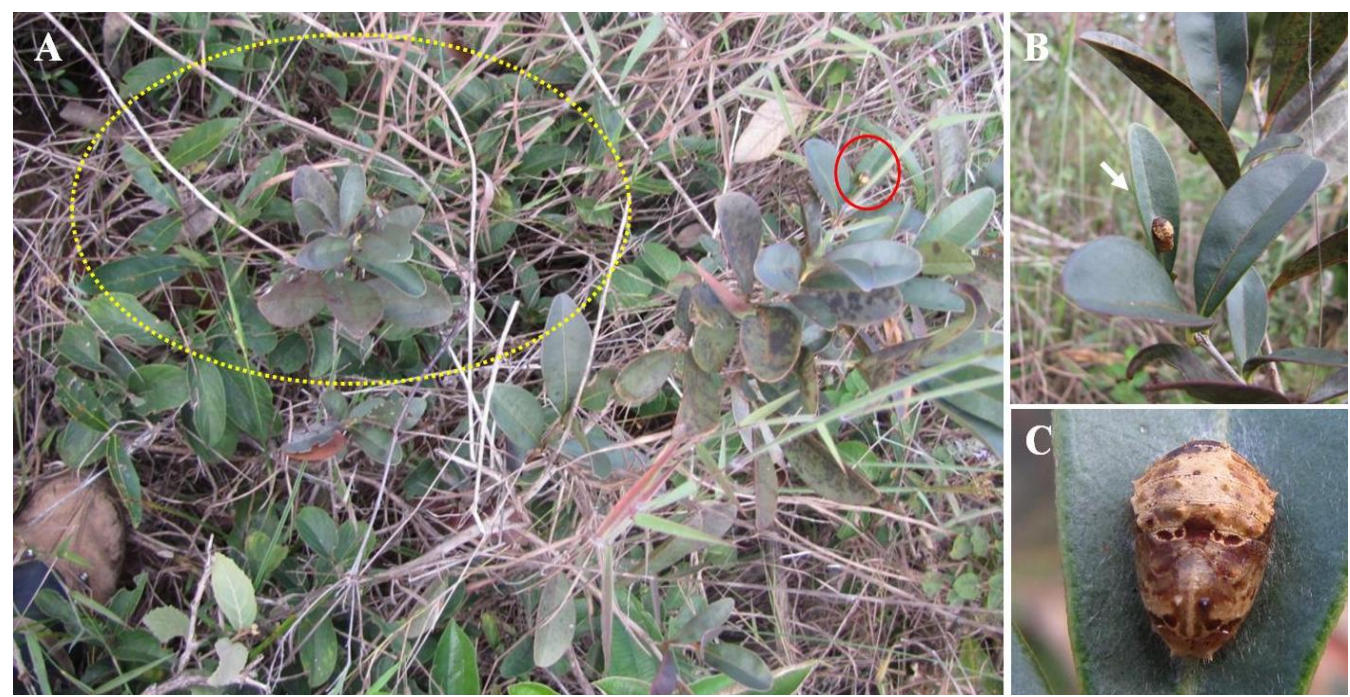

Figura 4. Pupa encontrada sobre uma espécie de Myrtaceae no campo (4B-C). (4A) Círculo amarelo indica localização da planta hospedeira, Peritassa campestris, círculo vermelho mostra onde a pupa foi encontrada. (Fotos: Neuza Silva).

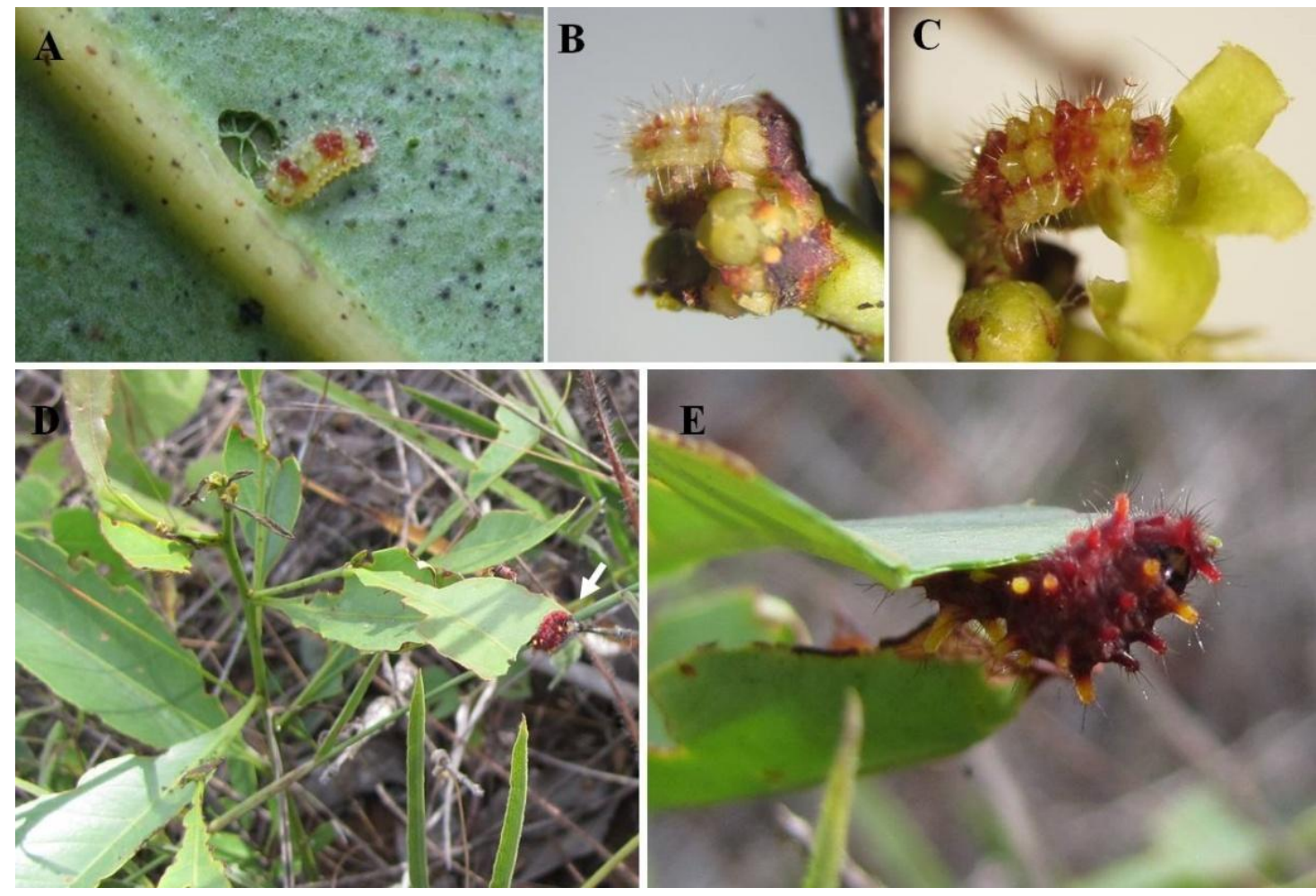

Figura 5. (A, B, C) Lagartas de primeiro ínstar de Paiwarria venulius sobre folha, botões e flor; (D, E) lagarta de Paiwarria aphaca em último ínstar em folha de Peritassa campestris no campo. (Fotos: Neuza Silva). 
As diferenças macroscópicas entre as lagartas de $P$. aphaca e $P$. venulius podem ser melhor visualizadas no último ínstar e, principalmente, entre aquelas que se alimentam de folhas (Figuras 6 a 8 e 13 e 16). P. venulius possui mancha amarela da placa protorácica mais definida no centro (Figura 7) e coloração vermelha uniforme, geralmente com escolos mais longos e amarelos no dorso sobre três segmentos, no mesotórax (T2), no segundo e no sexto segmentos abdominais (A2, A6) (Figuras 6 e 8), e sob esteromicroscopio é possível visualizar a cicatriz do órgão nectário dorsal (DNO) (Figura 7F). P. aphaca não possui DNO (Figura 7C), mas em P. venulius ele surge no terceiro ínstar, como ocorre com outros Eumaeini. Apesar da presença do órgão ele é rudimentar e não-funcional e nenhuma interação com formigas foi observada. De um modo geral, a coloração tende a variar mais com tonalidades mescladas entre os ínstares de P. aphaca (Figura 8A-F) do que em P. venulius.
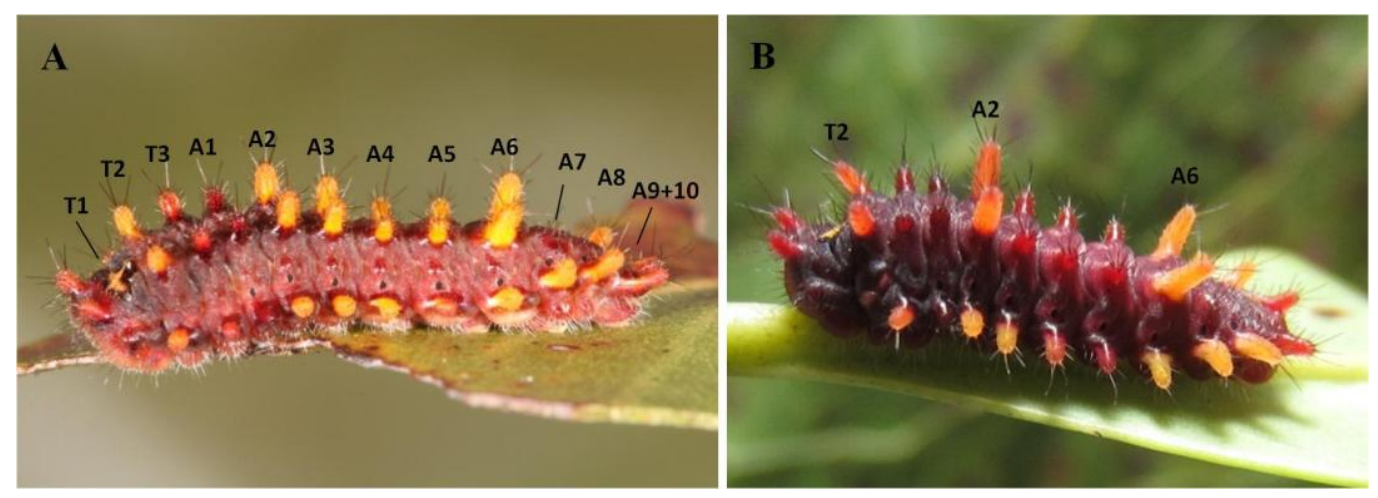

Figura 6. (A) Paiwarria aphaca último ínstar, letras e números indicando os segmentos: protórax (T1), mesotórax (T2), metatórax (T3) e segmentos abdominais (A1-10). (B) Paiwarria venulius, segmentos mais amarelados em T2, A2 e A6. (Fotos: Neuza Silva). 

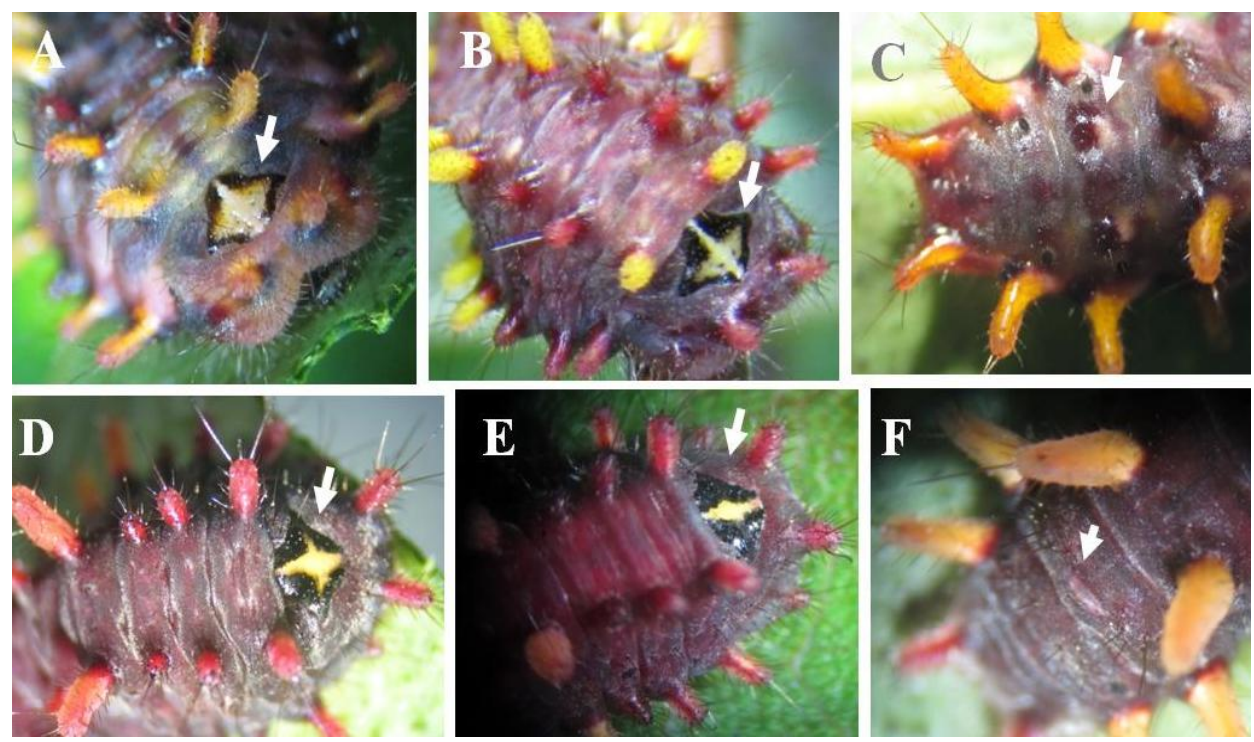

Figura 7. (A-C) Paiwarria aphaca, último ínstar, setas indicando a placa protorácica (A-B) e (C) detalhe mostrando ausência de órgão nectário dorsal (DNO) sobre o sétimo segmento abdominal. (D-E) P. venulius, último ínstar, setas indicam placa protorácica e (F) DNO sobre o A7. (Fotos: Neuza Silva).
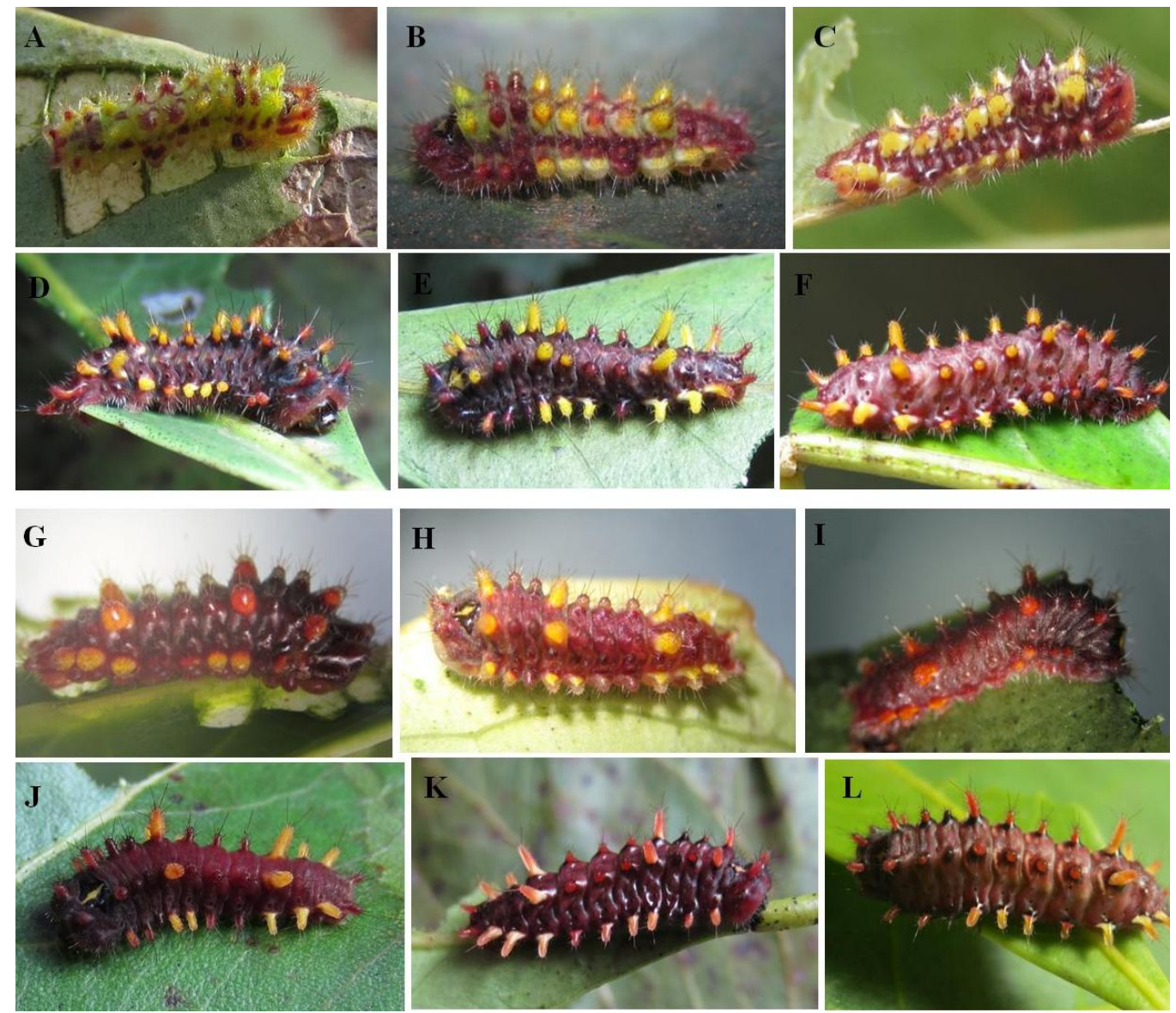

Figura 8. (A-F) Paiwarria aphaca, lagartas de terceiro ínstar (A-C) e de quarto ínstar (último) (D-F). (G-L) Paiwarria venulius, lagartas de terceiro ínstar (G-I) e de quarto ínstar (último) (J-L). (Fotos: Neuza Silva). 
As lagartas mantêm a mesma coloração sobre folhas entre as espécies de plantas, mas a tonalidade muda quando se alimentam apenas de inflorescências. No período de floração de P. campestris foram oferecidas somente inflorescências para lagartas a partir do segundo ínstar de $P$. aphaca $(\mathrm{n}=8)$ e de $P$. venulius $(\mathrm{n}=4)$. Como esperado, as lagartas adquiriram coloração críptica sobre as inflorescências, mas entre as duas espécies percebe-se que $P$. aphaca mantêm a coloração mais camuflada no final (Figura 9A-D). Contudo, exceções ocorrem em lagartas que só se alimentam de folhas (Figura 8A) e alterações na coloração, assim como no comportamento, podem ocorrer também devido ao parasitismo (Figura 10F).
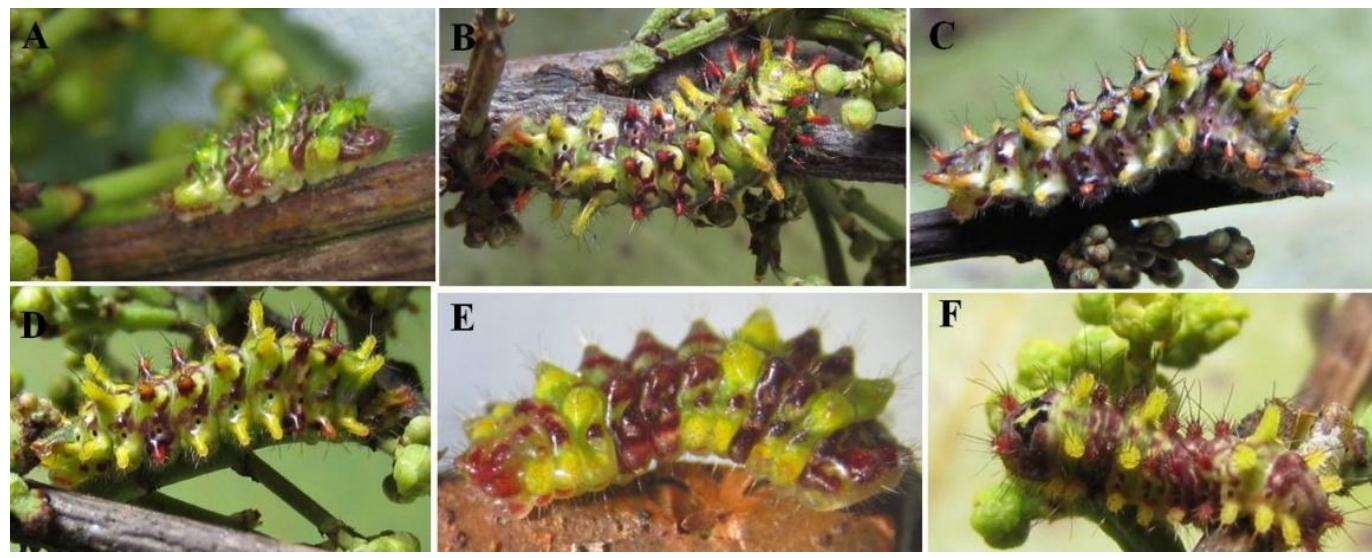

Figura 9. (A-D) Paiwarria aphaca. (A) Lagarta de terceiro ínstar em inflorescência de Salacia crassifolia no campo e (B-D) lagartas de quarto ínstar criadas com inflorescências de Peritassa campestris em laboratório. (E-F) Paiwarria venulius, terceiro e quarto ínstar, criadas com inflorescências. (Fotos: Neuza Silva).

Ovos, provavelmente das duas espécies, foram parasitadas por himenópteros. De apenas um ovo emergiam até cinco vespas de Trichogramma sp. de tamanho entre 0,250,35mm (Figura 10A, B). Diversos ovos foram registrados no campo com orifício de saída desse tipo de parasitoide e isto pode ter um efeito importante sobre a população de Paiwarria. Foram encontrados também ovos predados com corte longitudinal no centro (Figura 10C) e, curiosamente, espécies de ácaros (não identificadas) usam ovos eclodidos ou predados como abrigo (Figura 10D, E). Três lagartas de P. venulius e duas de $P$. aphaca estavam parasitadas. Adultos de parasitoides himenópteros emergiram do segundo e do terceiro ínstar do licenídeo (Figura 10F-K). Uma lagarta de P. venulius apresentou o aspecto "mumificado" após a emergência do parasitoide Brachonidae 
(Figura 10K). Uma lagarta de $P$. aphaca estava parasitada por Campopleginae (Ichneumonidae), também registrado por Silva et al. (2014, Fig. 23) e outra em terceiro ínstar foi observada sendo sugada por uma espécie de Diptera no campo, mas se desenvolveu normalmente até a fase adulta em laboratório.
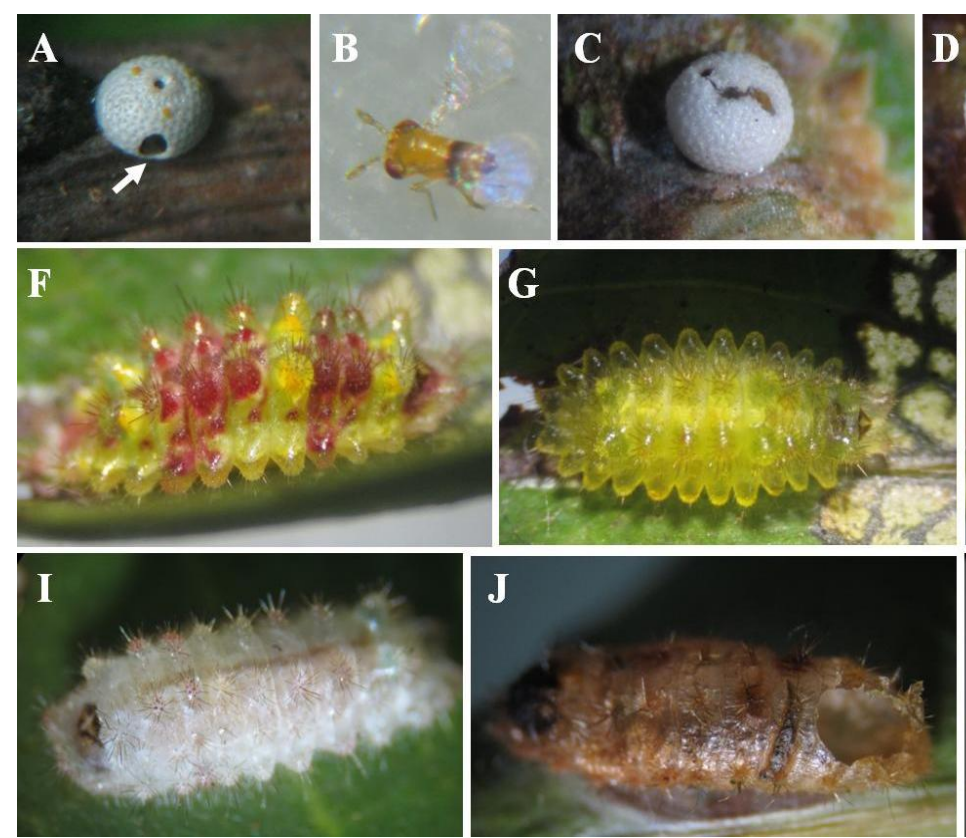
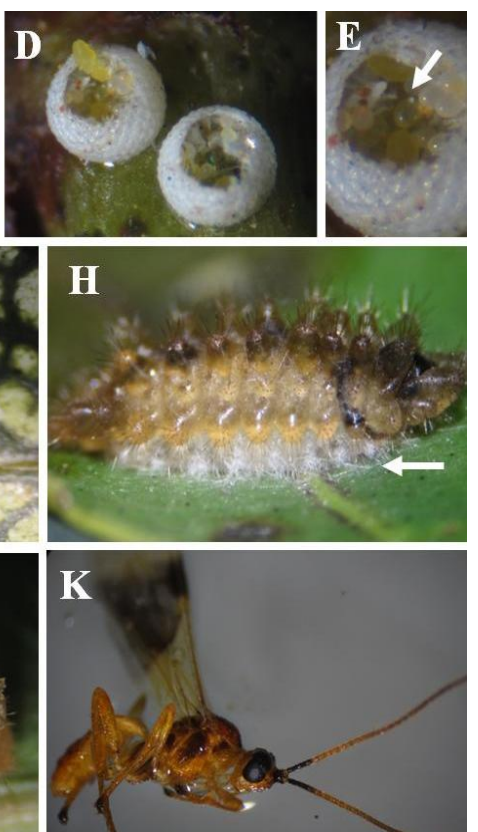

Figura 10. (A) ovo parasitado, seta indica abertura de saída do (B) parasitoide, (C) ovo predado no campo, (D-E) ovos eclodidos utilizados como abrigo e berçário pelos ácaros. (F-I) Lagartas de Paiwarria venulius parasitadas, seta $(\mathrm{H})$ indicando local de empupação do parasita, (J) lagarta "mumificada" e abertura de saída do himenóptero Braconidae (K). (Fotos: Neuza Silva).

Em nenhuma ocasião foram encontradas lagartas das duas espécies de Paiwarria juntas em uma mesma planta. Aparentemente, uma espécie evita a planta já ocupada pela outra. Por exemplo, no mês de maio foram registradas apenas lagartas de $P$. venulius nas mesmas manchas de plantas ocupadas um mês antes por P. aphaca. Também, não foram encontradas outras espécies de licenídeos nas Celastraceae examinadas.

Mas esta família de plantas abriga uma alta riqueza de lagartas de Lepidoptera, algumas dessas espécies estão ilustradas a seguir (Figura 11). Emesis russula Stichel (Figura 11A), um Riodinidae polífago, foi registrado em Plenckia e Peritassa. Lagartas semelhantes a Chorinea octauius (Fabricius) (Riodinidae) citada por Casagrande et al. (2009) nesta família de planta foram encontradas em folhas de Peritassa laevigata 
(Figura 11B) no PNB. Triommatodes subrita (Noctuidae) (Figura 11Q) é frequente em folhas de espécies de Celastraceae no cerrado e espécies de Limacodidae, Megalopygidae, Saturniidae e Dalceridae foram relativamente comuns nas plantas durante o período deste estudo, para algumas dessas estes foram os primeiros registros nessas plantas. Estavam presentes, construtoras de abrigos como das famílias Elachistidae e Oecophoridae. Lagartas de Symphyta (Hymenoptera) também foram registradas coocorrendo com as Paiwarria em P. campestris (Figura 10S).

Lagartas de nenhuma dessas espécies apresentam coloração parecida com as duas Paiwarria estudadas, exceto E. russula (Figura 11A), mas que a partir do terceiro ínstar constrói um abrigo rústico. Por outro lado, lagartas de últimos ínstares de ambas Paiwarria reagiram ao toque levantando a cabeça, comportamento conhecido como beat reflex e uma reação urticante local foi sentida quando os espinhos de lagartas maduras entraram em contato com a pele humana.

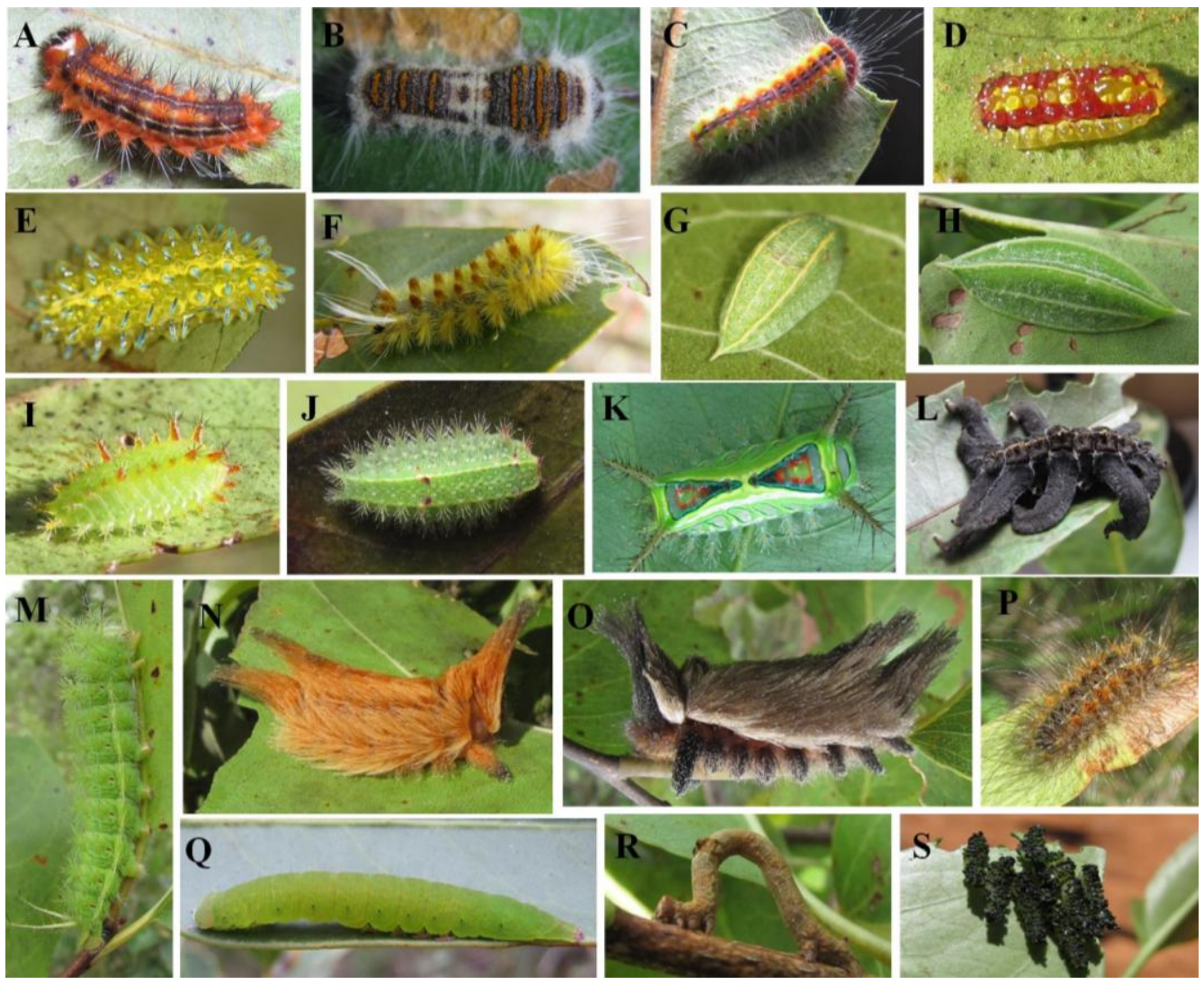

Figura 11. (A-R) Lagartas de lepidópteros e (S) Symphyta (Hymenoptera) presentes nas espécies de Celastraceae examinadas entre janeiro de 2015 a maio de 2016. (A-B) lagartas de Riodinidae, (C) não identificada, (D-E) Dalceridae, (F) Arctidae, (G-L) Limacodidae, (M) Saturniidae, (N-P) Megalopygidae, (Q) Triommatodes subrita (Noctuidae) e (R) Geometridae. (Fotos: Neuza Silva). 


\section{Paiwarria e Parides}

Ovos e lagartas de diferentes ínstares de Parides sp. foram encontrados em Aristolochia galeata Mart. comuns nas bordas e nas matas de galeria do PNB. No campo as lagartas foram encontradas se alimentando a partir da superfície abaxial das folhas (Fotos $12 \mathrm{~A}, \mathrm{~B}$ ).

A hipótese do mimetismo de Paiwarria com espécies de Parides foi investigada com buscas também por lagartas de Paiwarrria nas celastráceas na mata, hábitat de Parides, no entanto não foram encontradas lagartas de Paiwarria ocorrendo ao mesmo tempo na mata. Porém, vale ressaltar que por várias vezes espécies de Aristolochia spp. que são trepadeiras, foram encontradas envolvidas em plantas de Cheiloclinium cognatum, hospedeira de Paiwarria. Este é um forte indício que lagartas de ambos os gêneros possam coocorrer no mesmo ambiente. De toda a forma, foi possível verificar as similaridades entre as espécies. P. venulius, coletada em cerrado sensu stricto, apresenta mais forte semelhança em tamanho e forma com Parides sp. do que $P$. aphaca. Esta semelhança, aparentemente, está limitada aos primeiros ínstares de Parides sp. (Figura 12A, B), a partir disso as lagartas já com mais de $3 \mathrm{~cm}$ ficam mais expostas, e o tamanho e o padrão de cores entre as duas espécies diferem consideravelmente (Figura 12E).
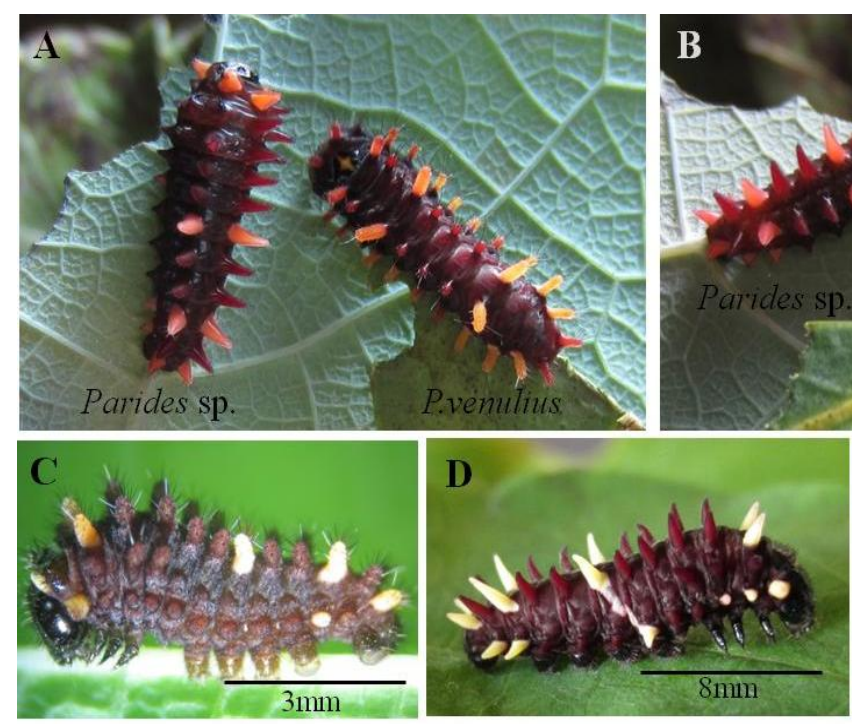
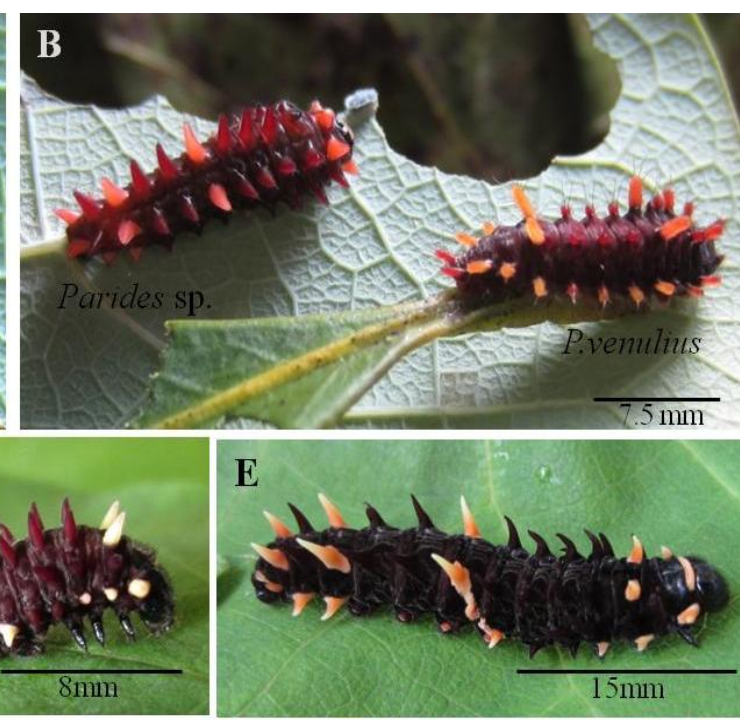

Figura 12. (A-B) Parides sp. e Paiwarria venulius último ínstar. (C-E) Parides sp. logo após a ecdise (C), (E) Parides sp. em último ínstar. (Fotos: Neuza Silva). 


\section{Descrição dos estágios imaturos}

\section{Paiwarria aphaca}

Ovo (Figuras 13A e 14A-C): Diâmetro: 0,63-0,70 mm. Altura: 0,32-0,40 mm ( $\mathrm{n}=15)$. Eclodiu em 4-5 dias após coleta no campo $(n=12)$. Amarelo claro logo após a postura, tornando-se branco poucas horas depois; arredondado em vista dorsal. Exocório esculpido por carenas levemente elevadas e expandidas, cobrindo grande parte da estrutura e delimitando as células em estreitas depressões. Aeropilas com abertura localizada na interseção mais elevada das carenas (Figura 14C). Área micropilar convexa em vista lateral, formada por carenas circundantes elevadas (Figura 14B). Aspecto geral é enrugado, mas sob estereomicroscópio são visualizadas esculturas hexagonais regulares.

Não foi possível perceber diferenças entre a morfologia dos ovos das duas espécies, $P$. aphaca Figuras 13A, 14A-C, e P. venulius 17A e 16A. O diâmetro foi maior em alguns de $P$. venulius.

Primeiro ínstar (Figura 13B): Comprimento do corpo: 1-2mm ( $\mathrm{n}=8)$. Largura da cápsula cefálica: 0,20-0,22 mm $(n=4)$. Tempo de desenvolvimento: 3-5 dias $(n=15)$. Cabeça amarelada com projeção hipognata, com a capacidade de retraí-la sob o tórax. Corpo onisciforme, amarelo logo após a eclosão do ovo. Quando começa a se alimentar na planta, proeminências dorsais com extremidades translúcidas ficam em evidência e adquirem tonalidade avermelhada no protórax (T1), metatórax (T3) e no primeiro, quarto, quinto e últimos segmentos abdominais ( $\mathrm{A} 1, \mathrm{~A} 4, \mathrm{~A} 5, \mathrm{~A} 7+)$. Placa protorácica com manchas castanhas claras, cerdas translúcidas amareladas na extremidade das proeminências, dorsais e laterais. Espiráculos esbranquiçados. Primeiro ínstar se alimenta de todo o córion próximo a micrópila e cessa a alimentação sobre o ovo assim que há espaço para emergir.

O primeiro ínstar de $P$. aphaca é muito semelhante ao de $P$. venulius (Figuras 13B, 16B) não sendo possível diferí-las nesse estágio.

Segundo ínstar (Figura 13C): Comprimento do corpo: 2,3 - $4 \mathrm{~mm}(\mathrm{n}=8)$. Largura da cápsula cefálica: 0,42-0,45 mm $(\mathrm{n}=6)$. Tempo de desenvolvimento: 3-5 dias $(\mathrm{n}=8)$. Cabeça castanha clara, placa protorácica castanho escura com mancha amarelada no centro; corpo segue a tonalidade do primeiro ínstar, mas com cores mais fortes, amarelo 
nos segmentos T2, A2, A3 e A6 e vermelho em T2, A1, A4, A5, e A7 com últimos segmentos. Proeminências dorsais e subespiraculares ganham aspecto de escolos com maior densidade de cerdas eretas do que no primeiro ínstar. Espiráculos esbranquiçados. Ao final deste ínstar se a lagarta estiver se alimentando em inflorescência a coloração pode se tornar mais amarelo/esverdeada, demonstrando o policromatismo críptico.

Novamente, é difícil distinguir entre as duas espécies (Figura 13C e 16C), embora $P$. venulius possa apresentar coloração amarela mais destacada nos escolos dorsais de três segmentos, pode ocorrer variação na intensidade da cor entre segmentos entre espécimes, inclusive relacionada à alimentação como citado, o que pode gerar dificuldade na identificação da espécie.

Terceiro ínstar (Figura13 D): Comprimento do corpo: 5-8,5mm (n=9). Largura da cápsula cefálica: 0,9-0,95 mm $(n=5)$. Tempo de desenvolvimento: 4-7 dias $(n=10)$. Cabeça castanha, placa protorácica castanho escura com mancha amarelada grande no centro; corpo com coloração similar ao segundo ínstar, mas, geralmente, com tegumento entre os escolos de tonalidade amarelada mesclada com vermelho. Orgãos perfurados em forma de cúpula (PCOs), espalhados pelo tegumento. Espiráculos esbranquiçados de fácil visualização.

Neste ínstar começam a surgir diferenças entre as duas espécies de Paiwarria. É possível notar que a mancha amarela na placa protorácica de $P$. aphaca não apresenta delineamento definido como em P. venulius (Figura 7D, E). Além disso, aparece a cicatriz do órgão nectário dorsal (DNO) sobre o A7 de P. venulius que está ausente em P. aphaca (Figura 7C).

Quarto ínstar (Figura 13E, F): Comprimento do corpo: 8,5-16 mm. Largura da cápsula cefálica: 0,95-1,35 mm $(\mathrm{n}=15)$. Tempo de desenvolvimento: 6-8 dias $(\mathrm{n}=18)$. Cabeça castanha, placa protorácica igual ao terceiro ínstar, mas com maior destaque da mancha amarela no centro (Figura 7A, B); corpo com coloração vermelho, geralmente uniforme, escolos ressaltados inclusive no protórax, amarelos em sua maioria, mantendo aqueles do segmento do metatórax (T3) e no primeiro segmento abdominal (A1) avermelhados (ver também Figura 8). Escolos cobertos de espinhos finos e mais longos nas extremidades (Figura 15B, C). Em alguns espécimes há uma diferença clara no tamanho dos escolos, sendo maiores no A2 e A6. Tegumento, entre os escolos com PCOs e cerdas curtas amplamente distribudas (Figura 15). Possui cerdas curtas e PCOs 
na região onde seria o DNO (A7) (Figura 15A, D), ausente nesta espécie. Espiráculos pretos. À medida que amadurece a lagarta torna-se mais escura, e adquire tonalidade castanho-avermelhada quando em pré-pupa (Figura 13F).

As diferenças entre as duas espécies são percebidas com maior clareza neste quarto e último ínstar. Além da mancha amarela na placa protorácica ser mais estreita e definida, em P.venulius a coloração é uniforme e, em geral, apenas os escolos sobre os segmentos T2, A2, A6 são amarelos e mais longos (Figura 8, 16E).

Pupa (Figura 13G, H): Comprimento 7.5-9.5 mm. Tempo de desenvolvimento: 10-13 dias $(n=20)$. Tegumento castanho claro com manchas brancas irregulares; desenho no primeiro segmento abdominal que lembra um par de olhos. Cerdas curtas distribuídas pelo tegumento, em maior quantidade no protórax. Pequenas verrugas na margem da cabeça, dois pares no tórax e duas fileiras dorsais. Espiráculos brancos, com destaque no mesotórax (Figura 13H, 15E). PCOs dispersos pelo tegumento, cerdas dendríticas presentes próximo aos espiráculos (Figura 15F). A pupa é presa ventralmente ao substrato com uma cinta de seda entre o primeiro e segundo segmento abdominal. Algumas pupas emitiram ruídos. Próximo da eclosão a pupa fica quase totalmente preta. Uma pupa encontrada no campo levou 17 dias até a emergência do adulto.

A diferença no aspecto geral entre as pupas das duas espécies de Paiwarria está no "par de olhos", P. venulius (Figura 16G, H) apresenta estes mais delicadamente delineados em relação aos de P. aphaca. 

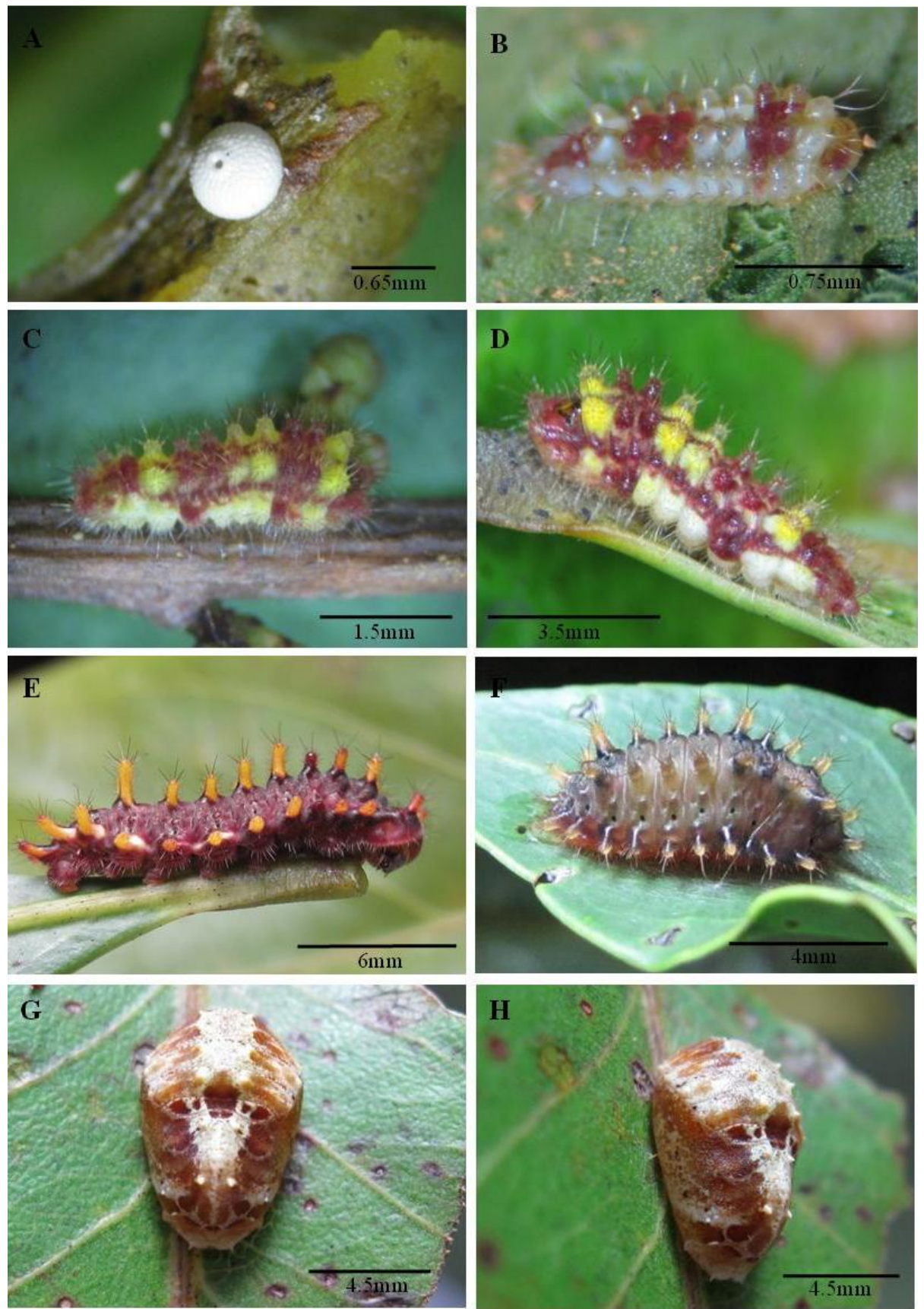

Figura 13. Paiwarria aphaca, estágios imaturos criados em folhas de Celastraceae: (A) ovo, (B) primeiro ínstar, (C) segundo ínstar, (D) terceiro ínstar e (E) quarto ínstar, (F) pré-pupa, (G-H) pupa, vista dorsal e lateral. (Fotos: Neuza Silva). 

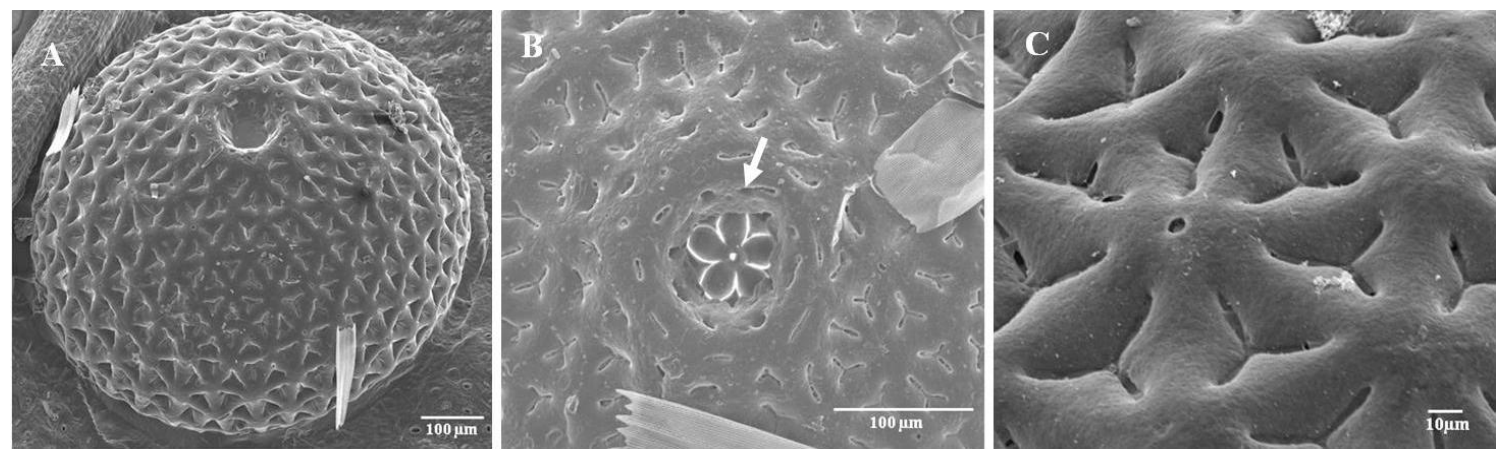

Figura 14. Microscopia eletrônica de varredura de ovos de Paiwarria aphaca. (A) vista anterior, (B) área micropilar, (C) seta indica aeropila.

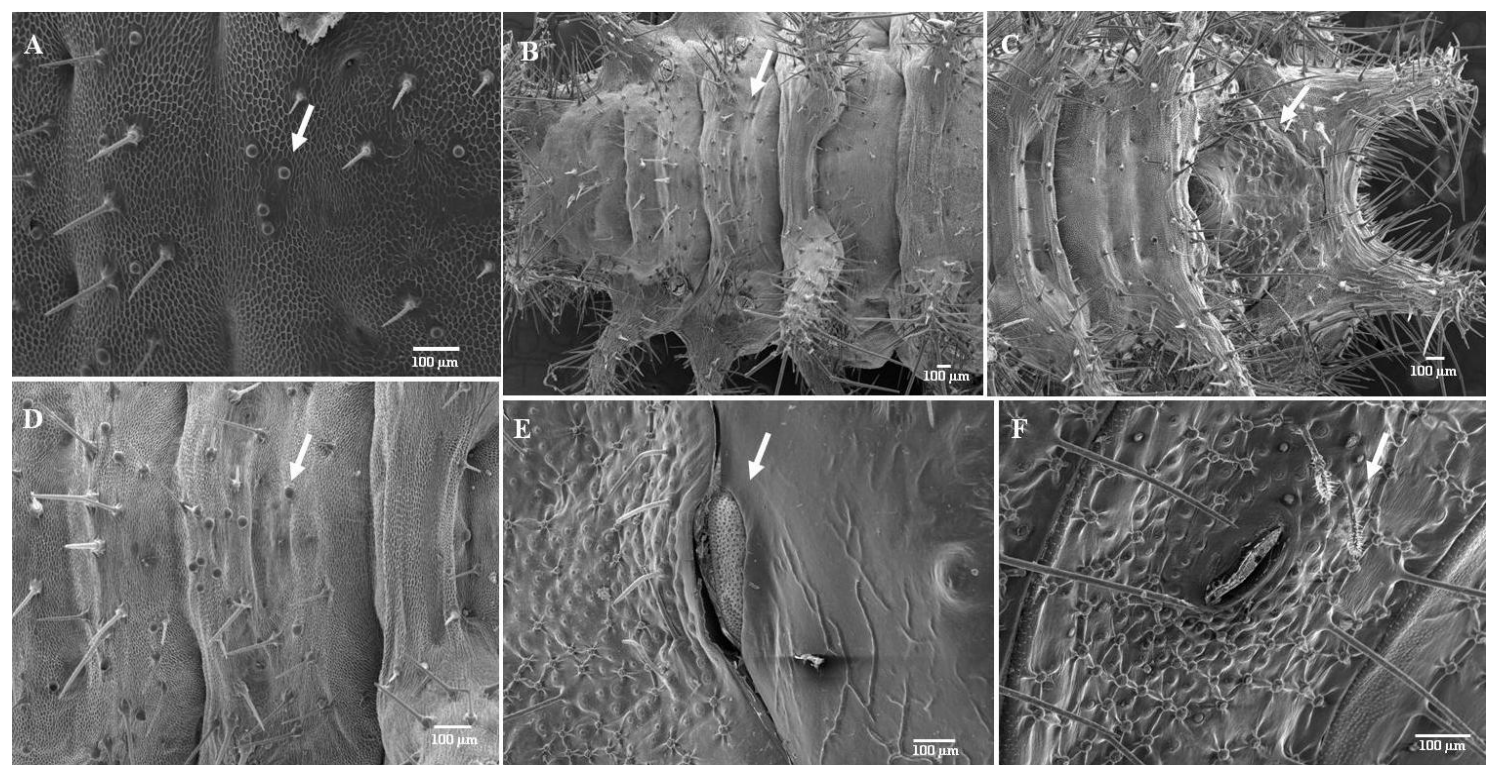

Figura 15. Microscopia eletrônica de varredura de P. aphaca. (A) detalhe do tegumento com PCOs sobre A7 em terceiro ínstar e quarto instar (B, D), (C) detalhe da placa protóracica, $(\mathrm{E}-\mathrm{F})$ pupa, detalhe do espiráculo no mesotórax e $(\mathrm{F})$ detalhe do segmento abdominal da pupa com cerdas dendríticas (seta).

\section{Paiwarria venulius}

Ovo (Figuras 16A e 17A): Diâmetro: $0,70-0,76 \mathrm{~mm}$. Altura: $0.40-0,43 \mathrm{~mm}(\mathrm{n}=7)$.

Eclodiu em 4-5 dias após coleta no campo $(\mathrm{n}=7)$. Similar ao de $P$. aphaca em relação à coloração, forma e ornamentação coriônica (17A). 
Primeiro ínstar (Figura 16B): Comprimento do corpo: 1,2-1,8 mm. Largura da cápsula cefálica: 0,20-0,23 mm $(\mathrm{n}=4)$. Tempo de desenvolvimento: 3-5 dias $(\mathrm{n}=8)$. lagarta morfologicamente similar a de P. aphaca. Coloração avermelhada no protórax (T1), metatórax (T3) e no primeiro, e do terceiro ao quinto e últimos segmentos abdominais (A1, A3-A5, A7+) e o restante do corpo amarelado.

Segundo ínstar (Figura 16C): Comprimento do corpo: 2,4 - $4 \mathrm{~mm}$. Largura da cápsula cefálica: 0,42-0,45 mm ( $\mathrm{n}=3)$. Tempo de desenvolvimento: 4-6 dias (n=8). Morfologia geral também similar a $P$. aphaca, mas com coloração amarelada mais destacada nos escolos dorsais sobre os segmentos do mesotórax T2, e abdome A2 e A6.

Terceiro ínstar (Figura 16D): Comprimento do corpo: 6-9 $\mathrm{mm}$. Largura da cápsula cefálica: 0,9-1mm $(n=3)$. Tempo de desenvolvimento: 4-5 dias $(n=10)$. Cabeça castanha, placa protorácica castanho escura com mancha amarelada estreita e delimitada ao centro em relação a de $P$. aphaca (Figura 7); corpo avermelhado com escolos amarelados como no segundo ínstar, mas com tonalidade mais vibrante (Figuras 8, 16D). Possui PCOs espalhados pelo tegumento e próximos a cicatriz do DNO, localizado sobre o sétimo segmento abdominal.

Quarto ínstar (Figura 16E, F): Comprimento do corpo: 9-16mm. Largura da cápsula cefálica: 1-1,35mm ( $\mathrm{n}=11)$. Tempo de desenvolvimento: 5-7 dias $(\mathrm{n}=8)$. Cabeça e placa protorácica como no terceiro ínstar, mas com mancha amarela bem delineada e centralizada na placa (Figura 7D, E); corpo com coloração vermelho uniforme, escolos cobertos de espinhos, mais amarelos e longos sobre os segmentos T2, A2, A6 (ver também figura 8). Tegumento com PCOs e cerdas curtas espalhadas (Figura 17B-D). DNO sobre o A7 com PCOs próximos (Figuras 7F, 17C, D). Espiráculos pretos. Como ocorre em P.aphaca a pré-pupa torna-se mais escura, e nesta os escolos amarelos ficam realçados (Figura 16F).

Pupa (Figura 16G-H): Comprimento 7-9,5 mm. Tempo de desenvolvimento: 8-15 dias $(\mathrm{n}=7)$. Morfologia geral é similar a de P. aphaca exceto pelo contorno mais delineado no "par de olhos" sobre o primeiro segmento abdominal. Não foi possível examinar ultraestrutura da pupa. 

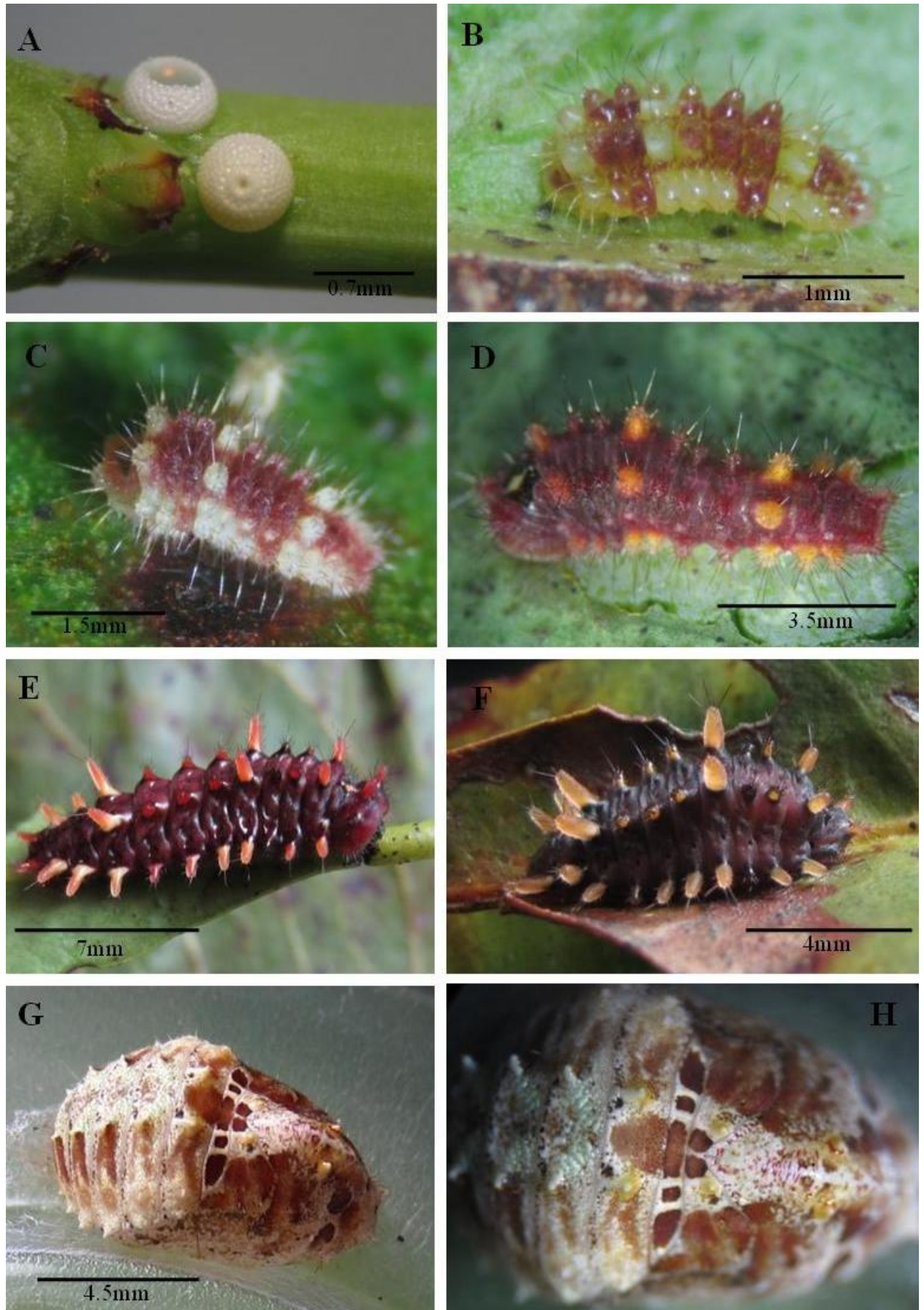

Figura 16. Paiwarria venulius, estágios imaturos criados sobre folhas de Celastraceae: (A) ovo, (B) primeiro ínstar, (C) segundo ínstar, (D) terceiro ínstar e (E) quarto ínstar, (F) pré-pupa, (G-H) pupa, vista dorso-lateral e dorsal. (Fotos: Neuza Silva). 

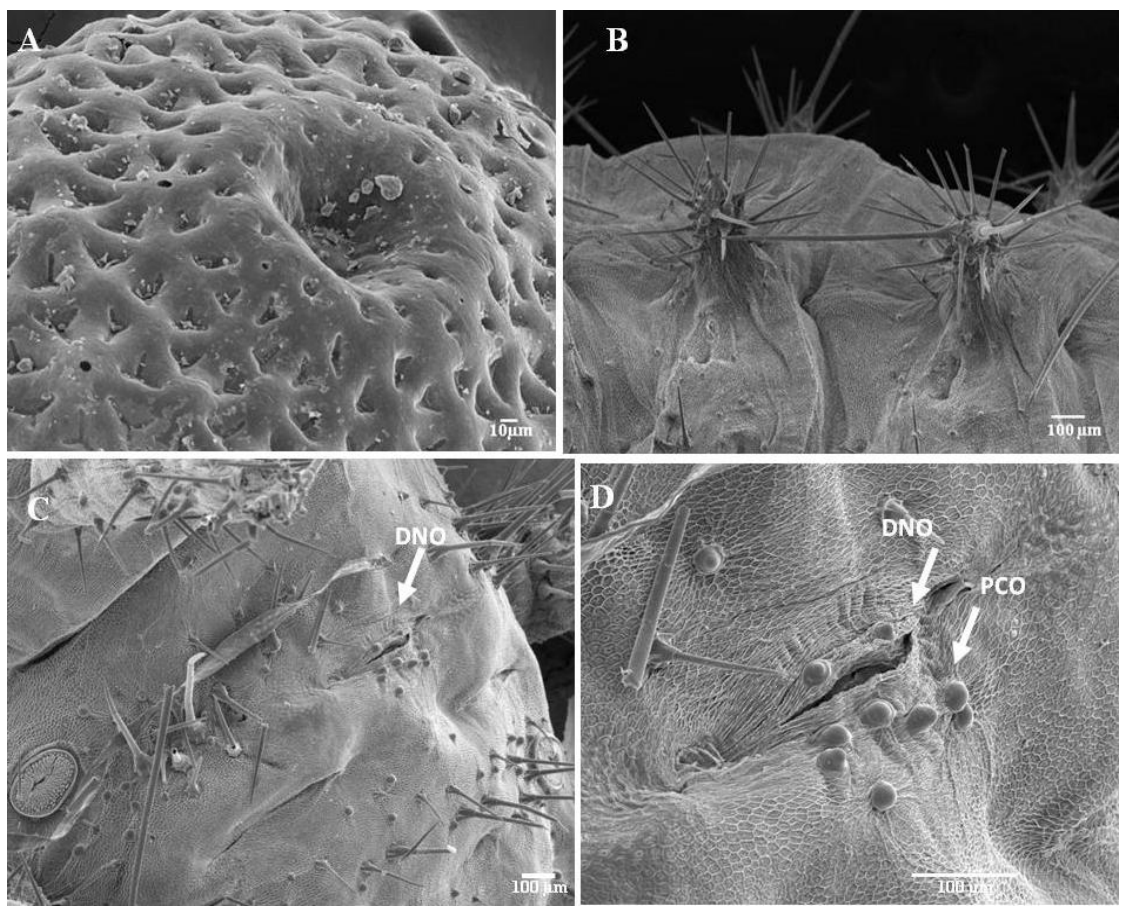

Figura 17. Microscopia eletrônica de varredura de Paiwarria venulis. (A) exocório do ovo, (B) detalhe dos escolos dorsais e (C, D) tegumento sobre o segmento A7 com abertura do órgão nectário dorsal (DNO) e órgãos perfurados em forma de cúpula (PCO).

\subsection{DISCUSSÃO}

A ocorrência de P. aphaca é comum em áreas de cerrado sensu stricto, enquanto que $P$. venulius tem ocorrência conhecida, a partir de adultos, em áreas de mata de galeria e cerrado denso (cerradão) no DF (E. Emery, com. pess.). Os registros de lagartas no cerrado, em contraste com as buscas na mata neste estudo, indicam que $P$. venulius pode utilizar as espécies de celastráceas presentes no cerrado de maneira efeciente. De todo modo, considera-se que $P$. venulius seja rara no DF, por que após um elevado número de horas de coleta de campo foi capturado um baixo número de indivíduos adultos sendo que nenhum macho foi coletado (E. Emery, com. pess.). Neste estudo foram obtidos três machos a partir da criação das lagartas, ressaltando a importância de complementar as informações com os diferentes tipos de coleta (Silva et al. 2011).

A alimentação preferencial de folhas chama a atenção em contraste com a diversidade de espécies Eumaeini que consomem inflorescências (Fiedler 1995, Silva et 
al. 2011, Bächtold 2014). Nessas estruturas as espécies teriam a vantagem de adquirir a coloração críptica como demonstrado, o que favorece o escape de predadores, e é visto como um dos precursores da ampliação da dieta (Robbins \& Aiello 1982, Monteiro 1991, Morais et al. 2009). Além disso, o conteúdo nutricional das estruturas reprodutivas pode favorecer um desenvolvimento mais rápido e resultar em indivíduos mais robustos em relação àqueles que se alimentam de folhas (Burghardt \& Fiedler 1996).

A forma geral dos ovos das espécies de Paiwarria se assemelha a outras espécies de Eumaeini (Downey \& Allyn 1981, 1984), mas a forma de cúpula com exocório elevado em torno da micrópila ajuda a diferencia-los com maior facilidade de outras espécies. O exocório difere daqueles apresentados para espécies de Eumaeus Hübner (Downey \& Allyn 1984), um gênero relacionado, pertencente à mesma seção Eumaeus proposta por Robbins (2004b) pela extensão das carenas que reveste quase todo o córion restando apenas estreitas depressões (Fig. 14); ligeiramente, lembra o revestimento do córion de uma espécie mais distante, Mitoura hesseli Raw. \& Zieg., ilustrado por Downey \& Allyn (1984). O desenvolvimento em quatro ínstares larvais é o mais comum entre os Eumaeini e, embora a forma geral das pupas seja similar a outros (Robbins \& Aiello 1982, Duarte \& Robbins 2009), o desenho no tegumento são típicos das espécies (Silva et al. 2014).

O padrão geral da morfologia entre as duas espécies é parecido, mas diferem fortemente daqueles conhecidos para outros Eumaeini, inclusive em relação a Paiwarria umbratus (Cramer) com aspecto liso, como discutido por Silva et al. (2014). Mas em comparação a Kolana ergina (Hewitson), em coletas recentes (citado no Cap. 1) foi observado que, além das proeminências parecidas entre lagartas de últimos ínstares, as de primeiro ínstar também são muito semelhantes. K. ergina é polífaga e se alimenta tanto de folhas quanto de inflorescências, não possui órgãos relacionados à mirmecofilia e também é capaz de mudar a coloração com a estrutura consumida (Silva et al. 2014, Kaminski et al. manusc. em preparação). Essa perda da mirmecofilia e o surgimento de estruturas de defesa, como prolongamentos e espinhos é discutida para licenídeos por Kaminski et al. $(2009,2010)$.

Entre as três espécies, P.aphaca, P. venulius e Kolana, um fato interessante é a presença do DNO apenas em $P$. venulius, mas este parece não ser funcional, pois na presença de formigas uma lagarta de último ínstar reagiu com beat reflex (L. Kaminski, com. pess.). Em ambas as espécies não foram observadas cerdas dendríticas, e é 
sugerido que o numero dessas cerdas na lagarta pode indicar a intensidade da relação com formigas (Ballmer \& Pratt 1992b). Por outro lado, PCOs estão presentes nas lagartas e pupas, como registrados para várias espécies do grupo e são considerados importantes, pois liberam substâncias que apaziguam o comportamento agressivo das formigas (Ballmer \& Pratt 1992b, DeVries 1991, Duarte et al. 2005, Kaminski \& Freitas 2010).

De forma geral, não há semelhança na cor ou forma das lagartas de Paiwarria com aquelas que coocorrem nas mesmas plantas, exceto pelos escolos presentes também em espécies de Limacodidae (p. ex. Fig. 11I, K), os quais podem causar reações importantes em contato com a pele humana (Specht et al. 2008). Estas coocorrências não representam o que foi sugerido em Silva et al. (2014), com P. umbratus mimetizando Evenus regalis (Cramer) (Eumaeini) sobre Sapotaceae na Costa Rica (Janzen \& Hallwachs 2013, Sermeño-Chicas et al. 2013).

O padrão de cores das duas espécies de Paiwarria sobre as folhas é típico de espécies aposemáticas (corpo avermelhado com amarelo, e escolos) e que indica possível impalatabilidade da presa ao predador guiado pela visão e repulsão ao toque (Rettenmeyer 1970, Bowers 1993). A semelhança morfológica, além da presença de $P$. venulius num mesmo hábitat de ocorrência de Parides, pressuposto para que ocorra a seleção (Wickler 1968, Owen 1980) é que alimenta a hipótese de mimetismo entre as espécies. Mas, tendo em vista que $P$. aphaca ocorre preferencialmente em áreas de cerrado sensu stricto, é razoável considerar que as duas espécies de Paiwarria sequestrem os compostos secundários das folhas das celastráceas consumidas resultando na coloração de advertência, como ocorre com espécies do gênero próximo, Eumaeus nas quais os compostos sequestrados das cicadáceas detêm potenciais predadores invertebrados (Bowers \& Larin 1989, Castillo-Guevara \& Rico-Gray 2002). Eumaeus atala e E. minyas, por exemplo, apresentam coloração vermelho brilhante, escolos amarelos sobre o tegumento e são gregárias; a pupa e os adultos também apresentam coloração de advertência (Bowers \& Larin 1989, Smith 2002, Contreras-Medina et al. 2003). Há registros de aposematismo somente para este gênero entre os Eumaeini (Brown Jr. 1993). A coloração mimética não é registrada entre licenídeos, e as poucas informações disponíveis são apenas sugestivas para alguns adultos, Podanotum Torres et Johnson e Theorema Hewitson, que ocorrem entre Equador, Colombia e Venezuela (ver Bálint \& Wojtusiak 2006, Bálint et al. 2009). 
Neste estudo foi descrita a historia natural e a morfologia das duas espécies de Paiwarria. Estas informações são fundamentais para entender um possível cenário para a evolução do mimetismo nas lagartas destes Lycaenidae. Os resultados mostram que $P$. venulius seria a principal candidata para o mimetismo, pois apresenta coocorrência espacial com Parides, ambas as espécies ocorrem em matas de galeria. Além disso, $P$. venulius possui maior convergência no padrão de coloração das lagartas com Parides e menor plasticidade quando alimentada com flores, ou seja, mantém o padrão conspícuo independente da dieta. Por outro lado, $P$. aphaca não ocorre nos mesmos ambientes das Parides, as lagartas usam inflorescências com maior frequência e são crípticas sobre as flores; embora as lagartas mantenham um padrão de coloração conspícuo quando comem folhas. Outro aspecto interessante é que as duas espécies perderam a interação com formigas, sendo que P. aphaca perdeu completamente o DNO. Claramente existem semelhanças e diferenças marcantes entre as duas espécies de Paiwarria e a chave destas diferenças está na transição do ambiente florestal (mata de galeria) para o savânico (cerrado) ou vice versa. Transições entre ambientes contrastantes fornecem experimentos naturais que podem ajudar a entender o valor adaptativo de caracteres ecológicos (p. ex. Nogueira et al. 2012).

Como próximos passos são necessários obter uma filogenia do gênero e mais informações sobre a morfologia e história natural de outras espécies de Paiwarria. Apesar de todas as outras espécies do gênero serem encontradas tipicamente em ambientes florestais úmidos não podemos inferir se a ocorrência de Paiwarria aphaca em ambientes savânicos é uma condição ancestral ou derivada dentro do gênero. Essa informação é fundamental para entender a evolução de Paiwarria e a importância dos diferentes tipos de padrões de coloração larval e estratégias defensivas neste grupo de borboletas. 


\subsection{REFERÊNCIAS BIBLIOGRÁFICAS}

Bächtold, A. 2014. "A comunidade de licenídeos de uma área de cerrado: especificidade de dieta, interações ecológicas e seleção de plantas hospedeiras". Tese de doutorado. Faculdade de Filosofia, Ciênciais e Letras de Ribeirão Preto, Universidade de São Paulo, Ribeirão Preto, SP.

Bächtold, A. \& Alves-Silva, E. 2012. Behavioral strategy of a lycaenid (Lepidoptera) caterpillar against aggressive ants in a Brazilian savana. Acta Ethologica. DOI 10.1007/s10211-012-0140-2.

Bálint, Z. \& Constantino, L.M.; Salazar, E.J.A.; Andrade, C.M.G. \& CamposSalazar, L.R. 2009. Notes on the genus Theorema with special regard to Colombia and description of a new species from Venezuela (Lepidoptera: Lycaenidae: theclinae). Centro de Museos, Boletín Científico Museo de Historia Naturales, 13 (2): $126-141$.

Bálint, B.Z. \& Salazar, J.A.E. 2003. Fasslantonius gen.n. a monotypic genus of Neotropical eumaeine lycaenids (Lepidoptera: Lycaenidae, Eumaeini). Annales Historico-Naturales Musei Nationalis Hungarici. 95:173-183.

Bálint, Z. \& Wojtusiak, J. 2006. Notes on the genus Podanotum with description of a new species (Lepidoptera: Lycaenidae: Eumaeini). Genus, 17(2): 283-289.

Ballmer, G.R. \& Pratt, G.F. 1988. A survey of the last instar larvae of the Lycaenidae of California. Journal of Research on the Lepidoptera, 27(1):1-81.

Ballmer, G.R. \& Pratt, G.F. 1992a. Loranthomitoura, a new genus of Eumaeini (Lepidoptera: Lycaenidae: Theclinae). Tropical Lepidoptera, 3(1): 37-46.

Ballmer, G.R. \& Pratt, G.F. 1992b. Quantification of ant attendance (myrmecophily) of lycaenid larvae. Journal of Research on the Lepidoptera, 30: 95-112.

Beccaloni, G.W.; Viloria, A.L.; Hall S.K. \& Robinson G.S. 2008. Catalogue of the hostplants of the Neotropical butterflies. Monografias Tercer Milenio. Vol. 8. Zaragoza (Spain): S.E.A., RIBES-CYTED, The Natural History Museum, Instituto Venezolano de Investigaciones Científicas. 536p.

Berenbaum, M.R. 1995. Aposematism and mimicry in caterpillars. Journal of the Lepidopterists' Society, 49: 386-396.

Bowers, M.D. 1993. Aposematic caterpillars: life-styles of the warningly colored and unpalatable. In: Stamp N.E. \& Casey T.M. (Eds): Caterpillars. Ecological and Evolutionary Constraints on Foraging. Chapman \& Hall, New York. pp. 331-371.

Bowers, M.D. \& Larin, Z. 1989. Acquired chemical defense in the lycaenid butterfly, Eumaeus atala. Journal of Chemical. Ecology, 15(4): 1133-1146.

Brown Jr., K.S. 1993. Neotropical Lycaenidae : an overview, p. 45-61; Selected Neotropical species, p. 146-149; Theclinae endemic to the Cerrado vegetation (central Brazil), p.152. ln: T. R. New (Ed.). Conservation biology of Lycaenidae (Butterflies). IUCN, Gland, Switzerland.

Burghardt, F. \& Fiedler, K. 1996. The influence of diet on growth and secretion behaviour of mirmecophilous Polyommatus icarus caterpillars (Lepidoptera: Lycaenidae. Ecological Entomology, 21: 1-8.

Calvo, R. 1998. Reprodución de Oenomaus ortignus (Lepidoptera: Lycaenidae) en Barva, Heredia, Costa Rica. Revista de Biologia Tropical 46(1): 101-104.

Camara, M.D. 1997. Predator responses to sequestered plant toxins in buckeye caterpillars: are tritrophic interactions locally variable? Journal of Chemical Ecology, 23(9).

Canfield, M.R., Chang, S. \& Pierce, N.E. 2009. The double cloak of invisibility: phenotypic plasticity and larval decoration in a geometrid moth, Synchlora frondaria, across three diet treatments. Ecological Entomology 34: 412-414. 
Casagrande, M.; Penz, C. \& DeVries, P.J.2009. Description of earlystages of Chorinea licursis (Fabricius) (Riodinidae). Tropical Lepidoptera Research, 19(2): 89-93.

Castillo-Guevara, C. \& Rico-Gray, V. 2002. Is cycasin in Eumaeus minyas (Lepidoptera: Lycaenidae) a predator deterrent? Interciencia, 27 (9). http://www.scielo.org.ve/scielo.php?script=sci_arttext\&pid=S037818442002000900004

Cavalcanti, T.B. \& Ramos, A.E. 2001. Flora do Distrito Federal, Brasil. Embrapa Recursos Genéticos e Biotecnologia, Brasília, DF. 359p.

Contreras-Medina, R.; Ruiz-Jiménez, C.A. \& Vega, I. L. 2003. Caterpillars of Eumaeus childrenae (Lepidoptera: Lycaenidae) feeding on two species of cycads (Zamiaceae) in the Huasteca region, Mexico. Revista de Biologia Tropical, 51(1).

Corsino, J.; Carvalho, P.R.F.; Kato, M.J.; Latorre, L.R.; Oliveira, O.M.M.F.; Araújo, A.R.; Bolzani, V.S.; França, S.C.; Pereira, A.M.S.; Furlan, M. 2000. Biosynthesis of friedelane and quinonemethide triterpenoids is compartmentalized in Maytenus aquifolium and Salacia campestris. Phytochemistry, 55:741-748.

Costa, A.A. \& Varanda, E.M. 2002. Building of leaf shelters by Stenoma scitiorella Walter (Lepidoptera: Elachistidae): Manipulation of host plant quality. Neotrop Entomol, 31: 537-540.

D'Abrera, B. 1995. Butterflies of the Neotropical region. Part VII. Lycaenidae. Victoria: Hill House 1270p.

DeVries, P.J. 1990. Enhancement of symbioses between butterfly caterpillars and ants by vibrational communication. Science 248: 1104-1106.

DeVries, P.J. 1991. Mutualism between Thisbe irenea butterflies and ants, and the role of ant ecology in the evolution of larval-ant associations. Biological Journal of the Linnean Society, 43: 179-195.

Diamond, S.E. \& Kingsolver, J.G. 2011. Host plant quality, selection history and trade offs shape the immune responses of Manduca sexta. Proceedings of the Royal Society B, 278(1703): 289-297.

Diniz, I.R.; Hay, J.D.; Rico-Gray, V.; Greeney, H.F. \& Morais, H.C. 2012. Shelter building caterpillars in the cerrado: seasonal variation in relative abundance, parasitism, and the influence of extra-floral nectaries. Arthropod-Plant Interactions, 6(4): 583-589. doi: 10.1007/s11829-012-9207-2.

Diniz, I. R. \& Morais, H. C. 1995. Larvas de Lepidoptera e suas plantas hospdeiras em um cerrado de Brasília, DF, Brasil.revista Brasileira de Entomologia, 39(4): 755770 .

Downey, J.C. 1966. Sound production in pupae of lycaenidae. Journal of the Lepidopterists ${ }^{\text {ee }}$ Society, 20(3): 129-155.

Downey, J.C. \& Allyn, A.C. 1981. Chorionic sculpturing in eggs of Lycaenidae. Part I. Bulletin of the Allyn Museum, 61: 1-29.

Downey J.C. \& Allyn, A.C. 1984. Chorionic sculpturing in eggs of Lycaenidae. Part II. Bulletin of the Allyn Museum, 84: 1-44.

Duarte, M. \& Robbins, R.K. 2009. Immature stages of Calycopis bellera (Hewitson) and $C$. janeirica (Felder) (Lepidoptera, Lycaenidae, Theclinae, Eumaeini): taxonomic significance and new evidence for detritivory. Zootaxa, 2325: 39-61.

Duarte, M. \& Robbins, R.K. 2010. Description and phylogenetic analysis of the Calycopidina (Lepidoptera, Lycaenidae, Theclinae, Eumaeini): a subtribe of detritivores. Revista Brasileira de Entomologia 54(1): 45-65.

Duarte, M.; Robbins, R.K. \& Mielke, O.H.H. 2005. Immature stages of Calycopis caulonia (Hewitson, 1877) (Lepidoptera, Lycaenidae, Theclinae, Eumaeini), with notes on rearing detritivorous hairstreaks on artificial diet. Zootaxa, 1063: 1-31. 
Dyer, L.A. 1995. Tasty generalists and nasty specialists? A comparative study of antipredator mechanisms in tropical lepidopteran larvae. Ecology, 76:1483-1496

Ehrlich, P.R. \& Raven, P.H. 1964. Butterflies and plants: a study in coevolution. Evolution, 18: 586-608.

Emery, E.O.; Brown Jr K.S. \& Pinheiro, C.E.G. 2006. As borboletas (Lepidoptera, Papilionoidea) do Distrito Federal, Brasil. Revista Brasileira de Entomologia, 50: $85-92$.

Felfili, J.M.; Santos, A.A.B.; \& Sampaio, J.C. 2004. Flora e diretrizes ao Plano de Manejo da APA Gama e Cabeça de Veado. Departamento de Engenharia Floresta, Universidade de Brasilia, Distrito Federal. 204p.

Fiedler, K. 1991. Systematic, evolutionary, and ecological implications of myrmecophily within the Lycaenidae (Insecta: Lepidoptera: Papilionoidea). Bonner Zoologische Monographien, 31:1-210.

Fiedler, K. 1995. Lycaenid butterfles and plants: hostplant relationships, tropical versus temperate. Ecotropica 1: 51-58.

Grant, J.B. 2007. Ontogenetic colour change and the evolution of aposematism: a case study in panic moth caterpillars. Journal of Animal Ecology, 76: 439-447.

Hall, J.P.W. \& Willmott, K.R. 2005. A new species of Paiwarria (Lepidoptera: Lycaenidae: Eumaeini) from western Ecuador. Proceedings of the Entomological Society of Washington, 107: 960-967.

Janzen, D.H. \& Hallwachs, W. 2013. Dynamic database for an inventory of the macrocaterpillar fauna, and its food plants and parasitoids, of the Area de Conservacion Guanacaste (ACG), northwestern Costa Rica. Disponível em: http://janzen.sas.upenn.edu.

Kaminski, L.A. \& Freitas, A.V.L. 2010. Natural history and morphology of immature stages of the butterfly Allosmaitia strophius (Godart) (Lepidoptera: Lycaenidae) on flower buds of Malpighiaceae. Studies on Neotropical Fauna and Environment, 45: 11-19.

Kaminski, L. A.; Rodrigues, D.; \& Freitas, A.V.L. 2012. Immature stages of Parrhasius polibetes (Lepidoptera: Lycaenidae): host plants, tending ants, natural enemies and morphology. Journal of Natural History, 46: 11-12.

Kaminski, L.A.; Sendoya, S.; Freitas, A.V.L. \& Oliveira, P.S. 2009. Ecologia comportamental na interface formiga-planta-herbívoro: Interações entre formigas e lepidópteros. Oecologia Brasiliensis, 13:27-44.

Kaminski, L.A.; Thiele, S.C.; Iserhard, C.A.; Romanowski, H.P. \& Moser, A. 2010. Natural history, new records, and notes on the conservation status of Cyanophrys bertha (Jones) (Lepidoptera: Lycaenidae). Proceedings of the Entomological Society of Washington, 112(1): 54-60.

Lamas, G. 2008. La sistemática sobre mariposas (Lepidoptera: Hesperioidea y Papilionoidea) en el mundo: Estado actual y perspectivas futuras. In: Contribuciones taxonómicas en órdenes de insectos hiperdiversos. LlorenteBousquets, J. \& A. Lanteri (Eds.). Las Prensas de Ciencias, UNAM. México D. F. pp. $57-70$

Lião, L.M.; Vieira, P.C.; Rodrigues-Filho, E.; Fernandes, J.B. \& Silva, M.F.G.F. 2002. Isomeric triterpenoids from Peritassa campestris. Zeitschrift für Naturforschung, 57: 403-406.

Lombardi, J.A. 2009. Neotropical Hippocrateaceae. In: Milliken, W.; Klitgård, B. \& Baracat, A. (2009 onwards), Neotropikey - Interactive key and information resources for flowering plants of the Neotropics. Disponível em: http://www.kew.org/science/tropamerica/neotropikey/families/Hippocrateaceae.htm 
Magalhães, C.G.; Ferrari, F.C.; Guimarães, D.A.S.; Silva, G.D.F.; Duarte, L.P.; Figueiredo, R.C. \& Filho, S.A.V. 2011. Maytenus salicifolia Reissek, Celastraceae: triterpenes isolated from stems and antioxidant property of extracts from aerial partsRevista Brasileira de Farmacognosia, 21(3): 415-419.

Malicky, H. 1970. New aspects of the association between lycaenid larvae (Lycaenidae) and ants (Formicidae, Hymenoptera). Journal of the Lepidopteristis' Society, 24: 190-202.

Massuda, K.F. \& Trigo, J.R. 2009. Chemical defence of the warningly coloured caterpillars of Methona themisto (Lepidoptera: Nymphalidae: Ithomiinae). European Journal of Entomology, 106: 253-259.

Monteiro, R.F. 1990. Aspectos ecológicos de teclíneos (Lepidoptera: Lycaenidae) com especial referência à coloração críptica de duas espécies de Rekoa Kaye. Doutorado em Ecologia, Universidade Estadual de Campinas, Campinas, SP, Brasil.

Monteiro, R.F. 1991. Cryptic larval polychromatism in Rekoa marius Lucas and $R$. palegon Cramer (Lycaenidae: Theclinae). Journal of Research on the Lepidoptera, 29: 77-84.

Morais, H.C.; Hay, J.D.V. \& Diniz, I.R. 2009. Brazilian cerrado folivore and florivore caterpillars: how different are they? Biotropica, 41(4): 401-405.

Nogueira, A.; Rey, P . J. \& Lohamann , L . G . 2012. Evolution of extrafloral nectaries: adaptive process and selective regime changes from forest to savanna. Journal of Evolutionary Biology, 25(11): 2325-40. doi: 10.1111/j.1420-9101.2012.02615.x

Núñez Bustos, E.O. 2009. Mariposas diurnas (Lepidoptera: Papilionoidea y Hesperioidea) del Parque Nacional Iguazú, Provincia de Misiones, Argentina. Tropical Lepidoptera Research, 19(2): 71-81.

Oliveira, C.R.; Menezes, A.C.S.; Moraes, M.O.; Vieira, L.M.; Pereira, A.G. \& Santos, M. L. 2012. Avaliação citotóxica em três linhagens de células tumorais das frações obtidas da casca do caule de Salacia crassifolia (Mart. ex. Schult.) G. Dom. (Celastraceae). Revista Colombiana de Ciencias Químico - Farmacéuticas, 41(2):133-142.

Owen, D. 1980. Camouflage and Mimicry. The University Chicago Press. 158p.

Pierce, N.E. \& Mead, P.S. 1981 Parasitoids as selective agents in the symbiosis between lycenid butterfly caterpillars and ants. Science, 211: 1185-1187.

Pierce, N.E.; Braby, M.F.; Heath, A.; Lohman, D.J.; Mathew, J.; Rand D.B. \& Travassos, M.A. 2002. The ecology and evolution of ant association in the Lycaenidae (Lepidoptera). Annual Review of Entomology, 47: 733-771.

Price, P.W. 2002. Resource-driven terrestrial interaction webs. Ecological Research, 17: 241-247.

Price, P.W.; Bouton, C.E.; Gross, P.; McPheron, B.A.; Thompson, J. N. \& Weis, A. E. 1980. Interactions among three trophic levels: influence of plants on interactions between insect herbivores and natural enemies. Annual Review of Ecology, Evolution, and Systematics, 19(11): 41-5.

Quental, T.B. 2008. Systematics, sexual selection and evolution of secondary sexual characters in Neotropical Eumaeini butterflies (Lepidoptera: Lycaenidae). Dissertation, Harvard University, Cambridge, MA, 226 p.

Rettenmeyer, C.W. 1970 Insect mimicry. Annual Review of Entomology, 15: 43-74.

Robbins, R.K. 2004a. Introduction to the checklist of Eumaeini (Lycaenidae). In: Lamas G, editor. Checklist: Part 4A. Hesperioidea - Papilionoidea. In: J.B. Heppner (Ed.). Atlas of Neotropical Lepidoptera. Volume 5A. Association for Tropical Lepidoptera, Gainesville.. pp. xxiv-xxx. 
Robbins, R.K. 2004b. Lycaenidae. Theclinae. Eumaeini. In: Lamas G, (Ed.). Checklist: Part 4A. Hesperioidea - Papilionoidea. In: J.B. Heppner (Ed.). Atlas of Neotropical Lepidoptera. Volume 5A. Association for Tropical Lepidoptera, Gainesville. pp. 118-137.

Robbins, R.K. 2010. The "upside down" systematics of hairstreak butterflies (Lycaenidae) that eat pineapple and other Bromeliaceae. Studies on Neotropical Fauna and Environment, 45(1): 21-37.

Robbins R.K. \& Aiello A. 1982. Foodplant and oviposition records for Panamanian Lycaenidae and Riodinidae. Journal of the Lepidopterist Society, 36: 65-75.

Robbins, R.K. \& Busby, R.C. 2008. Phylogeny, taxonomy, and sympatry of Timaeta (Lycaenidae: Theclinae: Eumaeini): an Andean montane forest endemic. Tijdschrift voor Entomologie, 151: 205-233.

Robbins, R.K. \& Nicolay, S.S. 2001. An overview of Strymon Hübner (Lycaenidae: Theclinae: Eumaeini). Journal of the Lepidopterists' Society, 55: 85-100.

Robbins, R.K. \& Small, J.G.B. 1981. Wind dispersal of Panamanian hairstreak butterflies (Lepidoptera: Lycaenidae) and its evolutionary significance. Biotropica, 13(4): 308-315.

Sermeño-Chicas, J.M.; Robbins, R.K.; Lamas, G. \& Gámez-Alas, J.A. 2013. Cría en laboratorio de las "joyas vivientes" de El Salvador, Evenus regalis (Cramer) y Evenus batesii (Hewitson) (Lepidoptera: Lycaenidae). Bioma, 3: 4-9.

Silva, N.A.P.; Duarte, M.; Araujo, E.B.; \& Morais, H.C. 2014. Larval biology of anthophagous Eumaeini (Lepidoptera: Lycaenidae, Theclinae) in the Cerrado of central Brazil. Journal Insect of Science, 14(184). DOI: 10.1093/jisesa/ieu046

Silva, N.A.P.; Duarte, M.; Diniz, I.R. \& Morais, H.C. 2011. Host plants of Lycaenidae on inflorescences in central Brazilian cerrado. Journal of Research on the Lepidoptera, 44: 95-105.

Smith, E.M. 2002. The effects of season, host plant protection, and ant predators on the survival of Eumaeus atala (Lycaenidae) in re-establishments. Journal of the Lepidopterists' Society, 56(4): 272-276.

Specht, A.; Corseuil, E. \& Abella H.B. 2008. Lepidópteros de importância médica: principais espécies no Rio Grande do Sul. Useb, Pelotas, RS. 240p.

Stamp, N.E. 1986. Physical constraints of defense and response to invertebrate predators by pipevine caterpillars (Battus philenor: Papilionidae). Journal of the Lepidopterists' Society, 40(3): 191-205.

Stehr, F.W. 1987. Order Lepidoptera. In: F.W. Stehr (ed.). Immature insects. Vol. 1. kendall-Hunt Publishing Company, Dubuque. pp. 288-305.

Stevens, P.F. 2012 (2001). Angiosperm Phylogeny Website. Version 13. Disponível em: http://www.mobot.org/MOBOT/research/APweb/.

Travassos, M.A. \& Pierce, N.E. 2000. Acoustics, context and function of vibrational signalling in a lycaenid butterfly-ant mutualism. Animal Behaviour, 60: 13-26.

Tyler, H. A.; Brown Jr, K.S. \& Wilson, K. H. 1994. Swallowtail butterflies of the Americas. A study in biological dynamics, ecological diversity, biosystematics, and conservation. Gainesville, FL: Scientific Publishers. 376p.

Wickler, W. 1968. El mimetismo em las plantas y em los animales. Biblioteca para el Hombre Actual, Ed. Guadarrama, Madri. 255 pp.

Willmott, K. R., Elias, M. \& Sourakov, A., 2011. Two Possible Caterpillar Mimicry Complexes in Neotropical Danaine Butterflies (Lepidoptera: Nymphalidae). Annals of the Entomological Society of America, 104(6): 1108-1118.

Zalucki, M.P.; Clarke, A.R. \& Malcolm, S.B. 2002. Ecology and behavior of first instar larval Lepidoptera. Annual Review of Entomology, 47: 361-393. 


\section{CAPÍTULO III}

Biologia dos estágios imaturos de Strymon crambusa (Lycaenidae, Theclinae) em Oxalidaceae

"Biology of the immature stages of Strymon crambusa (Lycaenidae, Theclinae) on Oxalidaceae" *

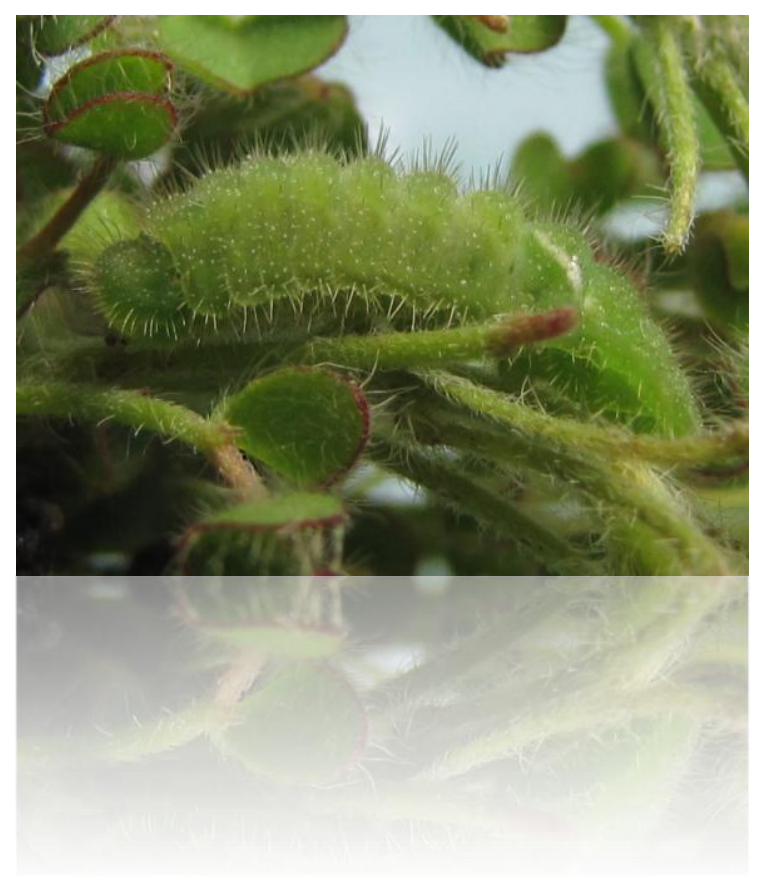




\title{
Entomologia \\ www.rbentomologia.com
}

Biology, Ecology and Diversity

\section{Biology of the immature stages of Strymon crambusa (Lycaenidae, Theclinae) on Oxalidaceae}

\author{
Neuza Aparecida Pereira da Silva ${ }^{\mathrm{a}, *}$, Cintia Lepesqueur ${ }^{\mathrm{b}}$, Agnelo Rodrigues Souza ${ }^{\mathrm{c}}$, \\ Helena Castanheira Morais ${ }^{c}$ \\ a Programa de Pós Graduação em Ecologia, Instituto de Ciências Biológicas, Universidade de Brasília, Brasília, DF, Brazil \\ b Departamento de Zoologia, Universidade de Brasília, Brasília, DF, Brazil \\ ${ }^{\mathrm{c}}$ Departamento de Ecologia, Universidade de Brasília, Brasília, DF, Brazil
}

\section{A R T I C L E I N F O}

\section{Article history:}

Received 23 July 2015

Accepted 4 November 2015

Available online 28 November 2015

Associate Editor: Hector A. Vargas

\section{Keywords:}

Abundance

Cerrado grassland

Hemiargus hanno

Oligophagous

Papilionoidea

\begin{abstract}
A B S T R A C T
We document the biology and morphology of the egg, caterpillar, and pupa of Strymon crambusa (Hewitson, 1874), a Neotropical Eumaeini. In the Cerrado, the caterpillar feeds on the inflorescences and leaves of Oxalis L. S. crambusa has four larval instars, all of which are illustrated. The density of caterpillars on plants is higher than that recorded for leaf-feeding caterpillars and other flower-feeding Eumaeini, which suggests that the species is a specialist on Oxalidaceae in the Cerrado.
\end{abstract}

(c) 2015 Sociedade Brasileira de Entomologia. Published by Elsevier Editora Ltda. This is an open access article under the CC BY-NC-ND license (http://creativecommons.org/licenses/by-nc-nd/4.0/).

\section{Introduction}

The Eumaeini Tribe (Lycaenidae, Theclinae) is primarily Neotropical (Robbins, 2004) and is often considered the most diverse tribe of butterflies (Papilionoidea) (Fiedler, 1996; Quental, 2008). Strymon Hübner is one of the most species-rich genera of Eumaeini (54 species) (Robbins, 2004). It is widely distributed, with some species restricted to dry areas of Central America and South America (Austin and Johnson, 1997; Brown, 1993; Johnson et al., 1990; Nicolay and Robbins, 2005; Robbins and Nicolay, 2002). Some species are highly polyphagous, and more than 30 plant families are cited as food plants for this genus (Beccaloni et al., 2008; Robbins and Nicolay, 2002; Silva et al., 2011).

There are few published works on the biology of Strymon immatures in South America, except those related to bromeliads, especially pests of pineapple (Lacerda et al., 2007; Robbins, 2010; Schmid et al., 2010). Strymon caterpillars, as well as several other Eumaeini, have specialized in eating the reproductive structures of plants (Badenes-Pérez et al., 2010; Chew and Robbins, 1984; Daniels et al., 2005; Silva et al., 2011). For the Neotropics in general, though, little information is available on the biology of Strymon immatures and their food plants (Vila and Eastwood, 2006; Silva

\footnotetext{
* Corresponding author.

E-mail: neuzaaps@gmail.com (N.A.P. da Silva).
}

et al., 2014). In the Distrito Federal (DF) of Brazil, there are 10 recorded species of Strymon (Brown and Mielke, 1967; Pinheiro and Emery, 2006; Pinheiro et al., 2008), with local food plant records for five of them (Silva et al., 2011). This paper focuses on the biology of the immature stages of Strymon crambusa (Hewitson, 1874).

S. crambusa is a medium sized Eumaeini that is rarely sampled in adult inventories (Austin and Johnson, 1997; Paluch et al., 2011). The distribution of this species includes parts of Argentina, Bolivia and Brazil in the states of Rondônia, Pernambuco, Rio de Janeiro, Minas Gerais and DF (Austin and Johnson, 1997; Johnson et al., 1990; Paluch et al., 2011; Pinheiro and Emery, 2006; Zikán and Zikán, 1968). The only recorded food plant for S. crambusa is Oxalis sp. (Silva et al., 2011), noted during a survey of Eumaeini caterpillars in inflorescences in the Cerrado of DF. The plant has now been identified as Oxalis densifolia Mart. and Zucc.

Subsequently, specific searches have been made for immatures of S. crambusa on Oxalidaceae and, recently the species was observed also on Oxalis cordata A. Saint-Hilaire. The objective of the present work is to document these findings on the biology and morphology of immature S. crambusa in the DF of Brazil.

\section{Material and methods}

Study area

The survey was conducted in the Fazenda Água Limpa (FAL) $\left(15^{\circ} 55^{\prime} \mathrm{S}-47^{\circ} 55^{\prime} \mathrm{W}\right)$ at $1050-1100$ m elevation. The FAL is a 4500 ha 


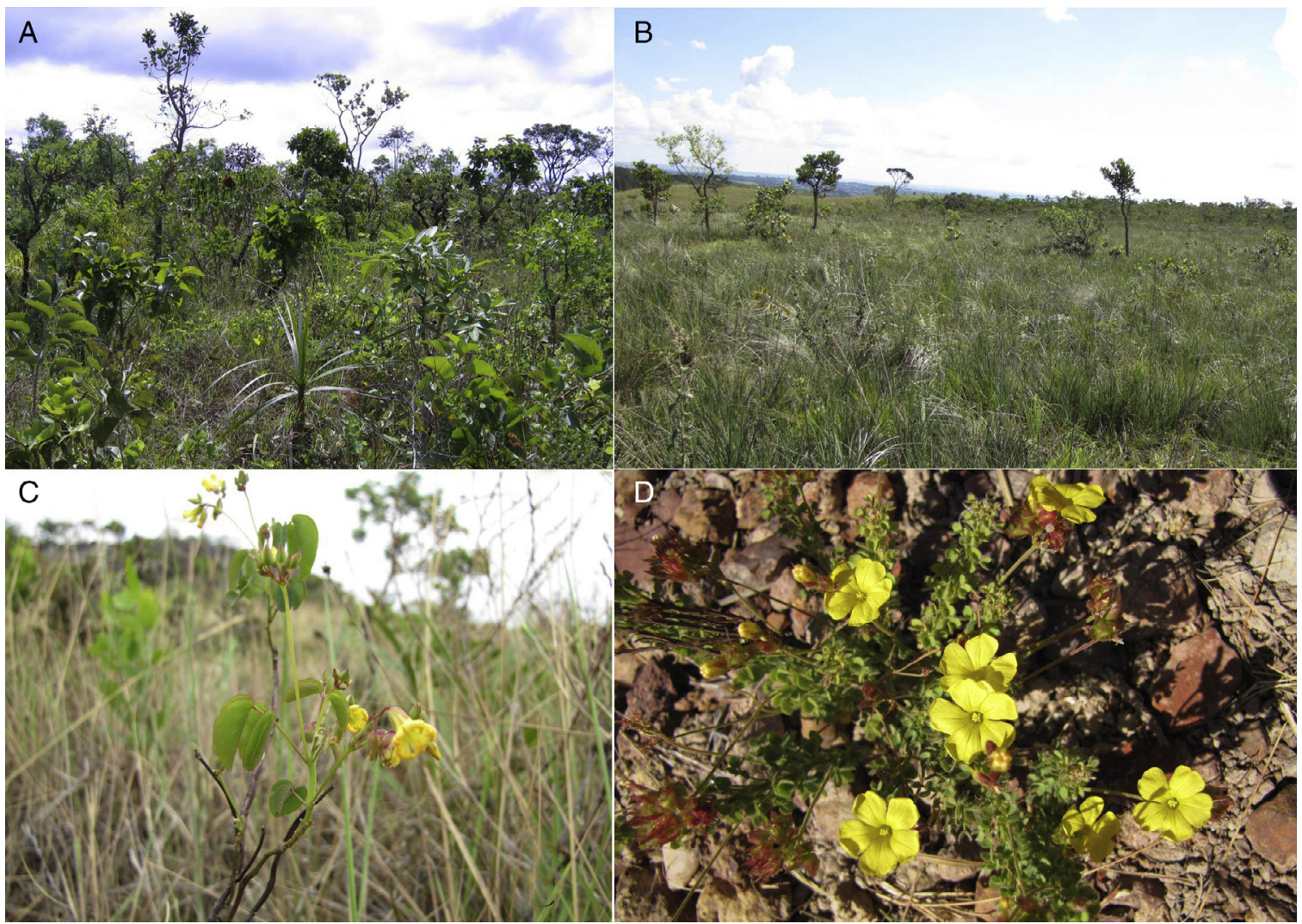

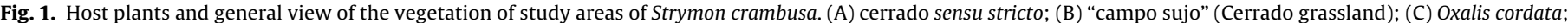
(D) Oxalis densifolia.

experimental farm with conserved and protected areas of Cerrado vegetation. It belongs to the Universidade de Brasília (UnB), being a part of the core of the Environmental Protection Area of Gama e Cabeça de Veado, DF, Brazil. The FAL vegetation has several Cerrado biome physiognomies, from open areas, such as grasslands, to gallery forests (Ratter, 1980; Munhoz and Felfili, 2005). Plants were searched in random areas of cerrado sensu stricto and "campo sujo" (Fig. 1A and B). "Campo sujo" is dominated by herbaceous plants, but may also contain shrubs and semi-shrubs, and cerrado sensu stricto is woody savannah with $15-30 \%$ tree cover (Munhoz and Felfili, 2006; Oliveira-Filho and Ratter, 2002). The region has defined dry (May-September) and wet (October-April) seasons, with a mean annual precipitation of $1417 \mathrm{~mm}$, and a mean annual temperature of $22^{\circ} \mathrm{C}$ (RECOR, 2014).

\section{Food plants}

There are approximately 185 recorded species of Oxalis L. (Oxalidaceae) in the Neotropics (Fiaschi, 2010). In the Cerrado of DF, this genus is represented by at least 10 native species, popularly known as "trevo" or "azedinha". Oxalis is well known for the presence of oxalic acid in its tissues (Cavalcanti and Ramos, 2001; Reis and Alvim, 2013). Two representative Oxalis species in the study areas, O. cordata (Fig. 1C) and O. densifolia (Fig. 1D), were inspected using similar methodology. These herbaceous shrub species can reach $50 \mathrm{~cm}$ tall, allowing the inspection of the plant as a whole. They possess nectaries on their leaves and yellow flowers. Without their flowers, it is not easy to see them in the vegetation. Seasonality of these plants is not well known. Flowering plants have been seen throughout the year, but 0 . densifolia blooms more frequently between October and January (Proença et al., 2006). O. cordata loses its leaves at the dry season peak (July and August). The subterranean root system of these Oxalis species allows them to re-grow and flower a few weeks after a fire in the Cerrado (Conceição and Giulietti, 1998; Munhoz and Felfili, 2006).

\section{Collection and rearing}

We searched for S. crambusa eggs and caterpillars from January to September 2012, and from August 2013 to July 2014. No plant was surveyed more than once. All eggs and caterpillars encountered in the field were collected, transferred to the laboratory in plastic bags with parts of the food plant. They were reared in individual plastic pots without temperature or humidity control. Caterpillars were supplied with the food plant ad libitum, and preferences for leaves or inflorescences were observed (following Silva et al., 2014). Head capsules were preserved and measured for each molt. Dead caterpillars and emerged parasitoids in the laboratory were fixed in Kahle solution and then preserved in $70 \%$ ethanol. We consulted Downey and Allyn (1984) and Stehr (1987) for the terminology of general morphology of immature stages. Photographs were taken with a Canon ${ }^{\circledR}$ PowerShot SX20 IS digital camera; measurements and general aspects of morphology were analyzed using a Leica ${ }^{\circledR}$ S8APO stereomicroscope with an attached micrometric scale. Measurements are presented as mean and standard deviation when possible. Immature and adult voucher specimens were deposited in the Coleção Entomológica do Departamento de Zoologia, UnB.

\section{Results}

We inspected 222 plants of 0 . densifolia and 0 . cordata. We found no immatures of S. crambusa on 67 (30.2\%) plants without flowers. However, we found nine eggs and 13 caterpillars of $S$. crambusa (Table 1) on 21 (13.5\%) of the 155 plants with flowers. These eggs and caterpillars were collected January-March, May, 
Table 1

Number of flowering plants examined, plants with egg/caterpillars and number of eggs and caterpillars (no.) and percentage (\%) of Strymon crambusa collected in two Oxalis species (O. cordata and $O$. densifolia) in areas of cerrado sensu stricto and "campo sujo" in the Fazenda Água Limpa, DF, Brazil, between 2012 and 2014.

\begin{tabular}{|c|c|c|c|c|c|c|}
\hline & \multicolumn{2}{|c|}{ O. cordata } & \multicolumn{2}{|c|}{ O. densifolia } & \multicolumn{2}{|c|}{ Total } \\
\hline & No. & $\%$ & No. & $\%$ & No. & $\%$ \\
\hline Examined plants & 107 & 69.0 & 48 & 31.0 & 155 & 100 \\
\hline Eggs & 5 & 55.6 & 4 & 44.4 & 9 & 100 \\
\hline Caterpillars & 9 & 69.2 & 4 & 30.8 & 13 & 100 \\
\hline Plants with egg/caterpillars & 14 & 63.6 & 7 & 36.4 & 21 & 13.5 \\
\hline
\end{tabular}

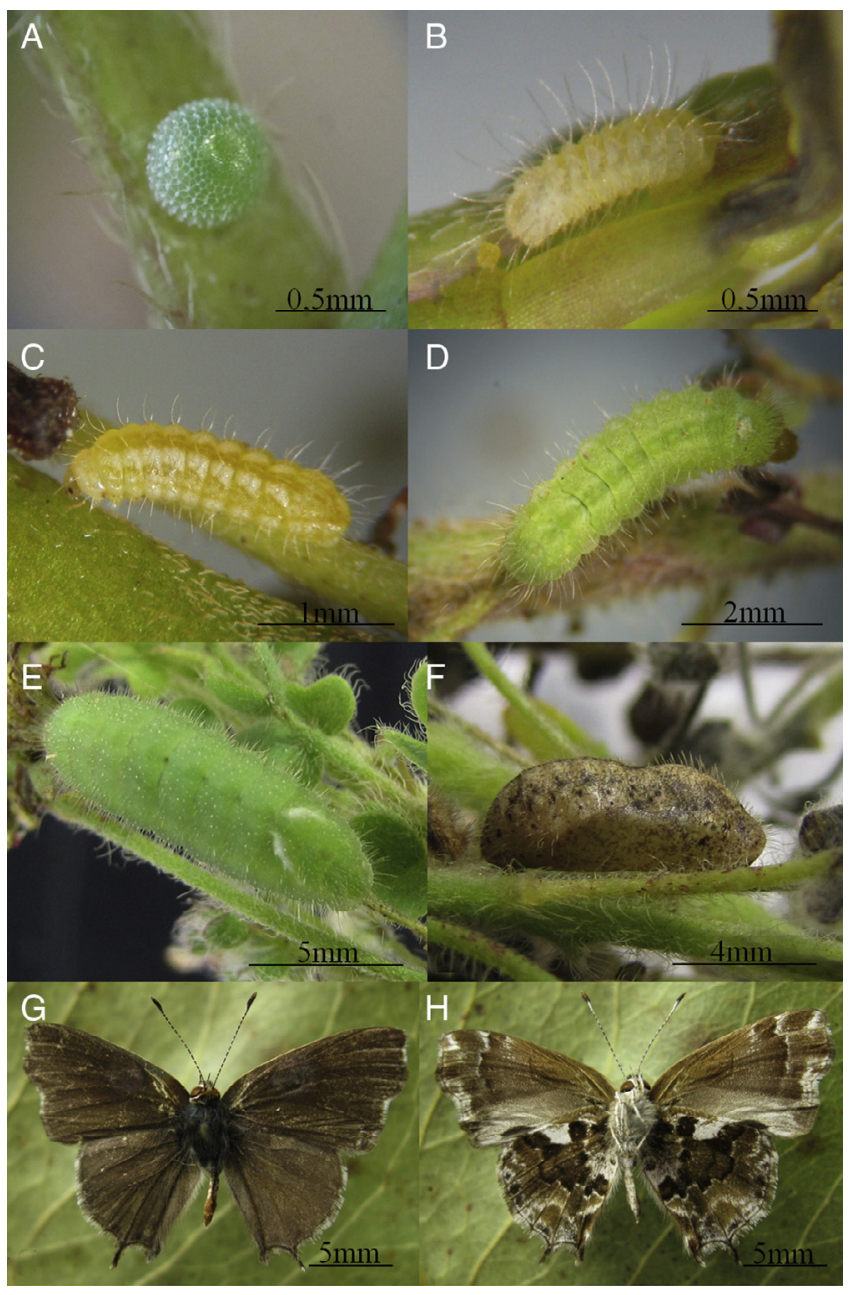

Fig. 2. Strymon crambusa, immatures and adult reared under laboratory conditions on Oxalis: (A) egg on the peduncle of inflorescences O. cordata; (B) first instar, (C) second instar, (D) third instar and (E) fourth instar on O. densifolia; (F) pupa; ( $G$ ) adult male, dorsal view and $(\mathrm{H})$ ventral view.

and August-October. Two eggs failed to hatch, four caterpillars died in different instars (L1-L3), one caterpillar was parasitized, one pupa did not reach adulthood, and 14 were reared to the adult stage (Fig. 2G and $\mathrm{H}$ ).

Eggs (Fig. 2A) were laid singly on floral buds, on the peduncle of inflorescences and on the leaves. The caterpillars were solitary. Only two eggs were recorded on the same plant of $O$. densifolia, and $S$. crambusa caterpillars co-occurred twice with caterpillars of Hemiargus hanno (Stoll) (Lycaenidae, Polyommatinae). The behavior and coloration of caterpillars were similar on each species of Oxalis. First instars feed on flowers, flower buds, and also on young fruits. The second to last instars also feed on leaves. While feeding, the larva holds its body straight or in a slight "s-curve" on the substrate, moving only its retractable head. In the field, symbiotic interactions with ants were not observed. The larvae became green at the end of the second instar and appeared to be cryptic. In the laboratory, pupation occurred on the plant or on the base of the rearing pot attached by a silk girdle. S. crambusa has four instars (Fig. 2). Development time from caterpillar to adult was approximately 30 days. One caterpillar found on 0 . densifolia was parasitized by a species of Conura Spinola (Hymenoptera: Chalcididae) that emerged through a hole in the pupal thorax 20 days after pupation.

\section{Immature stages}

Egg (Fig. 2A): On O. cordata $(n=1)$ and on O. densifolia $(n=1)$. Light green, changing to yellowish before hatching; rounded in dorsal view. Micropylar area slightly depressed and base flattened; exochorion sculptured with prominences at rib intersections. Diameter: $0.50-0.53 \mathrm{~mm}$. Height: $0.27-0.30 \mathrm{~mm}$. Hatching in $4-5$ days.

First instar (Fig. 2B): On 0 . cordata $(n=1)$ and on 0 . densifolia $(n=1)$. Head yellowish, hypognathous projected with the ability to retract it under the thorax. Body onisciform; yellow-whitish prothoracic shield, body and setae. Length of body: 0.98-1.2 mm. Head capsule width: $0.20-0.22 \mathrm{~mm}$. Duration: 5 days.

Second instar (Fig. 2C): On O. cordata $(n=1)$. Yellowish head and prothoracic shield. Yellow body; two subdorsal and lateral whitish strips; yellowish setae. Length of body: $2.2 \mathrm{~mm}$. Head capsule width: $0.42 \mathrm{~mm}$. Duration: 4 days.

Third instar (Fig. 2D): On O. densifolia $(n=1)$. Light brown head, greenish body with two cream subdorsal lines; white prothoracic shield; light oblique white lines start to appear, mainly, on the sixth abdominal segment (A6). A scar on the dorsal nectary organ (DNO) present on A7; pore cupola organs (PCOs) observed under a stereomicroscope. Length of body: $4.1 \mathrm{~mm}$. Head capsule width: $0.74 \mathrm{~mm}$. Duration: 3 days.

Fourth instar (Fig. 2E): On 0 . cordata $(n=3)$ and on 0 . densifolia $(n=2)$. Light brown head. Greenish body with yellowish setae; two oblique white lines on A6-A7, more conspicuous than in L3; light brown spiracles. DNO in A7; PCOs nearby to DNO and spread around the body. In the end of the instar, the caterpillars (prepupae) acquire a uniform tonality (greenish or pinkish). Length of body: $7-11 \mathrm{~mm}$ (mean $=8.6 \mathrm{~mm} \pm 1.35$ ). Head capsule width: 1.0-1.1 mm. Duration: $5-6$ days (mean $=5.4$ days $\pm 0.54, n=5$ ).

Pupa (Fig. 2F): On O. cordata $(n=3)$ and on O. densifolia $(n=2)$. Light brown tegument with some irregular black spots; black stripe on the dorsal midline of the abdomen. Body covered with yellowish setae. Pupa is ventrally attached to the substrate with a silken girdle between $A 1$ and A2. Length: $6.27-8.69 \mathrm{~mm}($ mean $=.48 \mathrm{~mm} \pm 0.88)$. Duration: $8-12$ days ( mean $=10$ days $\pm 1.41, n=5$ ).

\section{Discussion}

Caterpillars of $S$. crambusa resemble other Strymon species (Wagner, 2005; Silva et al., 2014). However, the two white oblique lines on the sixth and seventh segments occur more frequently in S. crambusa than in Strymon mulucha (Hewitson) (N.A.P. Silva, personal observation), another common Strymon species in the search area. The number of instars and the development time is similar to other Eumaeini in the Cerrado (Kaminski and Freitas, 2010; Monteiro, 1991). Parasitism by Conura is known in Eumaeini species and in general the adult wasp can to emerge within 30 days after the pupation of its host (Silva et al., 2014).

Despite the large number of plant families that are reported to be used by Strymon, and of the fact that Oxalis species are widely distributed in the Cerrado biome and fields of Brazil (Cavalcanti 
and Ramos, 2001; Conceição and Giulietti, 1998; Medeiros, 2011; Proença et al., 2006), Oxalidaceae is unrecorded as a food for any species of Eumaeini. A detritivore was shown to be able to eat leaves of Oxalis and to complete development in the lab (Johnson, 1985), but it is unclear whether this plant is used in nature. The polyphagy is common among the flower-feeding Eumaeini in the Cerrado (Kaminski et al., 2012; Silva et al., 2011). However the oligophagy, or the use of a narrow set of phylogenetically closely related plant species, has been more widespread than previously thought in the group (Beccaloni et al., 2008; Fiedler, 1996; Kaminski and Freitas, 2010; Kaminski et al., 2013; Monteiro, 1991; Robbins and Aiello, 1982; Silva et al., 2011, 2014). Ecologically, S. crambusa seems to be specialized on Oxalidaceae while $S$. mulucha is recorded on more than seven food plant families (see Silva et al., 2011).

In this study, the interaction between $S$. crambusa caterpillars and ants was not recorded despite the presence of myrmecophilous organs, such as the DNO and the PCOs. We believe that the some interaction between $S$. crambusa and ants may occur because the plants are visited by ants, which are attracted by extrafloral nectaries. Moreover, on $O$. densifolia in FAL, it is not rare to witness $H$. hanno caterpillars (facultative myrmecophilous; see Duarte et al., 2001 ) interacting with species of genus Crematogaster Lund (Formicidae, Myrmicinae) (unpublished data). The presence of the ants on the plant seems to indicate a protected area against natural enemies for the butterflies with myrmecophilous caterpillars. Studies have shown that the diet selection may be ant-dependent; the females prefer to lay eggs on plants that contain ants or that contain anttended treehoppers (Atsatt, 1981; Bächtold et al., 2014; Kaminski et al., 2010; Pierce and Elgar, 1985; Wagner and Kurina, 1997).

Another important factor in the female's choice of food plant is the presence/absence of inflorescences. The absence of $S$. crambusa caterpillars on plants without inflorescences in the field indicates that females use visual cues for oviposition (Chew and Robbins, 1984; Rodrigues et al., 2010). For flower-feeding caterpillars, phenological synchrony with the flowering food plant significantly reflects the density of eggs and larval survival (Rodriguez et al., 1994). The current results suggest that S. crambusa has a strong local connection with flowering Oxalidaceae.

The role of the secondary plant compounds in lycaenid food plants specificity has yet to be fully explored. Some species of Oxalis, for example, are toxic due to the presence of oxalic acid. Moreover, alkaloids, flavonoids and tannins have also been detected in these plants (Violante et al., 2009). The flavonoids, when present in the diet of caterpillars, can be sequestrated for multiple functions, including resembling the host plant by changing wing color (Burghardt et al., 2001; Mizokami et al., 2008; Monteiro, 1991). The presence of this compound was evaluated for eggs, caterpillars and the pupae of Pseudozizeeria maha (Kollar, 1844), a monophagous Polyommatinae from an Indian subcontinent, on the leaves of Oxalis corniculata L., and the authors suspect that the species also uses the flavonoids as a chemical defense compound (Mizokami et al., 2008; Mizokami and Yoshitama, 2009).

We found no $S$. crambusa caterpillars during surveys of more than 150 plant species (other than Oxalis) belonging to 35 families during 10 years of research in the Cerrado of DF (Diniz and Morais, 2002; Silva et al., 2011). Interestingly, the frequency of $S$. crambusa on Oxalis plants with flowers (13.5\%) is greater than that recorded for leaf-feeding caterpillars in the Restinga (see Monteiro et al., 2007) and in the Cerrado (see Andrade et al., 1995; Morais et al., 1996, 2007; Diniz et al., 2011; Braga et al., 2014). Silva et al. (2011, Table 1) also recorded a lower frequency of Lycaenidae in the extensive survey of inflorescences of different plants. On the other hand, it is known that different species of Lepidoptera can follow the temporal pattern of the host plant (Rodriguez et al., 1994; Muniz et al., 2012), which may not have coincided with collection periods. For example, Vargas (2014) noted a large difference in the abundance of flower-feeding lycaenids between two successive summers.

The results in this paper are significant because the preference for oviposition sites and larval feeding may represent different defense strategies and are key aspects for understanding the trophic relationships and evolution of Lepidoptera (Duarte and Robbins, 2010; Kaminski et al., 2012). Surveys of caterpillars that feed on inflorescences of plants in the Cerrado of FAL over the last 10 years have revealed a rich and little-known fauna (Diniz and Morais, 2002; Morais et al., 2009; Silva et al., 2011). Future studies in different areas, especially burned areas where the herbaceous species of the Cerrado have an intense flowering a few days or weeks after a fire (Munhoz and Felfili, 2006), can contribute to a better understanding of the ecological requirements and population dynamics of S. crambusa.

\section{Conflicts of interest}

The authors declare no conflicts of interest.

\section{Acknowledgments}

We are grateful to Marcelo Duarte for the identification of the Lepidoptera, André R. Nascimento for the identification of the parasitoid; Ivone R. Diniz for early suggestions on the manuscript. N. A. P. Silva received CNPq (Conselho Nacional de Desenvolvimento Científico e Tecnológico) scholarship; C. Lepesqueur was supported by a Postdoctoral Research Fellowship from CNPq (59606/2013-6) and A. R. Souza received a grant of research initiation from Programa Institucional de Bolsas de Iniciação Científica (Edital 2011 PIBIC-CNPq/UnB). We thank the anonymous reviewer for their comments and suggestions and especially to Dr. Robert K. Robbins for his critical review and for the inestimable help with providing important information, corrections, and comments to improve this paper.

\section{References}

Andrade, I., Diniz, I.R., Morais, H.C., 1995. A lagarta de Cerconota achatina (Zeller) (Lepidoptera, Oecophoridae, Stenomatinae): biologia e ocorrência em plantas hospedeiras do gênero Byrsonima Rich (Malpighiaceae). Rev. Bras. Zool. 12, $735-741$.

Atsatt, P.R., 1981. Ant-dependent food plant selection by the mistletoe butterfly Ogyris amaryllis (Lycaenidae). Oecologia 48, 60-63.

Austin, G.T., Johnson, K., 1997. Theclinae of Rondonia, Brazil: Strymon Hübner, with descriptions of new species (Lepidoptera: Lycaenidae). Insecta Mundi 11, 201-235.

Bächtold, A., Alves-Silva, E., Kaminski, L.A., Del-Claro, K., 2014. The role of tending ants in host plant selection and egg parasitism of two facultative myrmecophilous butterflies. Naturwissenschaften, http://dx.doi.org/10.1007/ s00114-014-1232-9.

Badenes-Pérez, F.R., Alfaro-Alpízar, M.A., Johnson, M.T., 2010. Diversity, ecology and herbivory of hairstreak butterflies (Theclinae) associated with the velvet trees, Miconia calvescens in Costa Rica. J. Insect Sci. 10, 209.

Beccaloni, G.W., Viloria, A.L., Hall, S.K., Robinson, G.S., 2008. Catalogue of the Host Plants of the Neotropical Butterflies. Monografias Tercer Milenio, vol. 8. S.E.A., RIBES-CYTED, The Natural History Museum, Instituto Venezolano de Investigaciones Científicas, Zaragoza.

Braga, L., Lepesqueur, C., Silva, N.A.P., Harterreiten-Souza, É.S., Tepedino, K.P.G., Neis, M., Scherrer, S., Nascimento, A.R., Motta, P., Diniz, I.R., 2014. Immature stages and ecological characteristics of Idalus lineosus Walker (Erebidae: Arctiinae). J. Lepid. Soc. $68,45-53$.

Brown Jr., K.S., 1993. Theclinae endemic to the Cerrado vegetation (central Brazil). In: New, T.R. (Ed.), Conservation Biology of Lycaenidae (Butterflies). Occasional Paper on the IUCN Species Survival Commission No, 8. Gland, Switzerland. , p. 152

Brown Jr., K.S., Mielke, O.H.H., 1967. Lepidoptera of the Central Brazil Plateau. I. Preliminary list of Rhopalocera (continued): Lycaenidae, Pieridae, Papilionidae. Hesperiidae. J. Lepid. Soc. 21, 145-168.

Burghardt, F., Proksch, P., Fiedler, K., 2001. Flavonoid sequestration by the common blue butterfly Polyommatus icarus: quantitative intraspecific variation in relation to larval hostplant, sex and body size. Biochem. Syst. Ecol. 29, 875-889.

Cavalcanti, T.B., Ramos, A.E., 2001. Flora do Distrito Federal, Brasil. Embrapa Recursos Genéticos e Biotecnologia, Brasília. 
Chew, F.S., Robbins, R.K., 1984. Egg-laying in butterflies. In: Wane-Wright, R.I., Ackery, P.R. (Eds.), The Biology of Butterflies. Symposium of the Royal Entomological Society of London, vol. 11. Academic Press, London, England, pp. 65-79.

Conceição, A.A., Giulietti, A.M., 1998. Flora da Serra do Cipó, Minas Gerais: Oxalidaceae. Bol. Bot. Univ. São Paulo 17, 115-122

Daniels, J.C., Pence, J.A., Emmel, T.C., 2005. A new hostplant record for Strymon martialis (Lycaenidae: Theclinae) in the Florida Keys. J. Lepid. Soc. 59, 174-175.

Diniz, I.R., Morais, H.C., 2002. Local pattern of host plant utilization by lepidopteran larvae in the Cerrado vegetation. Entomotropica 17, 115-119.

Diniz, I.R., Lepesqueur, C., Milhomen, M.S., Bandeira, F.C.S., Morais, H.C., 2011. Eloria subapicalis (Lepidoptera: Noctuidae: Lymantriinae): rare and specialist species on Erythroxylum (Erythroxylaceae) in the Cerrado. Zoologia 28, 58-62.

Downey, J.C., Allyn, A.C., 1984. Chorionic sculpturing in eggs of Lycaenidae. Part II. Bull. Allyn Mus. 84, 1-44.

Duarte, M., Robbins, R.K., 2010. Description and phylogenetic analysis of the Calycopidina (Lepidoptera, Lycaenidae, Theclinae, Eumaeini): a subtribe of detritivores. Rev. Bras. Entomol. 54, 45-65.

Duarte, M., Almeida, G.L., Casagrande, M.M., Mielke, O.H.H., 2001. Notes on the last instar and pupa of Hemiargus hanno (Stoll) (Lepidoptera, Lycaenidae, Polyommatinae). Rev. Bras. Zool. 18, 1097-1105.

Fiaschi, P., 2010. Neotropical Oxalidaceae. In: Milliken, W., Klitgård, B., Baracat, A. (Eds.), (2009 onwards) Neotropikey - Interactive Key and Information Resources for Flowering Plants of Neotropics. , Available at http://www.kew.org/science/ tropamerica/neotropikey/families/Oxalidaceae.htm (accessed 10.04.15).

Fiedler, K., 1996. Host-plant relationships of lycaenid butterflies: large-scale patterns, interactions with plant chemistry, and mutualism with ants. Entomol. Exp. Appl. 80, 259-267.

Johnson, S.A., 1985. Culturing a detritivore, Calycopis isobeon (Butler \& Druce). News Lepid. Soc. 3, 41-42.

Johnson, K., Eisele, R.C., MacPherson, B., 1990. The hairstreak butterflies (Lycaenidae, Theclinae) of Northwestern Argentina. II. Strymon, sensu stricto. Bull. Allyn Mus. $130,1-77$.

Kaminski, L.A., Freitas, A.V.L., 2010. Natural history and morphology of immature stages of the butterfly Allosmaitia strophius (Godart) (Lepidoptera: Lycaenidae) on flower buds of Malpighiaceae. Stud. Neotrop. Fauna Environ. 45, 11-19.

Kaminski, L.A., Freitas, A.V.L., Oliveira, P.S., 2010. Interaction between mutualisms: ant-tended butterflies exploit enemy-free space provided by ant-treehopper associations. Am. Nat. 176, 322-334.

Kaminski, L.A., Rodrigues, D., Freitas, A.V.L., 2012. Immature stages of Parrhasius polibetes (Lepidoptera: Lycaenidae): host plants, tending ants, natural enemies and morphology. J. Nat. Hist. 46, 645-667.

Kaminski, L.A., Motta, L.L., Freitas, A.V.L., 2013. Life history of Porthecla ravus (Druce) (Lepidoptera: Lycaenidae), with discussion on the use of Annonaceae by Eumaeini butterflies. An. Soc. Entomol. 48, 309-312.

Lacerda, J.T., Carvalho, R.A., Oliveira, E.F., 2007. Broca-do-fruto Strymon megarus um problema para a abacaxicultura do Brasil, vol. 1. Tecnologia \& Ciência Agropecuária, João Pessoa, Brazil, pp. 25-30.

Medeiros, J.D., 2011. Guia de campo: vegetação do Cerrado 500 espécies. MMA/SBF, Brasília, DF, Brazil.

Mizokami, H., Yoshitama, K., 2009. Sequestration and metabolism of host-plant flavonoids by the Pale Grass Blue, Pseudozizeeria maha (Lepidoptera: Lycaenidae). J. Entomol. Sci. 12, 171-176.

Mizokami, H., Tomita-Yokotani, K., Yoshitama, K., 2008. Flavonoids in the leaves of Oxalis corniculata and sequestration of the flavonoids in the wing scales of the pale grass blue butterfly, Pseudozizeeria maha. J. Plant Res. 121, 133-136.

Monteiro, R.F., 1991. Cryptic larval polychromatism in Rekoa marius Lucas and $R$. palegon Cramer (Lycaenidae: Theclinae). J. Res. Lep. 29, 77-84.

Monteiro, R.F., Macedo, M.V., Nascimento, M., Cury, R.S.F., 2007. Composição, abundância e notas sobre a ecologia de espécies de larvas de lepidópteros associadas a cinco espécies de plantas hospedeiras no Parque Nacional da Restinga de Jurubatiba, R. J. Rev. Bras. Entomol. 51, 476-483.

Morais, H.C., Diniz, I.R., Silva, J.R., 1996. Larvas de Siderone marthesia nemesis (Illlger) (Lepidoptera, Nymphalidae, Charaxinae) em cerrado de Brasília, Distrito Federal, Brasil. Rev. Bras. Zool. 13, 351-356.

Morais, H.C., Cabral, B.C., Mangabeira, J.A., Diniz, I.R., 2007. Stenoma cathosiota Meyrick (Lepidoptera: Elachistidae) in the Cerrado of Brasilia: temporal and spatial variation of caterpillar abundance. Neotrop. Entomol. 36, 843-847.

Morais, H.C., Hay, J.D., Diniz, I.R., 2009. Brazilian cerrado folivore and florivore caterpillars: how different are they? Biotropica 41, 401-405.

Munhoz, C.B.R., Felfili, J.M., 2005. Fenologia do estrato herbáceo-subarbustivo de uma comunidade de campo sujo na Fazenda Água Limpa no Distrito Federal, Brasil. Acta Bot. Bras. 19, 979-988.

Munhoz, C.B.R., Felfili, J.M., 2006. Fitossociologia do estrato herbáceo-subarbustivo de uma área de campo sujo no Distrito Federal, Brasil. Acta Bot. Bras. 20, 671-685.

Muniz, D.G., Freitas, A.V.L., Oliveira, P.S., 2012. Phenological relationships of Eunica bechina (Lepidoptera: Nymphalidae) and its host plant, Caryocar brasiliense (Caryocaraceae), in a Neotropical savanna. Stud. Neotrop. Fauna Environ. 47, 111-118.
Nicolay, S.S., Robbins, R.K., 2005. Five new dry-area South American Strymon species (Lycaenidae: Theclinae) and their biogeographic significance. J. Res. Lep. 38, 35-49.

Oliveira-Filho, A.T., Ratter, J.A., 2002. Vegetation physiognomies and woody flora of the Cerrado biome. In: Oliveira, P.S., Marquis, R.J. (Eds.), The Cerrados of Brazil: Ecology and Natural History of a Neotropical Savanna. Columbia University Press, New York, pp. 91-120.

Paluch, M., Mielke, O.H.H., Nobre, C.E.B., Casagrande, M.M., Melo, D.H.A., Freitas, A.V.L., 2011. Butterflies (Lepidoptera: Papilionoidea and Hesperioidea) of the Parque Ecológico João Vasconcelos Sobrinho, Caruaru, Pernambuco, Brazil. Biota Neotrop. 11, 229-238.

Pierce, N.E., Elgar, M.A., 1985. The influence of ants on host plant selection by Jalmenus evagoras, a myrmecophilous lycaenid butterfly. Behav. Ecol. Sociobiol. 16 209-222.

Pinheiro, C.E.G., Emery, E.O., 2006. As borboletas (Lepidoptera: Papilionoidea e Hesperioidea) da Ârea de Proteção Ambiental do Gama e Cabeça de Veado (Distrito Federal, Brasil). Biota Neotropica, vol. 6, Available at http://www. biotaneotropica.org.br/v6n3/pt/abstract?inventory.

Pinheiro, C.E.G., Malinov, I.C., Andrade, T.O., Maravalhas, J.B., Andrade, M.B.M., Deus L.P.A., Pedrosa, L.G.P., Zanatta, G.V., 2008. As borboletas (Lepidoptera, Papilionoidea) do Campus Universitário Darcy Ribeiro (Distrito Federal, Brasil). Biota Neotrop. 8, 139-144.

Proença, C.C., Oliveira, R.S., Silva, A.P., 2006. Flores e Frutos do Cerrado. Editora Rede de Sementes do Cerrado, Brasília, DF.

Quental, T.B., 2008. Systematics, sexual selection and evolution of secondary sexual characters in Neotropical Eumaeini butterflies (Lepidoptera: Lycaenidae). MS thesis, Harvard University, Cambridge.

Ratter, J.A., 1980. Notes on the Vegetation of Fazenda Água Limpa (Brasília, DF, Brazil). Royal Botanic Garden, Edinburgh.

(RECOR) Reserva Ecológica do IBGE, 2014. Dados meteorológicos, Available at http://www.recor.org.br/cid360/download/17-dados-meteorol\%C3\%B3gicos. html (accessed 11.02.14).

Reis, R.E., Alvim, M.N., 2013. Anatomia foliar comparada de três espécies do gênero Oxalis L. (Oxalidaceae). NBC-Periódico Científico do Núcleo de Biociências, Belo Horizonte, MG, vol. 3., pp. 59-72, http://dx.doi.org/10.15601/ 2238-1945/pcnb.v3n6p 59-72.

Robbins, R.K., 2004. Lycaenidae. Theclinae. Eumaeini. In: Lamas, G., Heppner, J.B. (Eds.), Checklist: Part 4A. Hesperioidea - Papilionoidea. Atlas of Neotropical Lepidoptera, vol. 5A. Association for Tropical Lepidoptera, Gainesville, pp. 118-137.

Robbins, R.K., 2010. The upside down systematics of hairstreak butterflies (Lycaenidae) that eat pineapple and other Bromeliaceae. Stud. Neotrop. Fauna Environ. 45, 21-37.

Robbins, R.K., Aiello, A., 1982. Foodplant and oviposition records for Panamanian Lycaenidae and Riodinidae. J. Lepid. Soc. 36, 65-75.

Robbins, R.K., Nicolay, S.S., 2002. An overview of Strymon Hübner (Lycaenidae: Theclinae: Eumaeini). J. Lepid. Soc. 55, 85-100.

Rodrigues, D., Kaminski, L.A., Freitas, A.V.L., Oliveira, P.S., 2010. Trade-offs underlying polyphagy in a facultative ant-tended florivorous butterfly: the role of host plant quality and enemy-free space. Oecologia 163, 719-728.

Rodriguez, J., Jordano, D., Fernandez, J.H., 1994. Spatial heterogeneity in a butterfly - host plant interaction. J. Anim. Ecol. 63, 31-38.

Schmid, S., Schmid, V., Kamke, R., Steiner, J., Zillikens, A., 2010. Association of three species of Strymon Hübner (Lycaenidae: Theclinae: Eumaeini) with bromeliads in southern Brazil. J. Res. Lep. 42, 50-55

Silva, N.A.P., Duarte, M., Diniz, I.R., Morais, H.C., 2011. Host plants of Lycaenidae on inflorescences in central Brazilian Cerrado. J. Res. Lep. 44, 95-105.

Silva, N.A.P., Duarte, M., Araujo, E.B., Morais, H.C., 2014. Larval biology of anthophagous Eumaeini (Lepidoptera: Lycaenidae, Theclinae) in the Cerrado of Central Brazil. J. Insect Sci. 14, 184.

Stehr, F.W., 1987. Order Lepidoptera. In: Stehr, F.W. (Ed.), Immature Insects, vol. 1 Kendall-Hunt Publishing Company, Dubuque, IA, pp. 288-305.

Vargas, H.A., 2014. Lycaenid caterpillars (Lepidoptera, Lycaenidae) eating flowers of Dalea pennellii var. chilensis (Fabaceae) in the northern Chilean Andes. Rev. Bras. Entomol. 58, 309-312.

Vila, R., Eastwood, R., 2006. Extrafloral nectar feeding by Strymon jaqueline Nicholay \& Robbins, 2005 (Lepidoptera: Lycaenidae: Eumaeini). Rev. Peru. Entomol. 13 $125-128$

Violante, I.M.P., Souza, I.M., Venturini, C.L., Ramalho, A.F.S., Santos, R.A.N., Ferrari, M., 2009. Avaliação in vitro da atividade fotoprotetora de extratos vegetais do cerrado de Mato Grosso. Rev. Bras. Farmacogn. 19, 452-457.

Wagner, D.L., 2005. Caterpillars of Eastern North America. Princeton Field Guides. Princeton University Press, Princeton.

Wagner, D., Kurina, L., 1997. The influence of ants and water availability on oviposition behavior and survivorship of a facultatively ant-tended herbivore. Ecol. Entomol. 22, 352-360

Zikán, J.F., Zikán, W., 1968. Inseto-fauna do Itatiaia e da Mantiqueira. III. Lepidoptera. Pesq. Agropec. Bras. 3, 45-109. 